\title{
O USO DO EVAPOTRANSPIROMMETRO NO ESTUDO DE ALGUMAS RELAÇÕES ENTRE EVAPOTRANSPIRAÇÃO MEDIDA E ESTIMADA
}

\author{
FRANCISCO NETO DE ASSIS \\ Engenheiro-Agrônomo \\ Pesquisador da EMBRAPA
}

Orientador: Nilson Augusto Villa Nova

Dissertação apresentada à Escola Superior de Agricultura "Luiz de Queiroz", da Universidade de São Paulo, para obłenção do título de Mestre em Agrometeorologia.

\author{
P I R A C I C A B A \\ Estado de São Paulo - Brasil
}

Fevereiro, 1978 
Aos meus pais

em suas bodas

de ouro

DEDICO

A minha esposa Vera

Aos meus irmãos e sobrinhos

Aos meus sogros

OFEREÇO 


\section{$\underline{A} \underline{G} \underline{A} \underline{D} \underline{E} \underline{C} \underline{I} \underline{M} \underline{E} \underline{\mathbb{N}} \underline{0} \underline{S}$}

Ao Prof. Dr. Nilson Augusto Villa Nova pelo apoio, incenti vo e orientação objetiva em todas as etapas deste trabalho.

A Coordenação do Curso de Pós-Graduação em Agrometerolō gia.

Ao Engenheiro Agrōnomo Paulo Leonel Libardi pelas críticas e sugestõeș apresentadas.

A Empresa Brasileira de Pesquisa Agropecuária pela ajuda financeira.

Aos colegas do Curso de Pós-Graduação em Agrometeorologia pela convivência amiga nos dois últimos anos.

A Srta. Vera Lucia Severino pelo excelente trabalho de da tilografia. 


\section{INDICE}

Pāg.

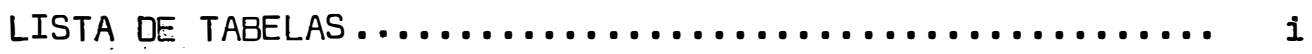

LISTA DE FIGURAS $\ldots \ldots \ldots \ldots \ldots \ldots \ldots \ldots \ldots \ldots \ldots \ldots \ldots \ldots \ldots \ldots \ldots$

RESUMD ................................... vii

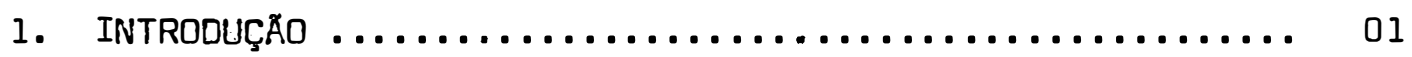

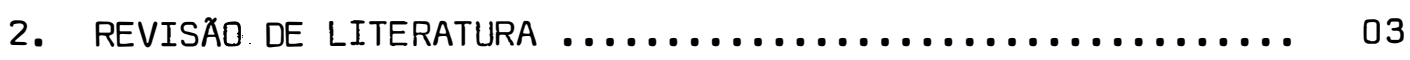

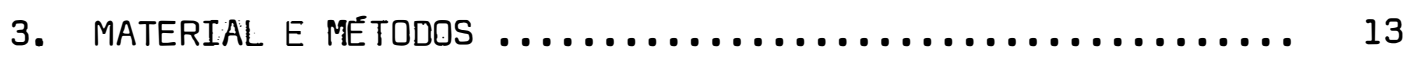

3.1. Material ............................... 13

3.1.1. Generalidades $. . \ldots \ldots \ldots \ldots \ldots \ldots \ldots \ldots \ldots . \ldots \ldots$

3.1.2. Medida da Evaporação $. . . \ldots \ldots \ldots \ldots \ldots \ldots . .13$

- Tanque Classe A ....................... 15

- Tanque Classe A à Nível Constante ........ 15

3.1.3. Medida da Evapotranspiração $\ldots \ldots \ldots \ldots \ldots \ldots .18$

3.1.4. Elementos do Clima ................... 22

3.2. Métodos $. . \ldots \ldots \ldots \ldots \ldots \ldots \ldots \ldots \ldots \ldots \ldots \ldots \ldots, 22$

3.2.1. Medida da Evaporação $\ldots \ldots \ldots \ldots \ldots \ldots \ldots \ldots .22$

3.2.1.1. Funcionamento do Tanque Classe $A$ à Nivel Constante ............... 23

3.2.1.2. Considerações sobre o Efeito da Tem peratura do Reservatório de Recarga nas Medidas da Evaporação no Tanque Classe A à Nível Constante ........ 25

3.2.2. Medida da Evapotranspiração $\ldots \ldots \ldots \ldots \ldots \ldots .27$

- 3.2.3. Estimativa da Evapotranspiração .......... 28

3.2.4. Elementos do Clima .................... 30

3.2.5. Utilização e Análise dos Dados ........... 31

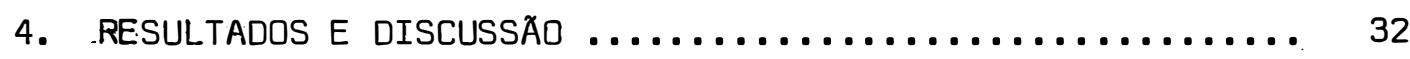

4.1. Relativos à Comparação entre Evapotranspiração Medi da (ETPM) e Estimada (ETPE)................... 32

4.2. Relativos à Comparação entre a Evapotranspiração Me dida (ETPM) e a Evaporação dos Tanques Classe A (TCA) e Classe A à Nível Constante (TCAM)............. 49 
4.2.1. 0 Coeficiente de Tanque Kp ............. 51

4.3. Relativos à Utilização do Tanque Classe A à Nível

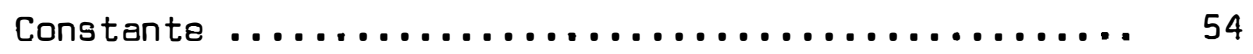

4.4. Relativos à Utilização do Evapotranspirómetro de Nível D'agua constante e Sistema de Registro ....... 57

5. CONCLUSÕES ............................. 60

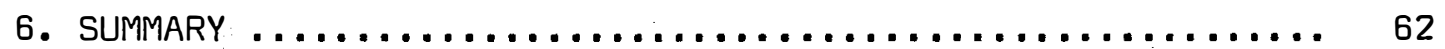

7. LITERATURA CITADA ............................... 63

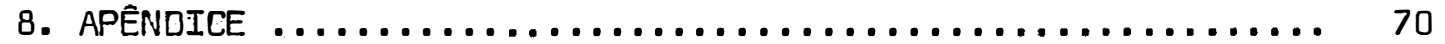




\section{LISTA DE TABELAS}

Pàg.

Tabela I - Valores diārios de Evapotranspiração medida(ETPM) e estimada (ETPE), Evaporação dos Tanques Classe A (TCA) e Classe A à nível Constante (TCAM), Precipitação Pluviométrica (PP), Temperatura do $\mathrm{Ar}$ (TM), Umidade Relativa do Ar (UR) e Velocidade

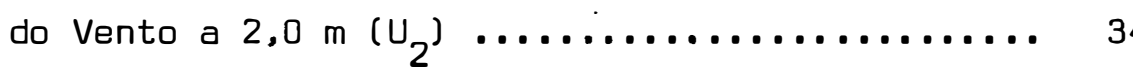

Tabela II - Valores médios de pêntadas de Evapotranspiração Medida (ETPM) e Estimada (ETPE), Evaporação dos Tanques Classe A (TCA) e Classe A à nível Cons-

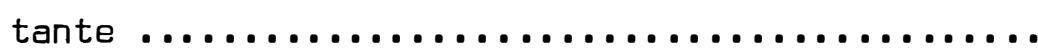

Tabela III - Análise de Variância dos dados de ETPM e ETPE - Va lores Diārios e Médios de pêntadas ............ 32

Tabela IV - Análise de Variância dos dados de Evapotranspiração Medida e da Evaporação dos Tanques Classe A e Classe $A$ à Nível Constante ................ 49

Tabela V - Teste. t para Comparação dos Parâmetros das Equações de Regressão da Tabela 4 ............... 50

Tabela VI - Valores dos Coeficientes de Conversão das Medidas da Evaporação em Tanques para Estimativa da Evapotranspiração Medida em Evapotranspirômetro..

Tabela VII - Valores Médios de ETPM e ET utilizados no Cálculo

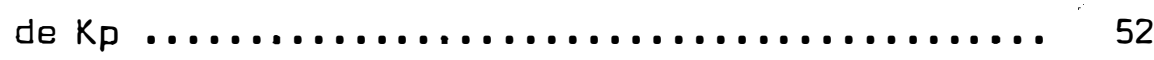

Tabela VIII - Valores Médios Mensais dos Coeficientes de Conver são das Medidas de Evaporação em Tanques para Estimativa da Evapotranspiração Medida em Evapotrans piraçãó Medida em Evapotranspirômetro ........... 


\section{LISTA DE FIGURAS}

Pāg.

Fig. 1 - Area Experimental $\ldots \ldots \ldots \ldots \ldots \ldots \ldots \ldots \ldots \ldots \ldots . .14$

Fig. 2 - Conjunto Tanque Classe A, Poço Tranquilizador, Para fuso Micrométrico e Estrado .................. 16

Fig. 3 - Conjunto Tanque Classe A à Nível Constante, Reserva tório de Recarga ........................... 17

Fig. 4 - Esquema do Evapotranspirômetro de THORNTHWAITE com nível d’água constante e Sistema de Registro ...... 19

Fig. 5 - Sistema de Registro do Evapotranspirômetro de nível

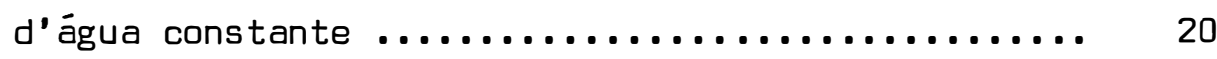

Fig. 6 - Esquema do Tanque Classe A à Nível Constante e Equí líbrio de Pressões ......................... 24

Fig. 7 - Curso Anual da Evapotranspiráção Medida e Estimada. 23

Fig. 8 - Curvas para Correção das Medidas de Evaporação no Tanque Classe A à Nível Constante ............. 56

Fig. 9 - Diagrama obtido no Evapotranspirômetro em um dia

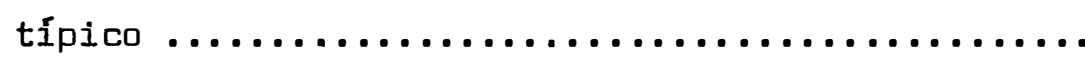

Fig. 10 - Diăgrama obtido no Evapotranspirômetro em um dia

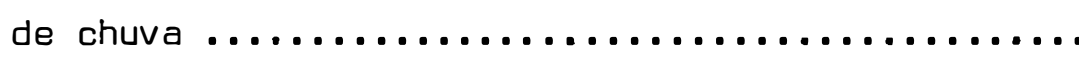




\section{RESUMO}

Trata este trabalho do estudo de algumas relações entre. vapotranspiração medida em Evapotranspirômetro e estimada pela equação de Penman e por tanques de evaporação.

Para medida da evapotranspiração foi adaptado ao Evapotranspirómetro de Thornthwaite de nível d'ágụa constante um sistema de re gistro diário, descrito no trabalho.

Descreve-se e discute-se uma modificação introduzida no Tanque Classe A baseada na manutenção da superfície evaporante e com dis pensa do parafuso micrométrico.

A análise dos dados revelou que a relação entre evapotrans piração estimada (ETPE) e medida (ETPM), em base diāria, para as condições da região de Piracicaba - SP, é de 0,81. Este valor foi atribuido à adveç çao local nao computada pela equação de Penman.

Apresentam-se valores médios mensais dos coeficientes de conversão das medidas de evaporação nos Tanques Classe A e Classe A à Ní vel Constante para estimativa da evapotranspiração. 


\section{INTRODUÇAO}

A evaporação e a transpiração que ocorre em uma superfície de solo vegetada, frequentemente combinadas no termo evapotranspiração , constitue uma fase importante do ciclo hidrológico,

Um grande número de problemas agrícolas requer, para sua solução, o conhecimento dos valores da evapotranspiração em períodos men sais, diários ou mesmo de poucas horas. Medidas diretas em períodos horá rios requerem o uso de equipamentos de custo elevado e de complexidade tal que limita seu uso por pessoal especializado a nível de instituições de pesquisa. Eles são utilizados, principalmente, em estudos do entendimento do processo físico da evaporação ou na calibração de outros instrumentos.

Muitas förmulas teóricas também são pasśiveis de fornecer estimativas precisas da taxa de evapotranspiração. O problema é que tais fórmulas, desenvolvidas em determinadas condições climáticaș e agrônomicas perdem parte de sua precisão quando transportadas para outras áreas , necessitando portanto' de correção local.

Neste sentido, equipamentos simples e fórmulas de fácil utilização para medidas e estimativas da evapotranspiração, com precisão 
adequada, é ó desejável para os projetos agrícolas.

.02 .

Talvez a maneira mais simples de estimar a evapotranspira ção de uma cultura sejà multiplicar a evaporação medida em um tanque por um fator adequado ou o coeficiente de cultura.

Em 1957, a Organização Meteorológica e a

"International Association of Scientific Hidrology" adotaram o Tanque Clas se A como um dos instrumentos de referéncia para uso nos trabalhos desen volvidos no Ano Geofísico Internacional, iniciado em julho daquele ano.

Em 1975, a FAO utilizou o Tanque Classe A nos es tudos das necessidades d'água para irrigação das culturas.

No Brasil, os estudos sobre evapotranspiração, são quase na totalidade, estimativas pelas fórmulas de Thornthwaite, Blaney e Criddle. Hargreaves e Penman, existindo poucas séries de medidas publicadas.

0 objetivo principal deste trabalho é estudar as relações entre a evapotranspiração medida em evapotranspirōmetro com nível d’água constante e sistema de registro diário e a evaporação medida em tanque Clas se $A$.

Outro objetivo é estudar uma adaptação efetuada no siste ma de medida da evaporaçäo no tanque Classe A. 


\section{REVISAO DA LITERATURA}

A evaporação da água do solo e a transpiração pelas plan tas constituem a perda d'água pelas superfícies vegetadas denominadas de evapotranspiração. Entretanto a evaporação mais a transpiração determinadas separadamente não são equivalentes a evapotranspiração, sendo mais conveniente considerar esta como uma única perda isolada (GANGOPADHYAYA, $1966)$.

Segundo THDRNTHWAITE e HARE (1965), a evapotranspiração compreende as seguintes fases: 1) movimento da água no perfil do solo em direção à sua superfície e à zona de absorção radicular; 2) movimento da ägua do sistema radicular para as superfícies das folhas; 3) evaporação da ägua através da superfície do solo e dos estômatos; 4) evaporação da água da chuva interceptada pelas folhas; 5) remoção do vapor d'água por fluxos turbulentos.

Com a mesma idéia geral, Thornthwaite em 1944 (THORNTHWA TE e HARE, 1965) e PENMAN (1956) introduziram o conceito de evapotranspi ração potencial. Para o primeiro autor a evapotranspiração potencial "é a perda d'água de uma superfície de solo úmido, completamente coberta por vegetação (sem especificar o tipo), suficientemente grande para tor 
nar desprezível o efeito de oásis. PENMAN (1956) acha desnecessário o ter mo evapotranspiração e prefere definir "transpiração potencial como a quantidade de água transpirada na umidade de tempo por uma cultura de por te baixo e altura uniforme, cobrindo totalmente o solo em condições óti 'mas de umidade". Completando a definição Penman acrescenta: "Para uma com pleta cobertura do solo por plantas de mesma cor, isto é, com o mesmo coe ficiente de reflexão, a taxa de transpiração potencial é a mesma indepen dentemente do tipo de planta pu solo, sendo determinada apenas pelas con dições do tempo". .

A.evapotranspiração e uma função de fatores meteorológicos, do solo e da planta (LEMON et alii,1957; SLATIER e McILROY, 1961). SEGI NER (1971) confirmando resultados de Monteith e van Bavel, demostra que em superfícies de solo ou planta, existe um valor crítico da resisténcia à difusão de vapor d'água abaixo do qual a evaporação cresce com a veloci dade do vento e acima do qual decresce com a aumento da velocidade do vento.

0 principal fator meteorológico que influencia a evapo transpiração é a radiação líquida (TANNER e LEMON, 1962; SEGINER, 1969) • Segundo TANNER (1960), a radiação líquida disponível a uma dada superfí cie vegetada é dividida em trés componentes básicos; aquecimento do ar, aquécimento do solo e evapotranspiração. Em regiões bem irrigadas, onde não existé déficit de água, mais de $80 \%$ da radiação líquidã é utilizada na evapotranspiração (UBING, 1961; LEMON, 1956). Por outro lado, a evapo transpiração pode exceder em muito a radiação líquida em culturas irrigadas circundadas por solo seco (HALSTEAD e COVEY, 1957; McILROY e ANGUS, 1964; EVANS, 1971). TANNER e LEMON (1962), relatam dados demonstrados que, em 
cultura irrigada de milho circundada por solo seco, a relação entre a eva potranspiração e a radiação líquida foi $20 \%$ maior do que quando a área ví zinha foi irrigada. LEMON . et alii (1975) encontraram para a mesma relação um valor de 1,65 para o período de 24 horas em cultura de algodão.

Para EAGLEMAN e DECKER (1965), a taxa potencial da evapotranspiração é governada somente pelas condições meteorológicas. A taxa a tual, entretanto, é influenciada pela dispoñäbilidade de água e pela deman da evaporativa da atmosfera. Já para VEIHMEYER e HENDCKSON (1965) a taxa de evapotranspiração é máxima, sob certas condições de demanda evaporativa, enquanto o teor da águia no solo se mantiver acima do ponto de murcha. Pró ximo desse ponto a evapotranspiração cai rapidamente passando a ser contro lada pelas características do solo. LEMON et alii (1957), são da opinião de que o potencial da água no solo, isoladdamente, não influencia a evapotrans piração, no que parece concordar com DENMEAD e SHAW (1962), quando afirmam que a relação entre a evapotranspiração e a umidade do solo varia com a demanda evaporativa da atmosfera.

A déterminação da evapotranspiração é um pró̀lema compartilhado por várias ciēncias que estudam o sistema solo-planta-atmosfera. Por causa das dificuldades de medidas diretas, diversos métodos empíricos ou semi-empíricos têm surgido. Assim, Thornthwaite (THORNTHWAITE e HARE, 1965) propós um método para estimar a evapotranspiração potencial baseado apenas em dados de temperatura média; Blaney e Cridle (PELTON et alii, 1960) desenvolveram um método baseado na correlação entre a temperatura e eva potranspiração com o ajuste de um coeficiente para cada cultura; Hargrea ves (HARGREAVES, 1974) apresenta uma fórmula que utiliza dados de umidade relativa do ar, temperatura média do ar e coeficiente de duração do dia e de cultura; Makkink (DODRRENBOS e PRUITT, 1975) baseia-se, principalmen- 
te, na radiação solar para estimativa da evapotranspiração potencial: PEN MAN, (1948, 1956) faz uso dos conceitos do balanço de energia e do método aerodinâmico no estabelecimento de uma equação que utiliza dados de radia ção líquida, temperatura média do ar, umidade relativa e velocidade do ven to.

Por meio de estudos de regressão entre valores medidos e estimados de evapotranspiração, DODRENBOS e PRUITT (1977) demonstram que todas as fórmulas empíricas necessitam de correção local.

Os métodos micrometeorológicos (ROSEMBERG, 1975; GOLTS

et alii, 1970) apresentam segundo TANNER (1960), a vantagem sobre os de mais por permitirem estimativas da evapotranspiração para períodos de uma hora ou menos o que é válido para aferição de outros métodos. GRANT (1975), utilizando lisímetro e sonda de néutrons como métodos "Padrão" para medida da evapotranspiração em uma cultura de cevada concluiu que, quando a ra zão de Bowen é pequena, este é o melhor método para medida da evapotranspi ração ao longo de todo o ciclo da cultura. Para TANNER (1960) todos os mé todos que usam medida de umidade do solo para estimativa da evapotranspira ção, não podem ser usados para períodos menores do que cinco dias devido aos erros associados às medidas diărias.

O único equipamento capaz de medir a evapotranspiração com razóavel eficiència é o lisímetro BLACK et alii, (1968).van BAVEL, 1962), recomenda a lisimetria como o único método praticável para determinar a evapotranspiração com precisão adequada. Lisímetros são dispositivos cons tituídos de um volume de solo isolado do solo circunvizinho de tal modo a medir todos (ou suprimir alguns) termos da equaçäo geral do balanço da ägua (TANNER, 1968). GANGOPADHYAYA et alii (1966) estabeleceram os princi 
pais cuidados na instalação dos lisímetros: 1) o lisímètro deve ser sufi cientemente grande para assegurar a sua representatividade no que diz res peito a cobertura vegetal e efeito de sua presença; 2) as condições físí cas no interior do equipamento devem ser as mesmas da área vizinha; 3) de viem ser instalados em Iocais onde os efeitos de advecção sejam minimizados. KING et aliii (1957) chamam a atenção para o fato de que na instalação dos lisímetros, sua superfície se apresente indistinguível da ärea circundante, igualmente vegetada e com as mesmas condições de umidade. Para SLATIER e McILROY (1961) essa área deve ser pelo menos dez vezes a área do lisímetro. Lisímetros de precisão, passíveis de fornecerem bons re sultados em períodos curtos (l hora ou menos) são utilizados por um gran de número de pesquisadores como PRUITT (1960); McILROY e ANGUS (1963);KING et alii (1957); BLACK et alii (1968); DENMEAD e MCILROY (1970); BLAINE e ROSEMBERG (1974) entre outros.

Um tipo de lisímetro foi proposto por Thornthwaite em 1945 (MATHER, 1954), denominado evapotranspirómetro. Consiste de um tanque de quatro metros quadrados com 70 centímetros de profundidade, dotado de dispositivos de suprimento e percolação de água como o nível de água manti do constante por meio de um sistema de válvula e bóia. GANGOPADHYAYA et alii, (1966) e MARQUES (1972) apresentam uma revisão relatando e discutindo as sucessivas modificações introduzidas no modelo original de Thornthwaite.

0 evạpotranspirómetro, basicamente, é um instrumento para medida da evapotranspiração potencial (GANGOPADHYAYA et alii 1961; SLATIER e McILROY, 1961), embora seja também utilizado em estudos de evaporação do SOlO (MARQUES, 1972). 
Os resultados de evapotranspiração potencial obtidos nes tes equipamentos só serão válidos, segundo SLATIER e McILROY, (1961) se $\underline{u}$ ma padronização da cultura for utilizada em todas as medidas e se o equipa mento estiver instalado em local com a área vizinha no mesmo regime de umi 'dade no solo.

$$
\text { EKERN (1966) utilizando evapotranspirómetros de }
$$
thwaite com cobertura vegetal de Capim-bermuda, observou valores médios da relação evapotranspiração medida e evapotranspiração de tanques iguais a 0,60, 0,68 e 0,69 para 1957, 1958 e 1959, respectivamente.

CAMARGO (1966), em três localidades do Estado de São Pạ 10, comparou evapotranspiração medida em um tipo de evapotranspirómetro de THORNTHWAITE modificado e estimada segundo as fórmulas de Thornthawaite, Penman-Bavel, Blaney e Criddle e Blaney e Criddle adaptada para as suas condições, encontrando altas correlações entre os valore medidos e estima dos.

Uma alternativa para estimar a evapotranspiração é o uso de tanques. Embora com certa similaridade física o processo de evaporação não é idêntico à evapotranspiração (CHANG, 1971), pois mesmo com total a bertura estomática a resistência à difusão do vapor d’água é maior na su perfície das folhas do que numa superfície livre de água. Por outro lado, o. balanço de energia e a rugosidade aerodinàmica das superfícies de água diferem das vegetadas (TANNER, 1968; FRITS'̈HEN e SHAW, 1961). Entretanto a evapotranspiração potencial de uma culturapode ser estimada por tanques de evaporação com o uso de um coeficiente adequado, pré-determinado, como revę la a literatura, (PRUITT, 1966; SLATIER e MCILROY, 1961; THOMPSON e BOYCE, 1967; MCILROY e ANGUS, 1964; BOHNNME e GRANCHER, 1973; EAGLEMAN, 1967; YU e 
BRUTSAERT, 1967; HANSON e RAUZI, 1977; DILLEY e SHEPHERD, 1972; ARMY e OSTLE, 1957; FRITSCHEN e SHAW, 1961; GORNAT et alii, 1971; PECK et alii. , 1968; CLOVER e FORSGATE, 1964; PARMELE e MCGUINESS, 1974; KRISHAMIN e KUSHWA, 1973; PHENE e CAMPBELL, 1975; AGUIAR, 1975; PRUITT E DOORENBOS: , 1977; DOORENBOS e PRUITT, 1975; SCALOPI, 1972).

A validade da medida de evaporação em tanques para estimativa da evapotranspiração de uma cultura depende do tipo de tanque, cali bração e interpretação dos dados em relação ao ambiente (PRUITT, 1966), da precisão da medida do nível da água (PHENE e CAMPBELL, 1975) e da forma de expor o tanque (HANSON e RAUZY, 1977; OOORENBOS e PRUITT, 1965).

Segundo DALE e SCHEERINGA (1977) o tanque Classe A foi adotado pela Organização Meteorológica Mundial e a "International Association of Scientific Hidrology" como um dos instrumentos de referência para o Ano Geofísico Internacional.

DOORENBOS e PRUITT (1975), num estudo realizado para a FAO, utilizam o tanque Classe $A$ e os métodos de Pennam, Blaney e Criddle e Makkink para estimativa da evapotranspiração com vistas a práticas agrícolas. Os mesmos autores fornecem um exçelente guia de utilização dos méto dos acima citados.

Com a ajuda de um coeficiente que expressa a relação en Ie -a- evapotranspiração de uma cultura e a evaporação do tanque Classe A (aqui denominado de $\mathrm{Kp}$ ), estes dados podem ser utilizados no planejamento de práticas de irrigação. Alguns trabalhos mostram como Kp varia com o es tágio de crescimento da planta (DOSS et alii, 1964; EKERN, 1966; van BAVEL, 1962; DOORENBOS e PRUITT, 1975; FRITSCHEN e SHAW, 1961), com a umidade do solo (EAGLEMAN e DECKER, 1965; MAKKING e HEEMST, 1956; SLATIER, 1956; DALE 
e SCHEERINGA, 1977) e com a demanda evaporativa da atmosfera em interação com as condições de umidade do solo (BAHRANI e TAYLOR, 1961; LEMON et alii; 1957$)$.

Segundo PRUITT (1977) "embora a evaporação de tanques pa reça oferecer uma das melhores estimativas da evapotranspiração potencial em grande variedade de climas, diferenças no local de instalação do tạn que bem como valores de velocidade do vento, umidade e radiação podem afe tar grandemente os resuitados".

DILLEY e SHEPHERO (1972), em Aspendale, Austrália, confír mam a adaptabilidade do tanque Classe A para estimar a evapotranspiração de uma cultura de batata em diversas condições de umidade do solo. 0 coefí ciente de correlação entre a evapotranspiração da cultura computada pela fórmula e de McILROY e a evaporação do tanque foi de 0,94. Quando a correlação foi feita entre a evaporação do tanque e dados de lisímetros com gra mínea o coeficiente foi maior do que 0,97. Para as mesmas condições de Dilley e Shepher, McILROY e ANGUS (1964) demonstram que "a evapotranspiraçäo de uma superfície plantada com gramínea bem suprida de água pode exce der a evaporação do tanque Classe A $120 \%$ anvalmente e até $50 \%$ em alguns me ses) e que cada processo utiliza mais energia do que a disponível no local". "A principal razão para este fato é devida à diferença de rugosidade e ní vel das duas superfícies no primeiro caso e à magnitude da energia advecti va das áreàs relativamente áridas da região, no segundo. Resultados seme lhantes foram observados por EVANS (1971) trabalhando com cultura de arroz nas mesmas condições de clima.

THOMPSON e BOYCE (1967) comparam a evapotranspiração lisí métrica da cana-de-açúcar, no Hawai, com estimativas pela fórmula de 
Penmam e medidas em um tanque Classe A. A melhor relação encontrada foi en tre a evapotranspiração medida e a estimada pelo tanque Classe $A$, sendo obtido um valor de Kp igual a unidade, confirmando resultados de outros pes quisadores. A fórmula de Penman, subestĩmou a evapotranspiração quando a adveção foi "aparentemente" elevada.

AGUIAR (1975) comparando métodos de estimativa da evapotranspiração potencial em cultura de feijão comum, nas condições de Piraci caba, SP, encontrou um valor de Kp igual a 0,7 em relação à fórmula de Penman, concluindo que a evaporação do tanque Classe A superestimou a evapotranspiração determinada pelos métodos de Penman, Hargreaves, van Bavel e Thornthwaite e, ainda a evaporação do tanque GGI-3000 nos tratamentos irrigados. Nos tratamentos não-irrigados a evaporação dos tanques Classe A e GGI-3000 não apresentou diferença significativa.

SCALOPI ( 1972), numa cultura de batata, comparou a evapo transpiração medida pelo método gravimétrico com a estimada pela evaporação do tanque Classe $A$, encontrando valores de $K p$ de 0,59, 0,68 e 0,69 quan do os valores de umidade no solo variaram de 25, 50 e 75\% da água disponí vel, respectivamente. A fórmula de Penmam forneceu a estimativa mais apro ximada dos valores medidos, principalmente, nos tratamentos com níveis mais elevados de água disponível. SCARDUA (1970) utilizando os mesmos métodos na cuítura de milho apresentava valores médios de $\mathrm{Kp}$ de 0,56 para os tra tamentos não irrigados e 0,80 para os irrigados.

Para FERRAZ (1972), com o auxílio da tanque Classe A, Pode-se também acompanhar as variações do teor de água no solo desde que se conheça a relação entre a evaporação real e a evaporação do tạnque.Em seu trabalho foi observado que o valor de Kp médio variou de 0,70 para 0,29 
quando a tensão da água no solo cresceu de 500 para 1500 mb. A evapotranspiração real foi medida pela técnica de moderação de nêutronṣ.

Usando a mesma técnica de FERRAZ (1972), CRUCIANI (1972) apresenta resultados de evapotranspiração de uma cultura de cana-de-açúcar e da evaporação do tanque Classe A instalado no meio da cultura. Dividin do a cultura em três estágios de crescimento fixados pelas estações do a no, Cruciani encontrou os seguintes valores de Kp: $1^{8}$ estágio - outono- in verno-0,42; $2^{8}$ estágio- primavera-verão - 0,76 e $3^{8}$ estágio - outono - in verno - 0,71 sendo o valor central o mais significativo para projetos de irrigação, uma vez que caracteriza o estágio de maior consumo de água pe la cultura.

VILLA NOVA (1967) num estudo da evaporação potencial no Estado de São. Paulo apresenta um válor médio de Kp em relação a fórmula de Penman igual a 0,84. Já para OLIVEIRA (1971), nas condições de Piracicaba - valor do mesmo coeficiente foi de 0,72.

KRISHAN e KUSHWAHA (1973) com análise de regressão múltị pla encontraram coeficientes de correlação altamente significativos entre a evaporação do tanque Classe A e a Radiação Global, Radiação Líquida estị mada, velocidade do vento e déficit de saturação à máxima temperatura. . 
.13.

\section{MATERIAL E METODOS}

\subsection{Material}

\subsubsection{Generalidades}

Os dados utilizados neste trabalho foram obtidos na Estação Meteorológica do Departamento de Física e Meteorologia da Escola Superior de Agricultura "Luiz de Queiroz", Piracicaba, São Paulo, que apresenta as seguintes coordenadas geográficas (Fig. 1):

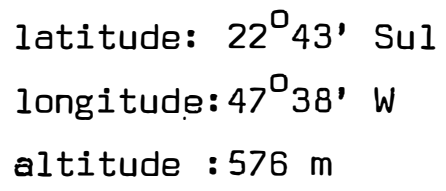

O solo foi classificado como Terra Roxa Estruturada, série Luiz de Queiroz (Alfisol), segundo RANZANI et alii (1966).

Utilizaram-se dados de evaporação, evapotranspiração medida e estimada, temperatura e umidade relativa do ar, velocidade do vento a $2,0 \mathrm{~m}$, insolação e precipitação pluviométrica, obtidos num período de 12 meses, de novembro de 1976 a novembro de 1977.

\subsubsection{Medida da Evaporação}




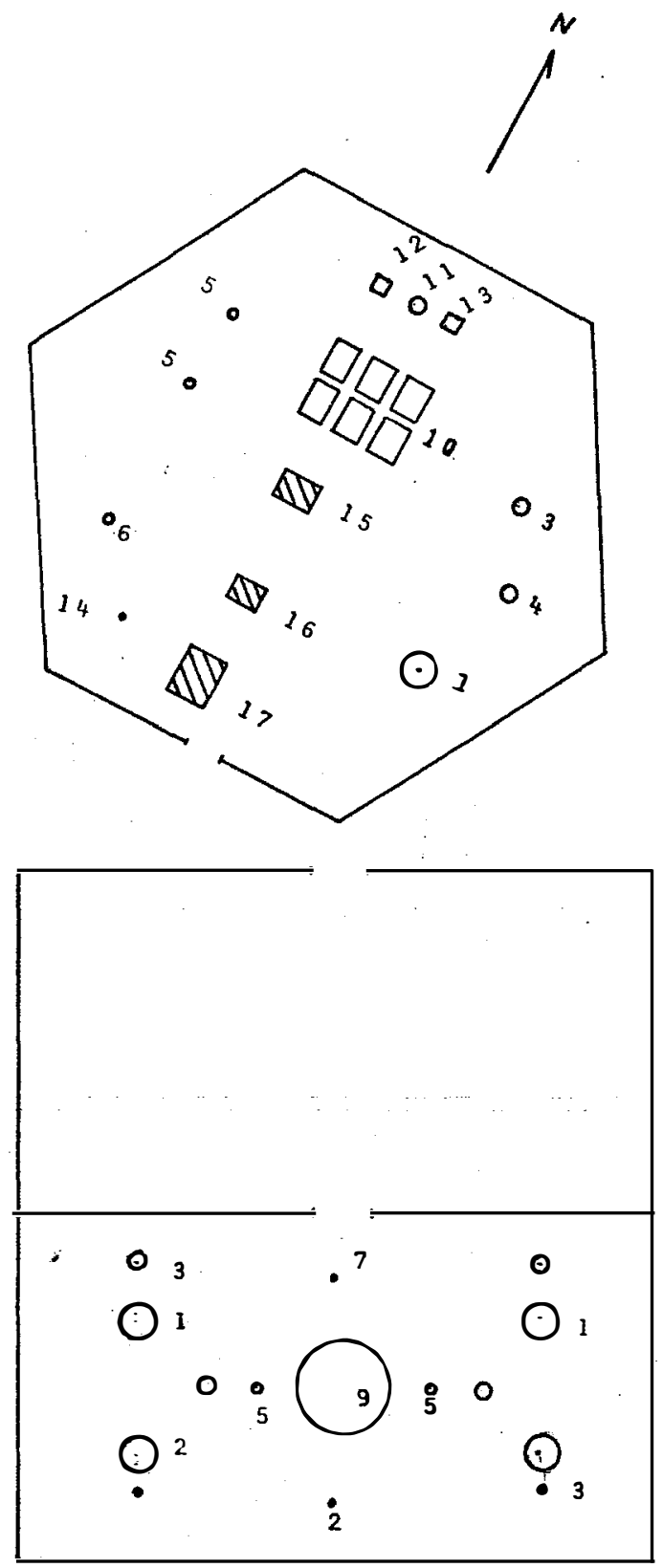

1. TCA

2. TCAM

3. GGI-3000

4. YSP

5. Pluviometro

6. Pluviógrafo

7. Anemómetro $(0,5 \mathrm{~m})$

8. Anemómetro $(2,0 \mathrm{~m})$

9. Tanquie de $20 \mathrm{~m}^{2}$.

10. Evapotranspi rómetro

11. Sistema 'de Registro do Evapot ranspi rômetro

12. Actinógrafo

13. Heliógrafo

14. Para-raio

15. Aurigo Meteorológico

16. Anemógrafo

17. Casa do Observador 
Os dados relativos a evaporação foram obtidos em tanques com as seguintes características:

- Tanque Classe A - Tanque cilíndrico, fundo plano, cons truído inteiramente de chapa de ferro galvanizada 22 (AWG), diāmetro de $120 \mathrm{~cm}$ e altura de $25 \mathrm{~cm}$; (Fig. 2); são sèus principais componentes: a) um poço tranquilizador construído de um tubo de ferro galvanizado, com $20 \mathrm{~cm}$ de altura, dotado, em sua base de parafusos niveladores; b) um parafuso mi crométrico em forma de gancho que se assenta sobre a borda do tranquilizador, com capacidade de medir variações no nível da água de 0,02 mm. 0 tan que foi instalado sobre um estrado de madeira convencional construído de caibros com as seguintes dimerisões: $10 \times 5 \times 124$ centímetros.

- Tanque Classe $A$ à Nível Constante - E um tanque com as mesmas características gerais do tanque Classe $A$, no que diz respeito as dimensões, construção e instalação; a moḍificação proposta neste trabalho encontra-se esquematizada na Fig. 3. O reservatório de recarga (A) é cons truído do mesmo material do tanq̣ue, porém pintado de branco. A relação en tre a seç̧ão do reservatório e a do tạnque permite leituras da variação do nível d’água com precisão de $0,05 \mathrm{~mm}$. 


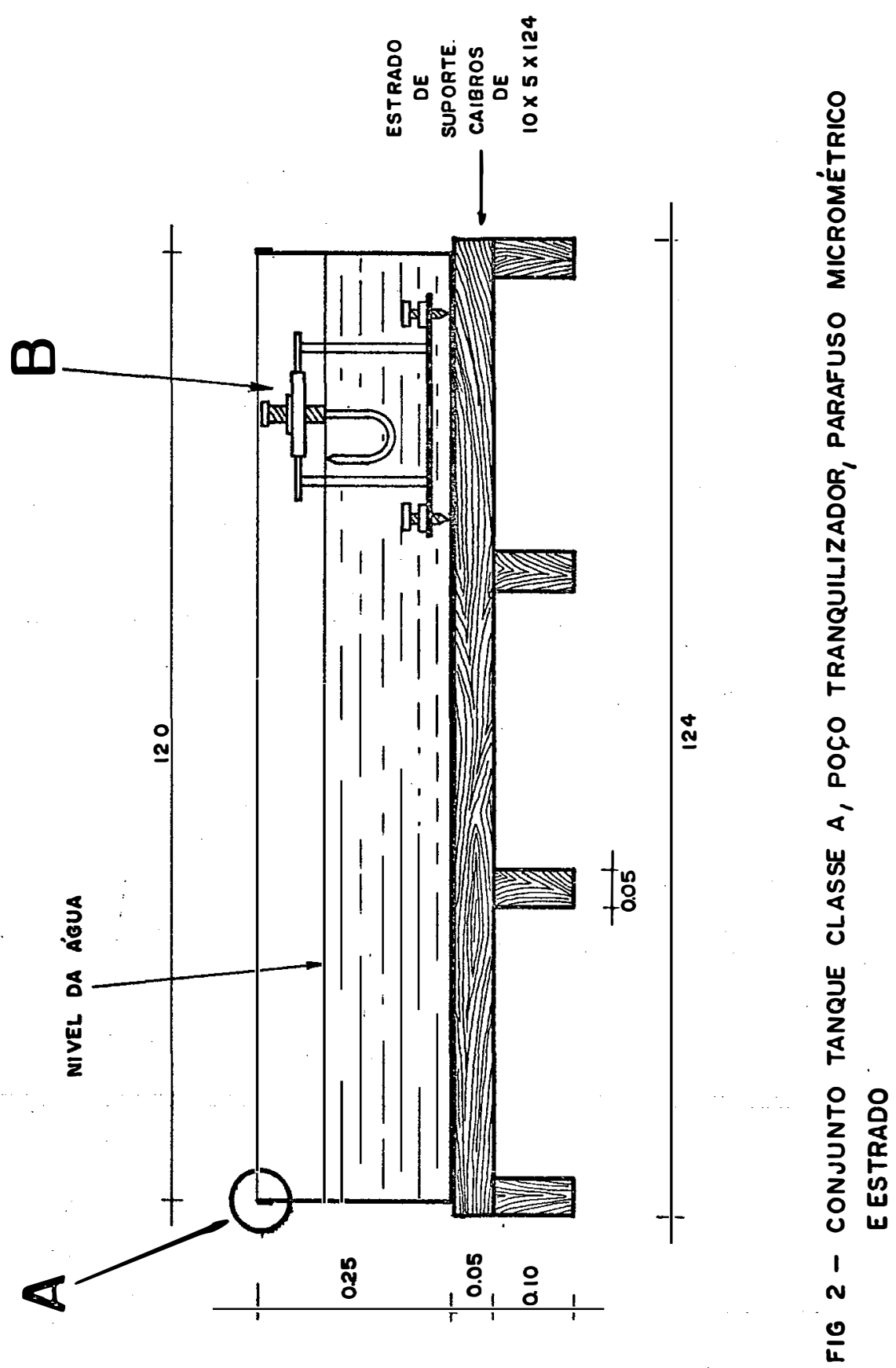




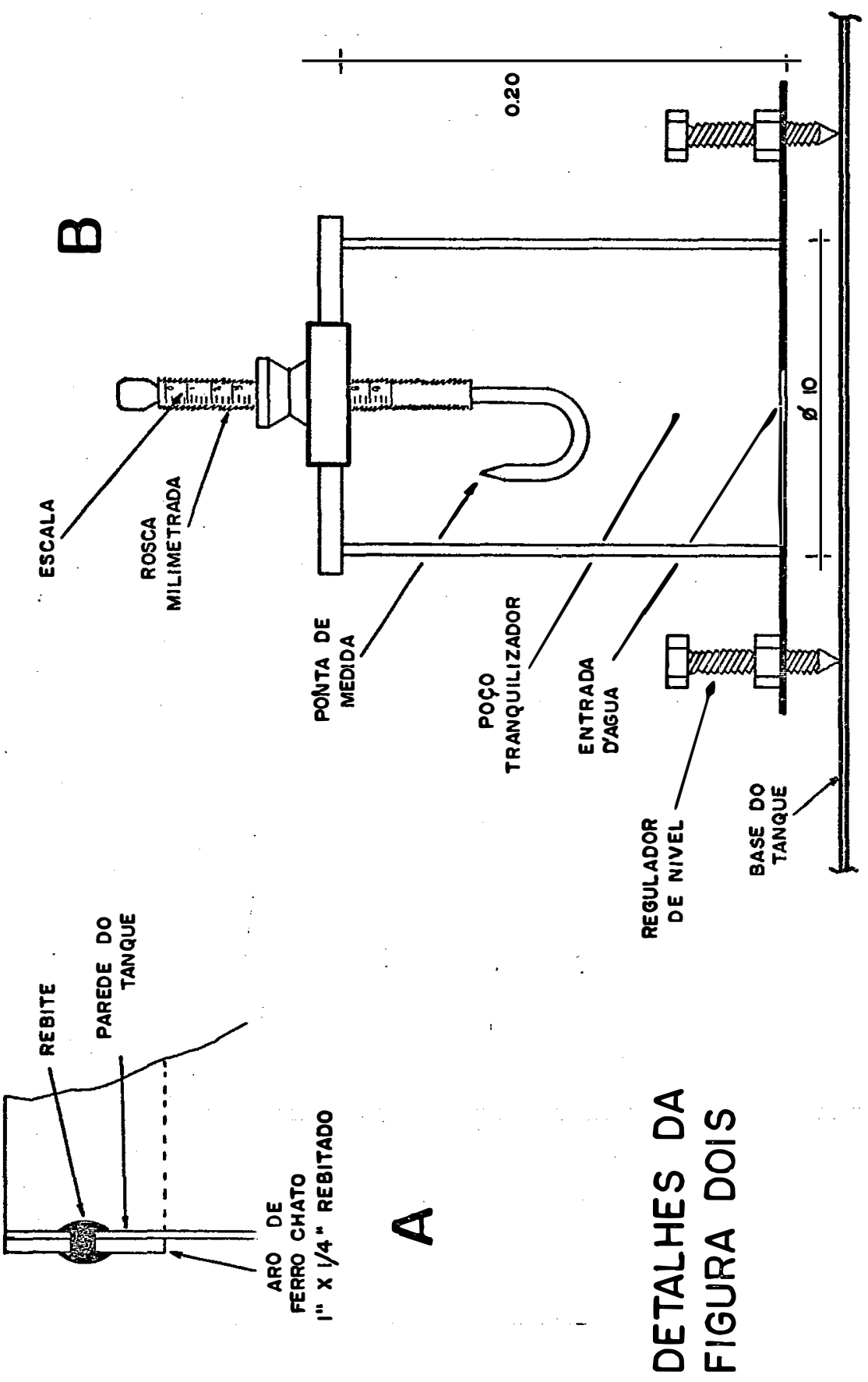




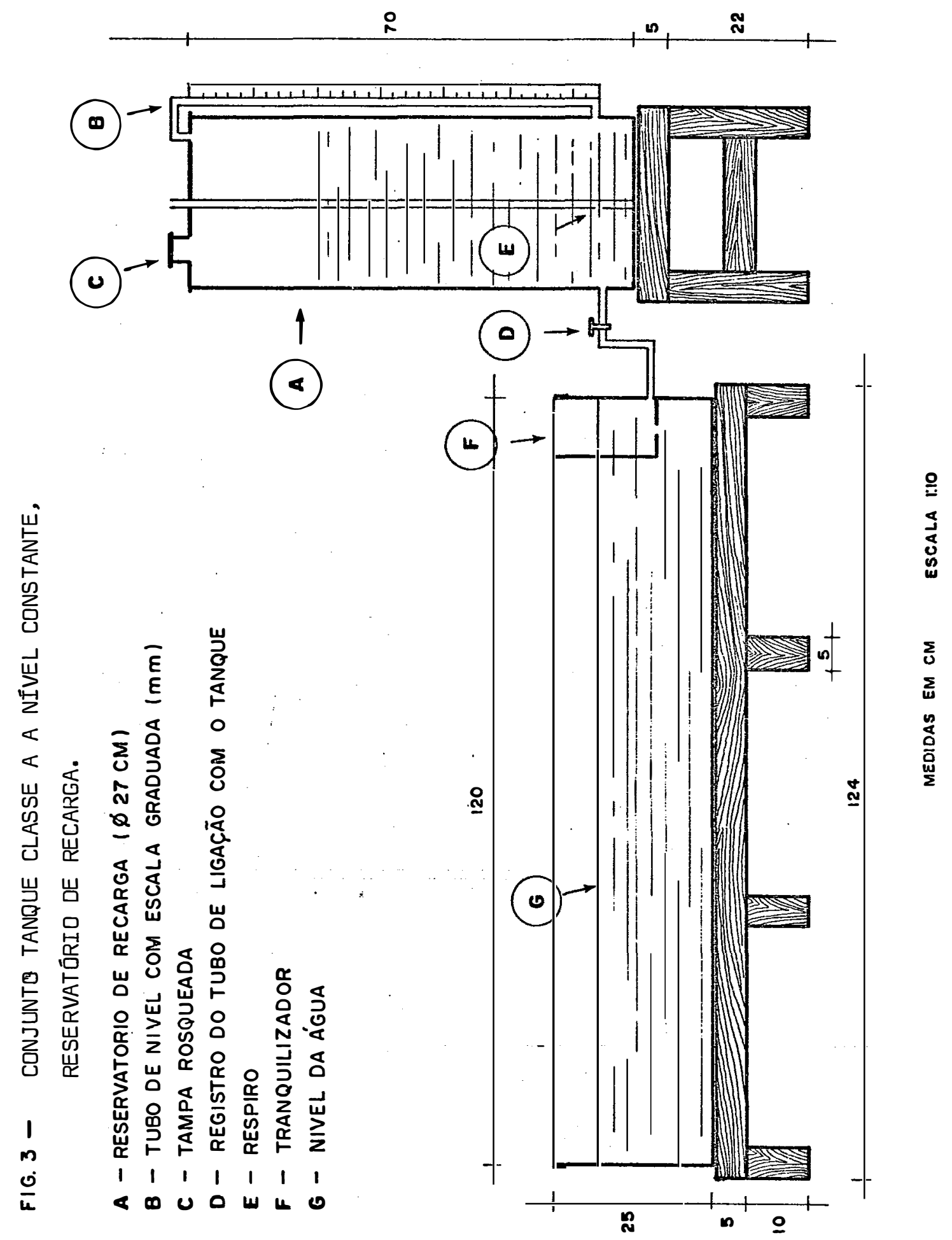




\subsubsection{Medida da Evapotranspiração}

As medidas de evapotranspiração foram efetuadas em ' evapo transpirômetro tipo Thornthwaite (THORNTHWAITE e HARE, 1965; MATHER, 1954) adaptado para a realização deste trabalho.

Utilizou-se uma bateria de 3 evapotranspirômetros dos cincojá instalados na Estação Meteorológica da ESALQ em 1956. Cada unidade consta de um tanque de alvenaria, convenientemente impermeabilizada, enterrado,de forma retangular nas seguintes dimensões: $135 \times 185 \mathrm{~cm}$ e com $70 \mathrm{~cm}$ de pro fundidade; tem no fundo uma zona de drenagem constituída de uma camada de brita $n^{8} 1$ e outra de areia grossa.E um tubo de ferro galvanizado de 4,0 cm de diāmetró que vai ter a outro tanque com as mesmas dimensões; o solo uti lizado no enchimento dos tanques, obedecendo o perfil natural, foi do mes mo tipo da área onde está instalado o equipamento; o revestimento vegetal é constituído de gramínea (Paspalum notatum, Flegg) mantida, por meio de cortes periódicos, à cerca de $10 \mathrm{~cm}$ de altura.

As três unidades selecionadas foram ligadas entre si por meio de tubos plásticos flexível, que partindo dos tubos de drenagem foram ajustados a uma cruzeta construída de tubos de ferro igual aqueles de dre nagem; o quarto ramo da cruzèta foi, de modo igual, ligado a uma caixa de ferro, galvanizado $n^{8} 22$ (AWG). (Fig. 4 ). No lado dia caixa oposto a liga ção com a cruzeta foi adaptada uma válvula do mesmo tipo da utilizado em cạ burador de automóvel, controlada por uma bóia de plástico. A saída da vál vula foi ligada com tubo plástico flexível ao reservatório de recarga. Es te era cilíndrico, contruído de chapa de ferro galvanizado $n^{\circ} 22$ (AWG) pin̄ tada de branco e com as seguintes dimensões: $55 \mathrm{~cm}$ de diámetro e $80 \mathrm{~cm}$ de altura; era dotado de sifão instalado de tal modo que a extremidade do seu 

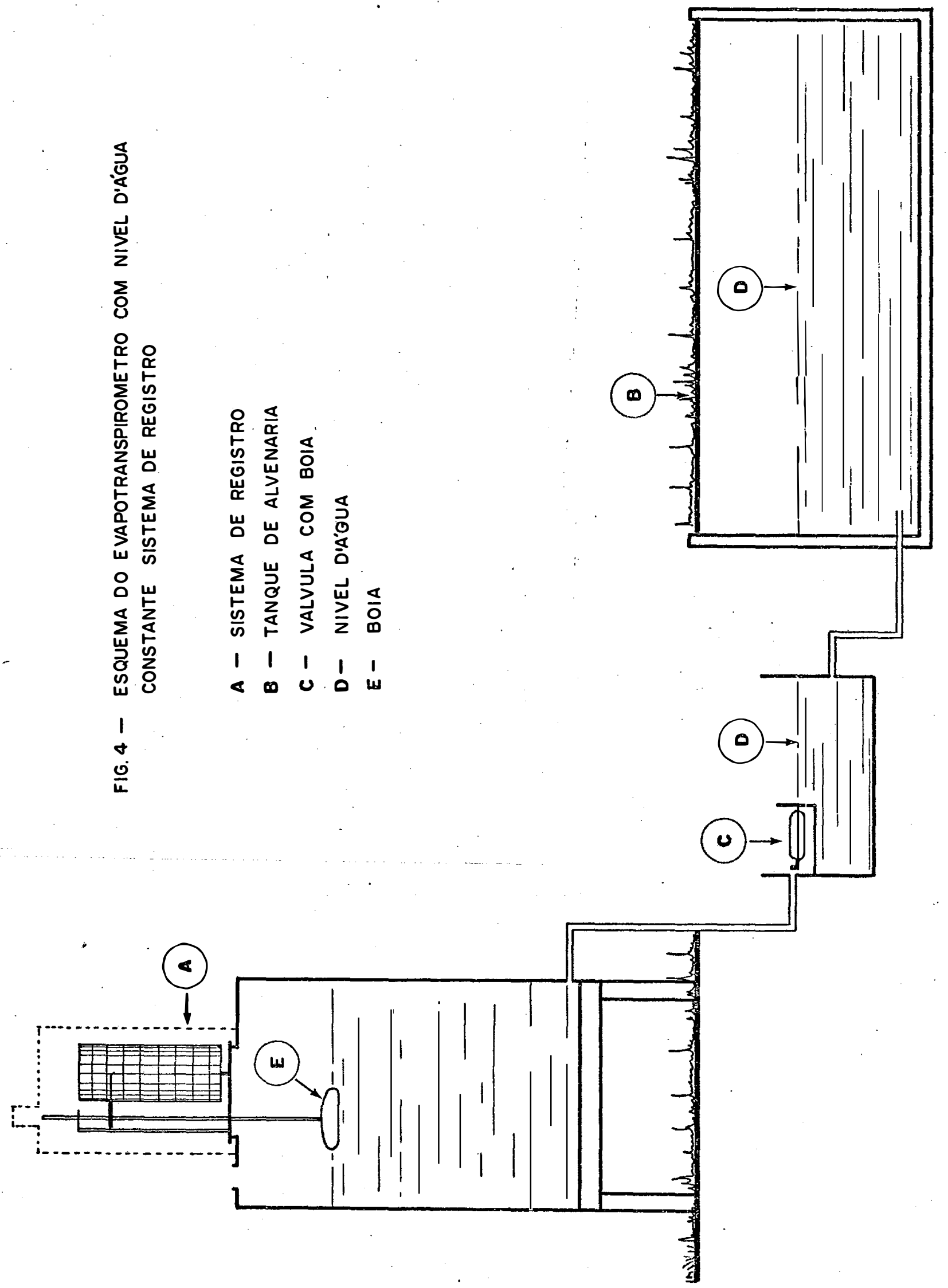


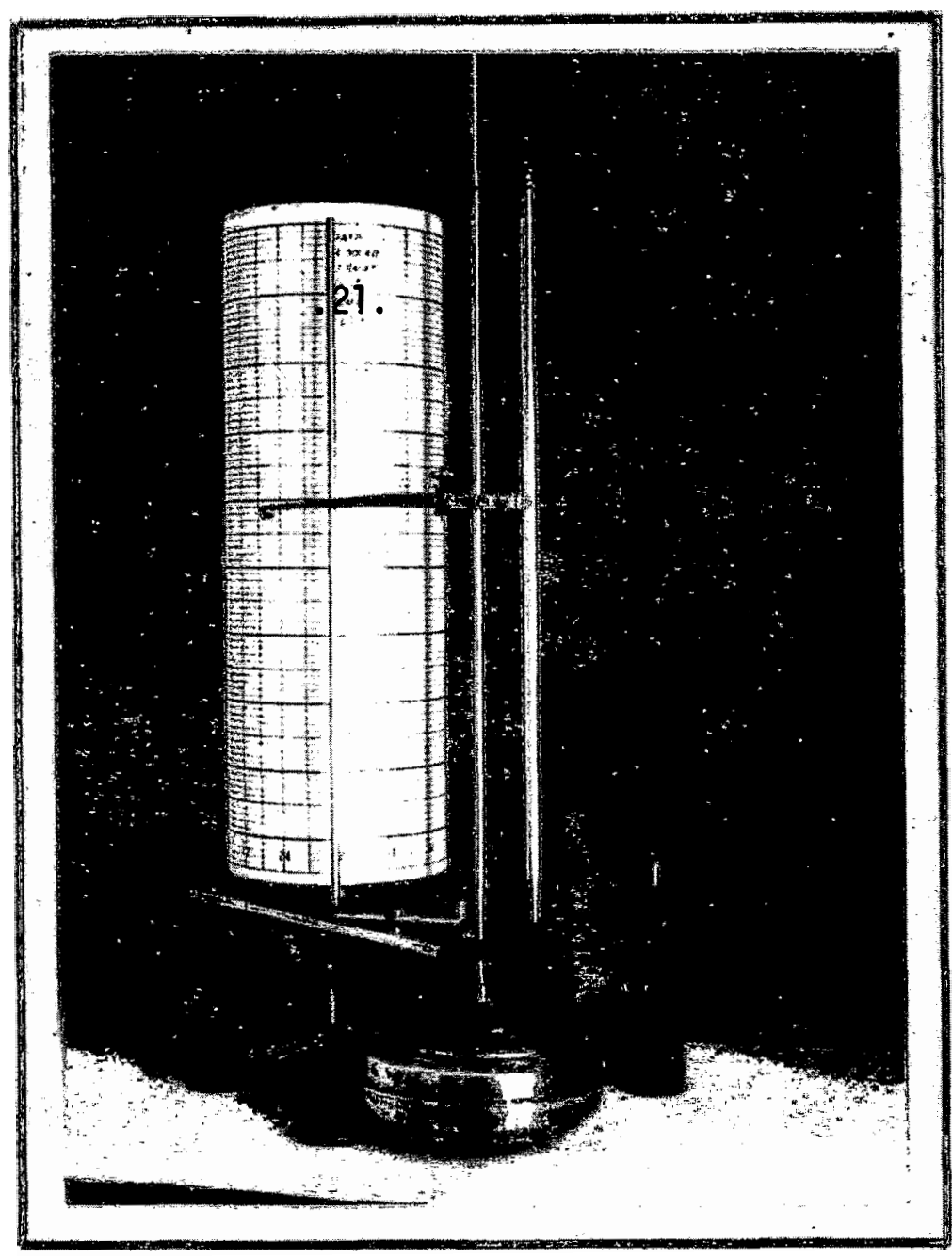

11g. 5 - Sistema de Registro do Evapotranspirōmetro 
ramo interno, com $3 \mathrm{~cm}$ de comprimento, fica a $10 \mathrm{~cm}$ da base superior do reservatório.

A principal adaptação proposta neste trabalho consta de um sistema de registro contínuo da evapotranspiração (Fig. 5). Tal sistema e ra constituído de um mecanismo de relógio e uma pena que traçava sobre um gráfico especial uma curva cumulativa da evapotranspiração em um dado pe ríodo. O mecanismo de relógio utilizado foì do mesmo tipo do termo-higrógra fo de marca Fuess de giro diário, com a altura do cilindro convenientemente aumentada para receber o papel registrado; o mecanismo de relógio foi instalado sobre uma base triangular de chapa de latão, dotada de parafusos niveladores simplesmente apoiados sobre a base do reservatório. A pena, com depósito de tinta, foi adapatada ao eixo de uma bóia de latão. Para o sistema assim constituído foi construído um abrigo de chapa de ferro galva nizado. 0 papel registrador (Fig. 9) com divisão de uma hora no sentido ver tical e com linhas espaçadas de uma distância igual a 0,1 mm de evapotrans piração, na horizontal, foi impresso em papel sulfite e tratado com uma so lução a 10\% de parafina em benzina. A montagem assim descrita, esquematiza da na Figura 4 permite o funcionamento do evapotranspirômetro,com nível d' ägua constante. 


\subsubsection{Elementos do Clima}

A temperatura do ar foi obtida por meio de termómetros de máxima e mínima de marca Fuess com sensibilidade de $0,2^{\circ} \mathrm{C}$ instalados em a brigo meteorológico. A umidade relativa do ar foi registrada, continuamente, em um termo-higrógrafo de marca Fuess, de rotação diária, apresentando precisão de 5\% para UR.

A velocidade do vento a 2,0 metros de altura foi medida em anemōmetro integrador marca Fuess modelo 92b que fornece uma leitura acumu lada em Km até um total de 9999,99.

Os dados de precipitação foram obtidos em um pluviógrafomar ca Fuess, modelo 95 com sifonação e registro diário. Apresenta um diagrama com variação de $10 \mathrm{~mm}$ e divisão de $0,1 \mathrm{~mm}$ de precipitação.

0 heliógrafo usado na obtenção dos dados de insolação foi de marca Fuess, modelo 26 c.

\subsection{Métodos}

\subsubsection{Medidas da Evaporação}

As medidas de evaporação foram efetuadas diariamente as 7 horas, em duas repetições. Adotou-se como critério só computar os dados nos dias de pouca precipitação.

0 nível da água no tanque classe A foi inicialmente deixado a $5,0 \mathrm{~cm}$ da borda e restabelecido quando se aproximasse ou atingisse 7,5 cm. As leituras foram efetuadas com o parafuso micrométrico. A evaporação computada em um período de 24 horas era obtida pela diferença entre a lei tura do dia anterior eventualmente acrescida da precipitação obtida no 
pluviógrafo.

No tanque Classe $A$ a Nível Constante, o nível da água foi. mantido a $6,2 \mathrm{~cm}$ da borda. Isto foi possível graças a modificação efetuada no método de leitura.

\subsubsection{Funcionamento do Tanque Classe $A$ a Nĩvel Constante}

A montagem proposta para o tanque Classe A está esquemati zada na Figura 6. Baseia-se na manutenção do nível da superfície evaporante. Estando o reservatório de recarga com água e o tanque com água até a altura "h", a pressão nos pontos "A" e "B" será igual a pressão atmosférí ca e o níveí no tanque permanecerá constante na ausência de evaporação. As sim o peso da coluna "L", no reservatório, será equilibrado pela pressão

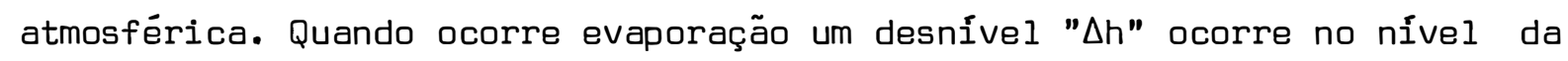
água do tanque provocando a formação de um menisco no respiro "B". Conti nuando a evaporação, o menisco aumenta até formar uma bolha de ar que se desprende e vai ocupar o espaço "vazio" na parte superior do reservatório. Cómo consequência a coluna de água do reservatório é reduzida de um valor " $\Delta \mathrm{L}$ ". 0 volume de água "s $\Delta \mathrm{L}$ ", corresponde a diminuição da coluna, será utí lizado no restabelecimento do nível "h" no tanque. Deste modo, o nível "h" permanecerá constante independentemente do comprimento da coluna "L". A montagem assim descrita tem seu funcionamento expresso pela relação

$$
H=f \frac{s \Delta L}{S}
$$

onde os termos significam:

$H:=$ somatório dos $n \Delta h$ ocorridos num intervalo de tempo = evaporação do período $(\mathrm{mm})$. 

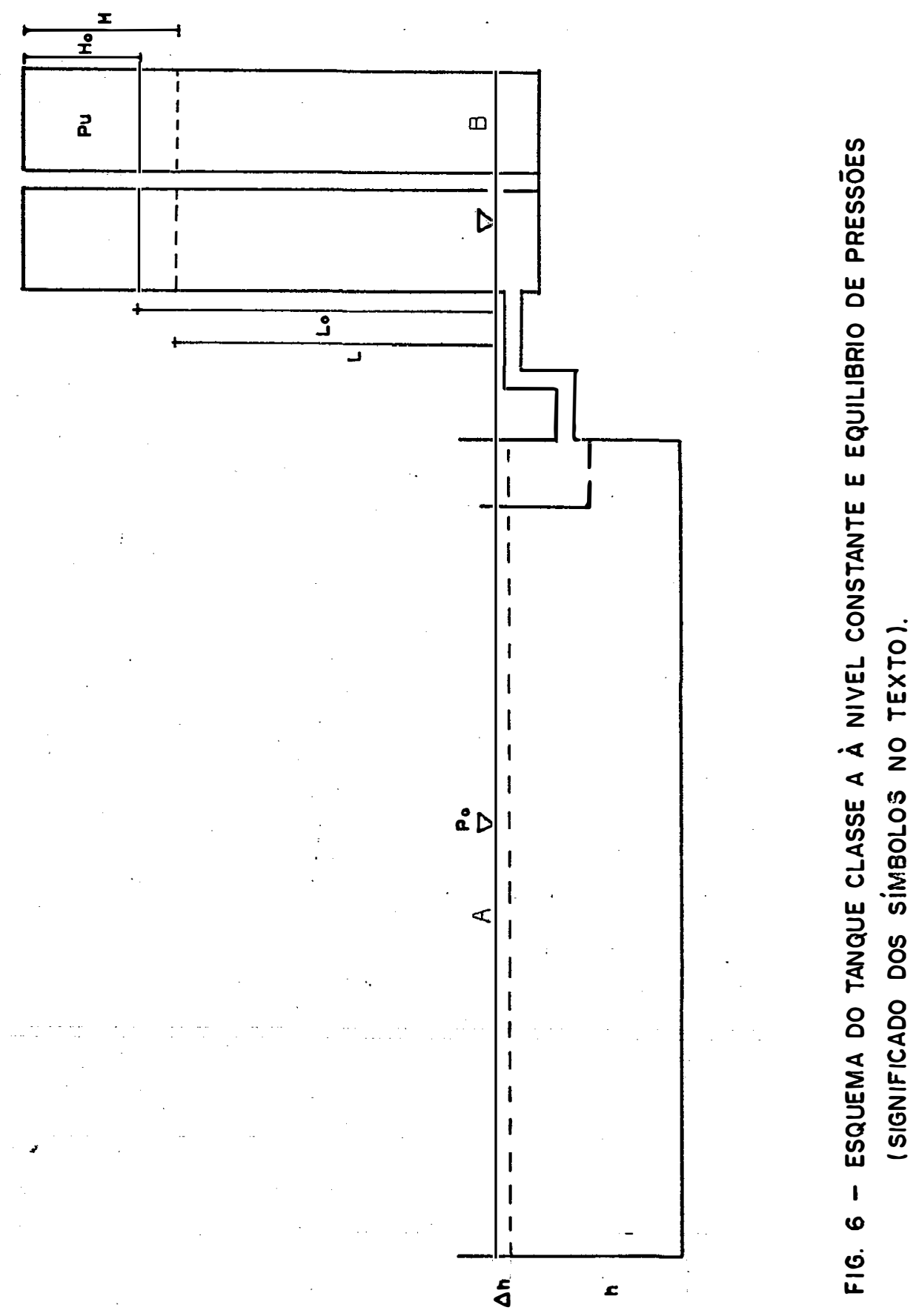
$\Delta \mathrm{L}=$ variação do comprimento da coluna d’água no reservatório $(\mathrm{mm})$.

$S=$ secção do tanque = superifície evaporante $\left(\mathrm{mm}^{2}\right)$.

$s$ = secção do reservatório $\left(\mathrm{mm}^{2}\right)$.

$f=$ fator de conversão dependente de $S$ e $\mathbf{s}$

\subsubsection{Considerações sobre o efeito da Temperatura do} Reservatōrio de Recarga nas Medidas da Evaporação

Observações num modelo reduzido do conjunto Tanque-Reservató rio de Recarga, demonstraram que a câmara livre (Fig. 6') se expande ou se contrai com a variação da sua temperatura. Deste modo as medidas da altura da coluna d'água (L) podem conter 始m erro devido a este efeito.

Na Figura 6 é apresentado o equilíbrio de pressões, sendo

Po $=$ pressão atmosférica

Ho = altura da câmara relativa as condições To, Puo

$\mathrm{H}$ = altura da câmara relativa as condições $\mathrm{T}, \mathrm{Pu}$

$P u_{0}=$ pressão do ar úmido no interior da câmara na condição de To

Pu $=$ pressão do ar úmido no interior da câmara na condição de $T$

$\mathrm{T}$ = temperatura do ar úmido na leitura atual

To = temperatura do ar úmido na leitura anterior

A correção de leitura, resultante, de acordo com exposto deverá ser então

$$
\Delta H=H-H_{0}
$$

De acordo com equação de eștado podemos escrever para o mo mento da leitura que 


$$
\frac{\dot{P}_{0} \cdot H_{0}}{T_{0}}=\frac{P_{U} H_{-}}{T}
$$

isolando Ho teremos

$$
H_{0}=H \cdot \frac{P_{U}}{P_{0}} \cdot \frac{T_{0}}{T}
$$

como nos interessa, Ho a relação 3.3. torna-se, depois, das transformações ne cessärias

$$
\Delta H=H\left(1-\frac{P_{u}}{P_{u_{0}}} \cdot \frac{T_{0}}{T}\right) \quad 3.4 \text {. }
$$

Substituindo $\frac{P u}{P U_{0}}$ da equação 3.4. por um valor $K$, teremos

$$
\Delta H=H\left(1-\dot{K} \frac{T_{0}}{T}\right) \quad 3.5 \text {. }
$$

Como pode-se observar na Fig. 6 , a pressão do ar úmido no interior da cámara livre do reservatório, num determinado instante é igual a pressão atmosférica (Po) menos a altura da coluna d'água L, ou se ja

$$
\begin{aligned}
& P u_{0}=P_{0}-\text { Lo } 3.6 \text {. }
\end{aligned}
$$

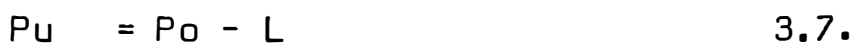

Através de 3.6 e 3.7. pode-se verificar que o valor $K$ da ex pressão 3.5. é praticamente igual a unidade porque a diferença Lo-L é mui to pequena em relação ao valor de Po. Deste modo a expressão 3.5. resultară em 


$$
\Delta H=H\left(1-\frac{T o}{T}\right)
$$

Deve-sé lembrar ainda que a secção do reservatório é 20 ve zes menor do que a secção do tanque. Assim o erro de medida de evaporação no tanque será:

$$
\Delta H=H\left(1-\frac{T o}{T}\right)
$$

De acordo com a relação 3.9. tem-se então as seguintes con dições:

$$
\begin{array}{ll}
\text { 1) }- \text { se To }=T & \Delta H=0 \\
\text { 2) }- \text { se To }<\text { T } & \Delta H>0 \\
\text { 3) }- \text { se To }>\text { T } & \Delta H<0
\end{array}
$$

\subsubsection{Medida da Evapotranspi ração}

O nível da água no evapotranspirômetro foi mantido constan te a cerca de $30 \mathrm{~cm}$ á́aixo da superfície do solo.

0 papel registrador foi trocado diariamente às 7 horas. Pa ra "zerar" o instrumento, colocava-se água no reservatório até o sifão ser acionádo, de modo que, ao cessar a sifonação, a pena estava na linha zero do gráfico, na hora ajustada.

0 funcionamento do instrumento é descrito com base no esque ma da Figura 4. Na ausência de evapotranspiração, o nível "H" da água no tanque permanece constante e a válvula fechada. Ocorrendo evapotranspiração ocorrera também um abaixamento do nível "H", abertura da válvula e simultạ 
neo abaixamento da altura da coluna d’água "h" no reservatório. Em conse quência a pena sofrerá um des̉locamento igual a variação de "h", traçando-o sobre o papel registrado. 0 movimento do mecanismo de relógio conjugado ao deslocamento da pena resultará numa curva cumulativa do tipo mostrado na Figura 9 para um determinado intervalo de tempo.

Para evitạ variações no armazenamento d'água no evapotrans pirômetro, os tanques foram protegidos da chuva quando necessário.

\subsubsection{Estimativa da Evapotranspiração}

A evapotranspiração foi estimada pela equação proposta por Penman (1948).

$$
\text { ETDE }=\frac{\frac{\Delta}{\gamma} \cdot H}{\frac{\Delta}{\gamma}+1}+\frac{E a}{\frac{\Delta}{\gamma}+1} \quad 3.10
$$

Os termos da equação foram determinados em função dos ele mentos de clima com o uso de um programa em linguagem FORTRAN processado em computader IBM-1130.

a) $\frac{\Delta}{x}$ foi determinado em função da temperatura do ar, média diária, e calculado segundo VILLA NOVA (1967).

$\gamma=$ constante psicrométrica $=0,57\left(\mathrm{~mm} \quad \mathrm{Hg} \cdot{ }^{{ }^{\circ}} \mathrm{C}^{-1}\right)$

$\Delta$ = tangente à curva de saturação de vapor, determinada pela expres são $3.11\left(\mathrm{~mm} \cdot{ }^{\circ} \mathrm{C}^{-1}\right)$.

$$
\left.\Delta=e_{s} \frac{6886}{T_{a}^{2}}-\frac{5,31}{T_{a}^{2}}\right)
$$


$T_{a}=$ temperatura do ar, média diária $\left({ }^{\circ} \mathrm{K}\right)$

$e_{s}=$ tensão de saturação de vapor sobre ägua, em milímetros, calculada se gundo a relação.

$$
e_{S}=\left(6,11 \cdot 10 \frac{A \cdot t}{B+t}\right) \cdot 0,75(\mathrm{~mm} \cdot \mathrm{Hg}) \quad 3.12
$$

$A=7,5$

$B=237,5$

$H=$ balanço de energia diärío, determinado pela relação $\left(\mathrm{mm} \cdot \mathrm{dia}^{-1}\right)$

$$
H=\frac{K \downarrow \downarrow}{59}(a+b n / N)(1-r)-\frac{T a^{4}}{59}(0,56-0,09 \sqrt{e})(0,1+0,9 n / N) \quad 3.13 .
$$

$K \downarrow \downarrow$ = radiação solar global recebida na ausência da atmosfera por uma sú perfície unitário e horizontal $\left(\mathrm{cal} . \mathrm{cm}^{-2}-\mathrm{dia}^{-1}\right)$. (Ver apêndice)

$n \quad$ = insolação diāria em horas e décimos

$\mathrm{N}$ = duração máxima da insolação em horas e décimos (Apèndice)

$r \quad$ = albedo médio para superfícies vegetadas, tomado como 0,25 segundo PENMAN

$\sigma \quad=$ constante de Stefan-Boltzman $\left(1,1707 \cdot 10^{-7} \mathrm{cal} \cdot \mathrm{cm}^{-2} \cdot \mathrm{dia}^{-1}\right)$

$\mathrm{Ta}=$ temperatura do ar, média diária $\left({ }^{{ }} \mathrm{K}\right)$

e = tensão parcial de vapor, valor médio diário, em milímetros de $\mathrm{Hg}$.da do pela expressão

$$
e=U R / 100 \cdot e_{s}
$$

UR $=$ umidade relativa do ar $(\%)$ 
c) $\mathrm{Ea}=$ poder evaporante do ar, determinado pela expressão

$$
\begin{aligned}
& \qquad a=0,35\left(1+0,54 U_{2}\right)\left(e_{s}-e\right)\left(\mathrm{mm} \cdot d i a^{-1}\right) \\
& U_{2}=\text { velocidade do vento a } 2,0 \text { metros de altura }\left(\mathrm{m}_{\mathrm{s}} \mathrm{s}^{-1}\right)
\end{aligned}
$$

Foram obtidos valores diários de ETPE para todos os dias do ano. Entretanto foram utilizados apenas aqueles dias em que foi possí vel comparar com a Evapotranspiração medida com o evapotranspirómetro a nível constante e a evaporação medida em Tanques.

\subsubsection{Elementos do Clima}

A umidade relativa do ar, média diária, foi determinada pela média aritmética dos valores horários registrados pelo termo-higrógrafo. A temperatura do ar, média diária, foi obtida de acordo com a expressão:

$$
\operatorname{Tm}=\frac{T m x+T m i n}{2}
$$

A velocidade do vento a 2,0 metros de altura, total diário, foi computada pela diferença entre duas leituras consecutivas fornecida pelo anemómetro.

Os dados de insolação, em horas e décimos, foram obtidos pela cotação da fita do heliógrafo assim como os dados de precipitação a partir do diagrama do pluviógrafo.

Valores astronómicos da duração do dia foram calculados pela expressão 3.17. com o auxílio de um programa de computador 
Os valores de radiação solar extra-terrestre para uso na equação de Penman foram obtidos do trabalho de SALATI et alli. (1967). (Ver apèndice).

\subsubsection{Utilização e Anālise dos Dados}

A análise dos dados foi dividida em duas partes:

18) Estudo das relações entre Evapotranspiração Medida estimada,

$\left.2^{\circ}\right)$ Relações entre Evapotranspiração Medida e a Evaporação dos tanques Clas se $A$ e Classe $A$ a nível Constante.

A análise dos dados foi feita em base diária e por média de pêntadas. Para cálculo das médias de péntadas considerou-se apenas a sequência de cinco dias sem interrupção nas medidas.

Para cálculo dos coeficientes de conversão da evaporação em tanques para estimativa da Evapotranspiração medida os dados diārios foram divididos em seis combinações de Umidade Relativa do Ar (2) e Velocidade do Vento (3), conforme metodologia de DOORENBOS e PRUITT (1975).

As equações de regressão e os coeficientes de correlação simples foram obtidos em computador IBM-1130 com o uso de um programa, em linguagem FORTRAN, já existente no Departamento de Matemática da ESALQ.

Na comparação dos parāmetros das equações de regressão oḅ tidas foi empregado o teste "t". A estimativa dos graus de liberdade neces sários para testar os contrastes foram obtidos pela förmula de Satterthwaite de acordo com GOMES (1970). 


\section{RESULTADOS E DISCUSSAO}

4.1. Relativos à Comparação entre Evapotranspiração Medida (ETPM) e Evapotranspiração Estimada (ETPE).

0 curso anual da ETPM e ETPE é mostrado na Figura 7 . Os dados utilizados na construção da figura são àpresentados na Tabela I. Na Tabela II são encontrados os valores médios de péntadas. A Tabela III apre senta a análise de variāncia efetuada.

Tabela III - Análise de variància dos dados de ETPM e ETPE - Valores diá rios e médios de péntadas.

Períodos

C. da Variação

G.L.

G.M.

Eq. de Regressão

$\mathrm{R}$

(dias)

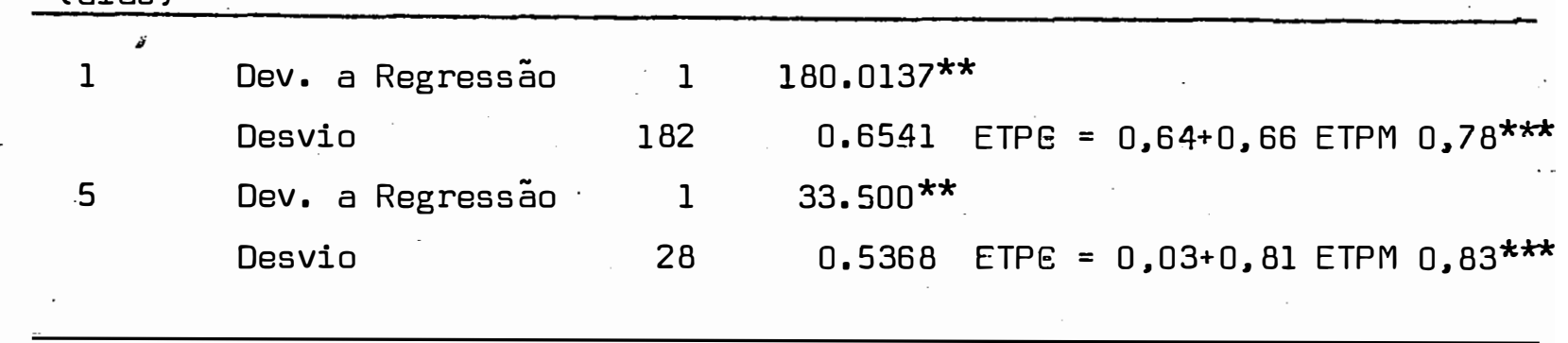

\footnotetext{
** significativo ao nível de $1 \%$

*** significativo ao nível de $0,1 \%$
} 


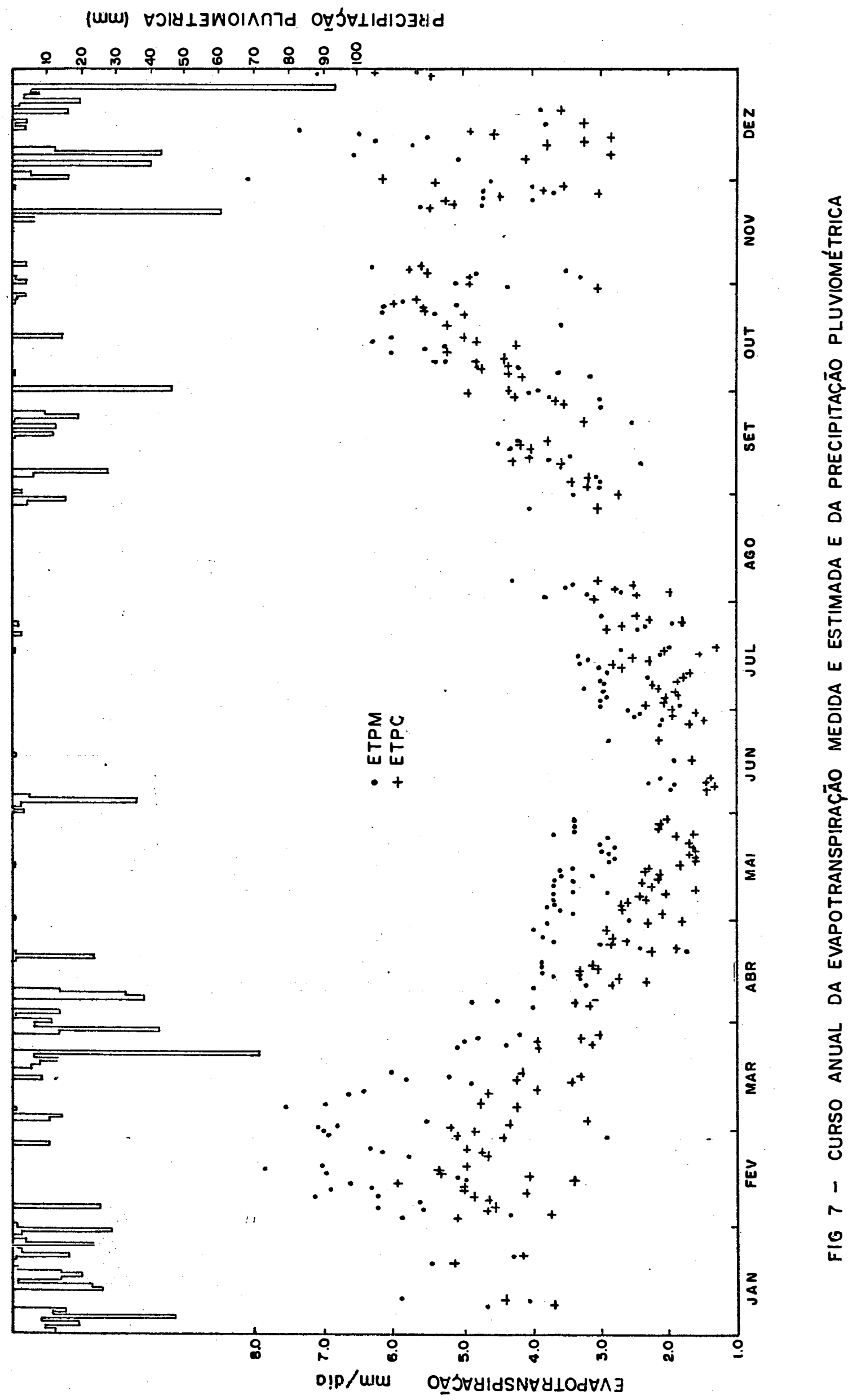


TABELA I - Valores diários de Evapotranspiração Medida (ETPM) e Estimada (ETPE), Evaporação dos Tanques Classe A (TCA) e Classe A a Nível Constante (TCAM), Precipitação Pluviométrica (PP), Temperatura Média (Tm), Velocidade do Vento a 2,0 metros $\left(U_{2}\right)$ e Umidade Rela tiva do Ar (UR).

Mês: Janeiro/1977

\begin{tabular}{|c|c|c|c|c|c|c|c|c|}
\hline Dia & $\begin{array}{l}\text { TCAM } \\
\mathrm{mm} / \mathrm{dia}\end{array}$ & $\begin{array}{c}\text { TCA } \\
\mathrm{mm} / \mathrm{dia}\end{array}$ & $\begin{array}{l}\text { ETPM } \\
\mathrm{mm} / \mathrm{dia}\end{array}$ & $\begin{array}{c}\text { ETPE } \\
\mathrm{mm} / \mathrm{dia}\end{array}$ & $\begin{array}{c}\mathrm{PP} \\
\mathrm{mm} / \mathrm{dia}\end{array}$ & $\operatorname{Tom}_{\mathrm{C}}$ & $\begin{array}{l}\text { UR } \\
\%\end{array}$ & $\underset{\mathrm{km} / \mathrm{U}_{\mathrm{ia}}}{\mathrm{U}}$ \\
\hline 01 & - & - & - & 3,34 & 18,2 & 23,4 & 86,3 & 92,62 \\
\hline 02 & - & - & - & 3,77 & 12,6 & 23,8 & 88,7 & 105,63 \\
\hline 03 & - & - & - & 4,66 & 9,3 & 23,3 & 80,9 & 155,09 \\
\hline 04 & - & - & - & 3,65 & 19,4 & 24,3 & 84,2 & 149,53 \\
\hline 05 & - & - & - & 2,63 & 8,6 & 22,7 & 85,3 & 93,40 \\
\hline 06 & - & - & - & 2,49 & 47,7 & 22,5 & 90,7 & 134,51 \\
\hline 07 & - & - & - & 2,31 & 11,7 & 21,3 & 92,0 & 60,92 \\
\hline 08 & - & - & - & 4,58 & 15,5 & 24,7 & 77,0 & 82,36 \\
\hline 09 & 6,30 & 6,02 & 4,66 & 3,70 & - & 23,4 & 77,5 & 66,24 \\
\hline 10 & $6,10^{\circ}$ & 6,12 & 4,07 & 4,39 & - & 25,5 & 74,5 & 157,27 \\
\hline 11 & 7,48 & 7,25 & - & 4,71 & - & 24,7 & 77,6 & 53,55 \\
\hline 12 & 5,45 & 5,82 & - & 5,03 & - & 24,4 & 71,3 & 99,77 \\
\hline 13 & 8,90 & 8,10 & - & 5,24 & - & 25,6 & 73,3 & 98,08 \\
\hline 14 & - & - & - & 4,26 & 26,0 & 25,1 & 79,7 & 126,21 \\
\hline 15 & 4,18 & 3,84 & - & 3,08 & 23,4 & 23,8 & 81,4 & 35,94 \\
\hline 16 & - & - & - & 3,14 & 1,3 & 23,6 & 89,3 & 141,36 \\
\hline 17 & - & - & - & 2,54 & 14,0 & 23,1 & 86,0 & 29,84 \\
\hline 18 & - & - & - & 2,76 & 20,5 & 23,3 & 81,3 & 75,93 \\
\hline 19 & - & - & - & 3,32 & 14,0 & 23,1 & 76,8 & 152,94 \\
\hline 20 & 7,90 & 7,89 & - & 5,05 & 1,4 & 23,3 & $81 ; 5$ & 253,71 \\
\hline 21 & 9,80 & 8,20 & 5,43 & 5,12 & - & 23,2 & 76,3 & 153,71 \\
\hline 22 & 4,70 & 4,14 & - & 4,15 & - & 23,8 & 81,6 & 93,88 \\
\hline 23 & 5,33 & 5,45 & 4,30 & 4,16 & 0,6 & 24,6 & 83,3 & 71,61 \\
\hline 24 & - & - & - & 4,05 & 16,9 & 25,0 & 87,2 & 71,61 \\
\hline 25 & 5,20 & $4,91$. & - & 3,85 & 2,2 & 25,6 & 88,9 & 85,14 \\
\hline 26 & - & - & - & 2,42 & 1,5 & 24,8 & 90,6 & - \\
\hline 27 & - & - & - & 2,70 & 23,4 & 24,8 & 93,0 & 15,69 \\
\hline 28 & - & - & - & 2,82 & 3,5 & 25,0 & 91,3 & 88,75 \\
\hline 29 & $\therefore \quad-$ & - & - & 3,24 & - & 25,1 & 90,5 & 47,16 \\
\hline 30 & 4,10 & 3,85 & - & 4,42 & 2,6 & 25,6 & 87,0 & 125,92 \\
\hline 31 & - & - & - & - & 28,4 & 23,8 & 93,6 & 125,86 \\
\hline
\end{tabular}


Mês: Fevereiro/1977

\begin{tabular}{|c|c|c|c|c|c|c|c|c|}
\hline Dia & $\begin{array}{c}\text { TCAM } \\
\mathrm{mm} / \mathrm{dia}\end{array}$ & $\begin{array}{c}\text { TCA } \\
\mathrm{mm} / \mathrm{dia}\end{array}$ & $\begin{array}{l}\text { ETPM } \\
\mathrm{mm} / \mathrm{dia}\end{array}$ & $\begin{array}{l}\text { ETPE } \\
\mathrm{mm} / \mathrm{dia}\end{array}$ & $\begin{array}{c}\mathrm{PP} \\
\mathrm{mm} / \mathrm{dia}\end{array}$ & $\begin{array}{l}\mathrm{Tm} \\
{ }^{\circ} \mathrm{C}\end{array}$ & $\begin{array}{l}\text { UR } \\
\%\end{array}$ & $\stackrel{U_{2}}{\mathrm{~km} / Z_{i a}}$ \\
\hline 01 & - & - & - & - & 1,2 & 24,6 & 75,4 & 198,49 \\
\hline 02 & 7,08 & 6,55 & - & 5,86 & - & 24,4 & 73,3 & 229,81 \\
\hline 03 & 8,28 & 7,09 & 5,87 & 5,07 & - & 24,2 & 79,5 & 135,36 \\
\hline 04 & 4,00 & 4,05 & 4,33 & 3,72 & - & 25,1 & 88,4 & 77,47 \\
\hline 05 & 5,15 & 5,82 & 5,57 & 4,65 & - & 26,2 & 84,4 & 57,52 \\
\hline 06 & 9,18 & 7,57 & 6,23 & 4,53 & - & 26,7 & 78,7 & 33,34 \\
\hline 07 & 5,38 & 4,76 & - & 4,69 & 25,4 & 26,7 & 79,3 & 86,54 \\
\hline 08 & 6,30 & 5,49 & 5,60 & 4,62 & - & 26,8 & 80,5 & 97,53 \\
\hline 09 & 8,45 & 6,98 & 7,13 & 4,86 & - & 27,0 & 72,6 & 46,05 \\
\hline 10 & 8,13 & 7,01 & 6,20 & 4,09 & - & 26,6 & 77,3 & 61,88 \\
\hline 11 & 7,50 & 8,44 & 6,93 & 5,00 & - & 26,8 & 73,3 & 62,79 \\
\hline 12 & 7,58 & 7,04 & 6,30 & 5,00 & - & 25,4 & 70,6 & 61,37 \\
\hline 13 & 7,78 & 7,82 & 6,63 & 5,93 & - & 26,0 & 73,4 & 90,62 \\
\hline 14 & 6,33 & 5,27 & 4,97 & 3,40 & - & 24,9 & 80,3 & 56,41 \\
\hline 15 & 7,75 & 6,41 & 5,10 & 4,04 & - & 25,6 & 76,1 & 129,50 \\
\hline 16 & 8,63 & 8,54 & 7,00 & 5,31 & - & 26,2 & 74,5 & 176,32 \\
\hline 17. & 8,93 & 8,95 & 7,87 & 5,34 & - & 25,7 & 63,3 & 113,15 \\
\hline 18 & 7,85 & 6,38 & 7,01 & 4,94 & - & 26,4 & 71,8 & 104,90 \\
\hline 19 & 7,65 & 8,32 & - & 4,91 & - & 25,9 & 73,9 & 125,51 \\
\hline 20 & 8,10 & 7,50 & - & 4,81 & - & 26,2 & 73,7 & 107,17 \\
\hline 21 & 9,10 . & 7,41 & 5,77 & $4 ; 64$ & - & 25,5 & 72,8 & 97,19 \\
\hline 22 & 8,03 & 6,43 & 6,16 & 4,73 & - & 25,4 & 74,8 & 85,08 \\
\hline 23 & 8,55 & 7,47 & 6,31 & 4,49 & - & 25,3 & 75,8 & 120,93 \\
\hline 24 & 7,65 & 8,08 & - & 4,96 & - & 25,5 & 71,7 & 77,32 \\
\hline 25 & - & - & - & 4,07 & 10,7 & 25,0 & 81,1 & 71,58 \\
\hline 26 & 7,37 & 6,78 & 2,90 & 4,45 & - & 24,6 & 75,1 & 90,60 \\
\hline 27 & 9,68 & 8,16 & 6,94 & 5,10 & - & 26,3 & 71,6 & 80,01 \\
\hline 28 & 7,45 & 6,45 & 7,00 & 4,82 & - & 26,4 & 69,1 & 65,12 \\
\hline
\end{tabular}


Mês: Março/1977

\begin{tabular}{|c|c|c|c|c|c|c|c|c|}
\hline Dia & $\begin{array}{l}\text { TCAM } \\
\mathrm{mm} / \mathrm{dia}\end{array}$ & $\begin{array}{c}\text { TCA } \\
\mathrm{mm} / \mathrm{dia}\end{array}$ & $\begin{array}{l}\text { ETPM } \\
\mathrm{mm} / \mathrm{dia}\end{array}$ & $\begin{array}{c}\text { ETPE } \\
\text { mm/dia }\end{array}$ & $\begin{array}{c}\mathrm{PP} \\
\mathrm{mm} / \mathrm{dia}\end{array}$ & $\begin{array}{l}\text { Tm } \\
{ }^{\circ} \mathrm{C}\end{array}$ & $\begin{array}{l}\text { UR } \\
\%\end{array}$ & $\stackrel{\mathrm{U}_{2}}{\mathrm{~km} / \mathrm{dia}}$ \\
\hline 01 & 7,83 & 9,02 & 7,07 & 5,19 & - & 27,0 & 66,1 & 119,02 \\
\hline 02 & 9,13 & 8,48 & 6,80 & 4,34 & - & 25,4 & 80,8 & 157,52 \\
\hline 03 & 5,88 & 5,33 & 5,50 & 3,23 & - & 23,4 & 83,1 & 94,31 \\
\hline 04 & - & - & - & 3,56 & 11,8 & 24,8 & 87,5 & 136,34 \\
\hline 05 & - & - & 5,13 & 3,89 & 14,1 & 25,2 & 81,6 & 85,02 \\
\hline 06 & 10,68 & 7,15 & - & 4,40 & - & 24,0 & 76,9 & 54,67 \\
\hline .07 & 6,63 & 6,17 & 8,06 & 4,26 & 0,90 & 25,6 & 77,5 & 99,61 \\
\hline 08 & 9,73 & 9,10 & 7,00 & 4,76 & - & 25,8 & 73,5 & 116,00 \\
\hline 09 & 5,35 & 6,73 & - & 4,57 & - & 25,1 & 78,0 & 79,31 \\
\hline 10 & $8,38^{\circ}$ & 7,61 & - & 4,65 & - & 25,4 & 77,0 & 128,44 \\
\hline 11 & 9,43 & 8,70 & 6,65 & 4,65 & - & 25,6 & 73,4 & 145,91 \\
\hline 12 & 5,78 & 6,95 & 6,40 & 3,97 & - & 25,4 & 79,0 & 96,69 \\
\hline 13 & - & 6,39 & 6,10 & 4,31 & - & 24,8 & 72,5 & 65,99 \\
\hline 14 & 7,85 & 6,99 & 4,90 & 3,44 & - & 25,6 & 83,3 & 74,49 \\
\hline 15 & 6,75 & 6,40 & 5,80 & 4,25 & - & 27,1 & 75,3 & 61,93 \\
\hline 16 & 4,38 & 5,40 & 5,20 & 3,30 & 8,5 & 26,4 & 85,9 & 119,20 \\
\hline 17 & 8,15 & 7,82 & 6,00 & 4,19 & - & 24,5 & 78,5 & 178,67 \\
\hline 18 & - & - & 2,50 & 2,31 & - & 21,5 & 87,7 & 74,93 \\
\hline .19 & - & - & 4,80 & 3,29 & 5,50 & 23,5 & 87,9 & 101,13 \\
\hline 20 & - & - & 4,00 & 3,47 & 8,00 & 23,8 & 87,7 & 156,52 \\
\hline 21 & - & - & - & 2,66 & 13,20 & 24,9 & 95,4 & 98,37 \\
\hline 22 & - & - & 2,30 & 3,09 & 6,00 & 24,0 & 88,0 & 91,50 \\
\hline 23 & - & - & 1,70 & 2,73 & 71,80 & 22,9 & 94,4 & 117,92 \\
\hline 24 & 5,60 & 5,37 & 5,10 & 3,42 & - & 23,4 & 83,4 & 45,77 \\
\hline 25 & 5,18 & 4,80 & 4,40 & 3,13 & - & 24,2 & 87,9 & 55,54 \\
\hline 26 & 7,48 & 6,06 & 5,00 & 3,97 & - & 24,9 & 83,1 & 83,88 \\
\hline 27 & 5,88 & 5,60 & 4,80 & 3,30 & - & 24,5 & 80,1 & 63,42 \\
\hline 28 & 6,85 & 6,21 & 4,20 & 3,04 & - & 24,0 & 83,3 & $.75,87$ \\
\hline 29 & $=-$ & - & 3,00 & 2,61 & 13,20 & 23,8 & 89,1 & - \\
\hline 30 & - & - & 1,40 & 2,10 & 42,40 & 23,4 & 94,5 & 68,08 \\
\hline 31 & - & - & 1,80 & 2,30 & 6,50 & 23,6 & 92,3 & 81,68 \\
\hline
\end{tabular}


Mês: Abril/1977

\begin{tabular}{|c|c|c|c|c|c|c|c|c|}
\hline Dia & $\begin{array}{l}\text { TCAM } \\
\mathrm{mm} / \mathrm{dia}\end{array}$ & $\begin{array}{c}\text { TCA } \\
\mathrm{mm} / \mathrm{dia}\end{array}$ & $\begin{array}{l}\text { ETPM } \\
\mathrm{mm} / \mathrm{dia}\end{array}$ & $\begin{array}{c}\text { ETPE } \\
\mathrm{mm} / \mathrm{dia}\end{array}$ & $\begin{array}{c}\mathrm{PP} \\
\mathrm{mm} / \mathrm{dia}\end{array}$ & ${ }_{\mathrm{C}}^{\mathrm{Tm}}$ & $\begin{array}{l}\text { UR } \\
\%\end{array}$ & $\underset{\mathrm{km} / \mathrm{dia}}{\mathrm{U}_{2}}$ \\
\hline 01 & - & - & 1,95 & 2,21 & 11,1 & 20,7 & 87,2 & 193,16 \\
\hline 02 & - & - & 3,45 & 2,88 & - & 19,8 & 81,7 & 331,32 \\
\hline 03 & - & - & 3,90 & 2,47 & 0,8 & 20,6 & 85,5 & 131,64 \\
\hline 04 & - & - & 1,50 & 1,72 & 13,8 & 22,2 & 98,5 & 55,03 \\
\hline 05 & 5,65 & 4,39 & 4,00 & 3,18 & - & 21,4 & 84,8 & 96,92 \\
\hline 06 & 6,93 & 6,93 & 4,85 & 3,40 & - & 19,8 & 76,7 & 149,34 \\
\hline 07 & 5,95 & 4,71 & 4,50 & 3,10 & - & 20,4 & 82,2 & 82,46 \\
\hline 08 & - & - & 2,50 & 2,47 & 37,90 & 19,5 & 91,1 & 149,34 \\
\hline 09 & $-\quad:$ & - & - & 1,52 & 32,10 & 19,3 & 98,9 & 115,88 \\
\hline 10 & - & - & 2,30 & 2,14 & 13,40 & 22,0 & 90,3 & 156,84 \\
\hline 11 & 3,98 & 3,82 & 4,00 & 2,82 & - & 20,3 & 85,7 & 44,56 \\
\hline 12 & 3,50 & 3,28 & 3,25 & 2,34 & - & 21,8 & 94,2 & 67,10 \\
\hline 13 & 3,88 & 3,81 & 3,30 & 2,77 & - & 24,3 & 87,9 & 43,63 \\
\hline 14 & 7,13 & 5,62 & 3,70 & 3,37 & - & 24,3 & 80,9 & 39,40 \\
\hline 15 & 6,23 & 5,49 & 3,90 & 3,32 & - & 24,0 & 80,6 & 55,13 \\
\hline 16 & 5,43 & 5,22 & 3,90 & 3,07 & - & 24,2 & 84,2 & 90,46 \\
\hline 17 & 5,40 & 8,14 & 3,90 & 3,13 & - & 24,7 & 85,6 & 75,93 \\
\hline 18 & - & - & 3,70 & $2-64$ & - & 23,9 & 94,8 & 72,99 \\
\hline 19 & 4,90 & - & 2,90 & 2,51 & 1,00 & 25,1 & 89.0 & 115.57 \\
\hline 20 & - & - & 1,00 & 1,32 & 23,30 & 19,2 & 99,3 & 60,87 \\
\hline 21 & 3,03 & 3,21 & 1,70 & 2,26 & - & 20,9 & 90,4 & 122,07 \\
\hline 22 & 2,93 & 2,97 & 2,40 & 1,86 & - & 19,5 & 89,7 & 77,06 \\
\hline 23 & 5,13 & 4,73 & 3,00 & 2,86 & - & 22,0 & 84,8 & 142,58 \\
\hline 24 & 7,43 & 5,23 & 3,70 & 2,67 & - & 20,1 & 88,0 & 136,97 \\
\hline 25 & 5,83 & 5,21 & 3,85 & 2,82 & - & 20,6 & 83,3 & 143,04 \\
\hline 26 & - & - & 3,90 & 2,76 & - & 20,6 & 82,0 & 113,76 \\
\hline 27 & 5,50 & 5,33 & 4,00 & 2,97 & - & 20,7 & 71,7 & 126,56 \\
\hline 28 & 6,13 & 5,12 & - & 2,63 & - & 19,6 & 79,4 & 128,84 \\
\hline 29 & 6,00 & 4,72 & 3,80 & 2,37 & - & 18,7 & 79,5 & 102,18 \\
\hline 30 & 3,05 & 2,77 & 2,60 & 1,80 & - & 18,1 & 83,5 & 68,18 \\
\hline
\end{tabular}


Mês: Maio/1977

\begin{tabular}{|c|c|c|c|c|c|c|c|c|}
\hline Dia & $\begin{array}{l}\text { TCAM } \\
\mathrm{mm} / \mathrm{dia}\end{array}$ & $\begin{array}{c}\text { TCA } \\
\mathrm{mm} / \mathrm{dia}\end{array}$ & $\begin{array}{c}\text { ETPM } \\
\mathrm{mm} / \mathrm{dia}\end{array}$ & $\begin{array}{c}\text { ETPE } \\
\mathrm{mm} / \mathrm{dia}\end{array}$ & $\begin{array}{c}\mathrm{PP} \\
\mathrm{mm} / \mathrm{dia}\end{array}$ & $\begin{array}{l}\mathrm{Tm} \\
{ }^{\circ} \mathrm{C}\end{array}$ & $\begin{array}{l}\text { UR } \\
\%\end{array}$ & $\underset{\mathrm{km} / Z_{i a}}{U_{i a}}$ \\
\hline 01 & 2,88 & - & 2,20 & 1,55 & 0,5 & 18,5 & 89,7 & 97,49 \\
\hline 02 & 2,93 & 3,59 & 3,40 & 2,11 & - & 21,2 & 91,1 & 68,60 \\
\hline 03 & 4,93 & 4,65 & 3,60 & 2,70 & - & 21,6 & 84,6 & 118,28 \\
\hline 04 & 5,03 & 2,39 & 3,80 & 2,68 & - & 21,5 & 82,5 & 101,03 \\
\hline 05 & 5,33 & 4,14 & 3,70 & 2,60 & - & 23,3 & 83,4 & 39,10 \\
\hline 06 & 5,10 & 4,63 & 3,70 & 2,38 & - & 20,7 & 79,9 & 72,19 \\
\hline 07 & 4,13 & 4,71 & 3,70 & 2,45 & - & 19,7 & 82,3 & 118,97 \\
\hline 08 & 2,75 & 2,85 & 2,90 & 2,02 & - & 20,0 & 86,5 & 80,89 \\
\hline 09 & 4,00 & 2,62 & 3,40 & 1,60 & - & 22,0 & 88,1 & 80,13 \\
\hline 10 & 4,58 & 4,16 & 3,70 & 2,23 & - & 21,3 & 83,2 & 56,16 \\
\hline 11 & 5,88 & 4,71 & 3,70 & 2,40 & - & 21,8 & 79,9 & 54,98 \\
\hline 12 & 5,58 & 4,21 & 3,40 & 2,15 & - & 20,1 & 83,4 & 95,10 \\
\hline 13. & 4,15 & 4,08 & 3,60 & 2,22 & - & 19,3 & 76,2 & 87,91 \\
\hline 14 & 4,68 & 4,12 & 3,60 & 2,34 & - & 19,9 & 74,2 & 69,98 \\
\hline 15 & 4,93 & 4,42 & 3,40 & 2,28 & - & 19,3 & 66,0 & 72,74 \\
\hline 16. & 2,45 & 2,63 & 1,90 & 1,84 & 0,3 & 16,9 & 81,9 & 213,63 \\
\hline 17 & 3,40 & 3,42 & 2,90 & 1,61 & - & 9,4 & 72,0 & 147,83 \\
\hline 18 & 3,43 & 2,92 & 2,80 & 1,60 & - & 13,6 & 82,8 & 157,78 \\
\hline 19 & 3,70 & 3,15 & $2 ; 90$ & 1,68 & - & 14,7 & 77,9 & 96,80 \\
\hline 20 & 3,05 & 3,42 & 3,00 & 1,61 & - & 14,3 & 76,6 & 69,12 \\
\hline 21 & 3,05 & 3,03 & 2,80 & 1,64 & - & 14,0 & 75,3 & 101,54 \\
\hline 22 & 3,83 & 3,04 & 3,00 & 1,66 & $: \quad-$ & 14,3 & 73,6 & 79,45 \\
\hline 23 & - & 3,09 & 1,80 & 1,20 & - & 13,8 & 83,0 & 19,43 \\
\hline 24 & 4,38 & 3,96 & 2,90 & 1,90 & - & 17,7 & 75,4 & 89,58 \\
\hline 25 & 3,30 & 2,27 & 3,70 & 1,62 & - & 18,1 & 80,4 & 43,10 \\
\hline 26 & 2,60 & 2,63 & - & 1,65 & - & 18,6 & 80,2 & 73,61 \\
\hline 27 & 2,65 & 4,98 & 3,40 & 2,13 & - & 19,5 & 74,2 & 101,32 \\
\hline 28 & 5,00 & 4,26 & 3,40 & 2,09 & - & 18,8 & 75,3 & 123,11 \\
\hline 29 & 5,45 & 3,93 & 3,40 & 2,02 & - & 18,7 & 73,0 & 92,57 \\
\hline 30 & 5,03 & - & 2,10 & 1,86 & - & 20,1 & 79,8 & 86,50 \\
\hline-31 & 3,50 & 3,10 & - & - & - & 18,4 & 80,0 & 114,43 \\
\hline
\end{tabular}


Mês: Jụnho/1977

\begin{tabular}{|c|c|c|c|c|c|c|c|c|}
\hline Dia & $\begin{array}{c}\text { TCAM } \\
\mathrm{mm} / \mathrm{dia}\end{array}$ & $\begin{array}{c}\text { TCA } \\
\mathrm{mm} / \mathrm{dia}\end{array}$ & $\begin{array}{l}\text { ETPM } \\
\mathrm{mm} / \mathrm{dia}\end{array}$ & $\begin{array}{c}\text { ETPE } \\
\mathrm{mm} / \mathrm{dia}\end{array}$ & $\begin{array}{c}\mathrm{PP} \\
\mathrm{mm} / \mathrm{dia}\end{array}$ & $\begin{array}{l}\operatorname{To}_{\mathrm{C}} \\
{ }^{\prime}\end{array}$ & $\begin{array}{l}\text { UR } \\
\%\end{array}$ & $\begin{array}{c}U_{2} \\
\mathrm{~km} / \mathrm{dia}\end{array}$ \\
\hline 01 & - & - & - & 1,31 & 3,3 & 17,2 & 87,4 & 89,43 \\
\hline 02 & - & - & - & 1,54 & - & 18,0 & 82,8 & 75,61 \\
\hline 03 & - & - & - & 1,14 & 2,50 & 17,1 & 90,5 & 36,80 \\
\hline 04 & - & - & - & 1,18 & 35,90 & 18,2 & 91,5 & 61,99 \\
\hline 05 & - & - & - & 1,22 & 5,00 & 18,4 & 91,8 & 42,52 \\
\hline 06 & 2,88 & 2,78 & - & 1,57 & - & 18,1 & 84,0 & 56,93 \\
\hline 07 & 2,48 & 2,20 & 1,95 & 1,41 & - & 16,8 & 84,4 & 72,02 \\
\hline 08 & 3,33 & 2,14 & 1,90 & 1,33 & - & 15,7 & 81,8 & 36,36 \\
\hline 09 & 2,48 & 2,30 & 2,30 & 1,43 & - & 16,6 & 80,3 & 40,10 \\
\hline 10 & 3,48 & 3,00 & 2,10 & 1,38 & - & 15,3 & 78,9 & 46,58 \\
\hline 11 & - & - & 2,50 & 1,67 & - & 15,8 & 78,8 & 144,71 \\
\hline 12 & - & - & - & 1,32 & - & 14,3 & 79.8 & $\quad 57.88$ \\
\hline 13 & - & - & 1,80 & 1,51 . & - & 18,0 & 82,7 & 80,67 \\
\hline 14 & - & - & 1,60 & $1,28^{\circ}$ & _ & 18,6 & 86,5 & 41,63 \\
\hline 15 & 2,15 & 1,25 & 1,90 & 1,67 & - & 19,7 & 82,1 & 96,65 \\
\hline 16 & - & 2,11 & 1,50 & 1,32 & - & 18,2 & 85,6 & 70,31 \\
\hline 17 & - & - & 2,30 & 1,87 & 0,8 & 19,8 & 74,3 & 110,72 \\
\hline 18 & - & - & 2,75 & 2,05 & - & 20,2 & 78,3 & 131,02 \\
\hline 19 & 2,45 & - & 2,85 & 2,06 & - & 20,7 & 78,3 & 137,88 \\
\hline 20 & 4,20 & - & 2,25 & 1,73 & - & 19,4 & 78,4 & 79,77 \\
\hline 21 & 3,90 & 3,64 & 2,90 & 2,15 & - & 20,3 & 73,0 & 133,00 \\
\hline 22 & 3,25 & - & 1,70 & 1,34 & - & 17,9 & 84,3 & 58,77 \\
\hline 23 & - & 2,39 & 2,10 & 1,42 & - & 18,5 & 85,5 & 61,28 \\
\hline 24 & - & - & 2,10 & 2,02 & - & 19,8 & 75,4 & 29,99 \\
\hline 25 & 3,95 & 3,85 & - & 1,86 & - & 19,7 & 81,4 & 118,18 \\
\hline 26 & 2,75 & 2,64 & 2,10 & 1,70 & - & 19,9 & 80,5 & 50,87 \\
\hline 27 & 3,30 & 2,52 & 2,10 & 1,48 & - & 18,4 & 83,7 & 33,01 \\
\hline 28 & $.5,50$ & 4,85 & 2,50 & 1,95 & - & 18,9 & 67,7 & 91,81 \\
\hline 29 & 3,55 & 3,53 & 2,40 & 1,58 & - & 16,3 & 75,2 & 81,05 \\
\hline 30 & 4,15 & 4,35 & 2,60 & 1,95 & - & 17,8 & 75,8 & 167,69 \\
\hline
\end{tabular}


Mês: Jưlho/1977

\begin{tabular}{ccccccccr}
\hline Dia & $\begin{array}{c}\text { TCAM } \\
\mathrm{mm} / \mathrm{dia}\end{array}$ & $\begin{array}{c}\text { TCA } \\
\mathrm{mm} / \mathrm{dia}\end{array}$ & $\begin{array}{c}\text { ETPM } \\
\mathrm{mm} / \mathrm{dia}\end{array}$ & $\begin{array}{c}\text { ETPE } \\
\mathrm{mm} / \mathrm{dia}\end{array}$ & $\begin{array}{c}\text { PP } \\
\mathrm{mm} / \mathrm{dia}\end{array}$ & $\begin{array}{c}\text { Tm } \\
\text { C }\end{array}$ & $\begin{array}{c}\text { UR } \\
\%\end{array}$ & $\begin{array}{r}\mathrm{U}_{2} \\
\mathrm{~km} / \mathrm{dia}\end{array}$ \\
\hline 01 & 4,98 & 4,44 & 1,80 & 2,36 & - & 22,4 & 71,3 & 160,48 \\
02 & 5,35 & 4,46 & 3,00 & 2,01 & - & 16,8 & 70,7 & 166,19 \\
03 & 5,08 & 4,80 & 3,00 & 2,06 & - & 17,5 & 72,2 & 171,73 \\
04 & 4,45 & 4,05 & 2,95 & 1,84 & - & 17,6 & 73,1 & 107,12 \\
05 & 4,60 & 4,47 & 2,95 & 1,89 & - & 18,3 & 70,3 & 90,49 \\
06 & 3,93 & 5,00 & 3,25 & 2,17 & - & 18,6 & 70,0 & 151,30 \\
07 & 6,60 & 6,42 & 2,95 & 2,27 & - & 18,1 & 68,5 & 179,35 \\
08 & 3,80 & 2,48 & 3,00 & 1,81 & - & 17,7 & 69,7 & 74,00 \\
01 & 3,43 & 3,08 & 2,30 & 1,78 & - & 18,1 & 71,8 & 72,53 \\
10 & 4,65 & 4,75 & 2,90 & 2,18 & - & 18,6 & 68,1 & 132,92 \\
11 & 3,38 & - & 3,10 & 2,14 & - & 19,5 & 70,9 & 114,35 \\
12 & 4,68 & 4,48 & 3,00 & 2,70 & - & 19,0 & 69,7 & 132,54 \\
13 & 6,03 & 5,63 & 3,30 & 2,85 & - & 19,4 & 55,3 & 191,17 \\
14 & 6,10 & 6,20 & 3,20 & 2,33 & - & 19,5 & 69,2 & 145,41 \\
15 & 5,45 & 5,67 & 3,35 & 2,56 & - & 20,1 & 60,5 & 144,23 \\
16 & 2,48 & 2,08 & 2,10 & 1,56 & 0,2 & 19,0 & 78,6 & 42,14 \\
17 & 3,20 & 3,58 & 2,70 & 2,02 & 0,4 & 20,3 & 80,3 & 110,81 \\
18 & 3,90 & 2,58 & 2,00 & 1,79 & - & 19,2 & 81,7 & 103,08 \\
19 & - & 4,73 & 2,80 & 1,97 & - & 18,0 & 78,9 & 131,61 \\
20 & - & 3,46 & 2,75 & 1,83 & - & 17,2 & 76,0 & 95,75 \\
21 & - & 7,42 & 3,00 & 3,56 & - & 18,4 & 58,3 & 342,25 \\
22 & 4,15 & - & 2,10 & 2,89 & 2,90 & 22,2 & 68,2 & 210,99 \\
23 & 4,15 & 5,75 & 2,45 & 2,91 & - & 23,0 & 65,5 & 145,96 \\
24 & 4,20 & 2,91 & 2,35 & 2,69 & - & 22,5 & 72,8 & 203,93 \\
25 & 2,63 & 2,59 & 1,95 & 1,80 & 2,00 & 19,5 & 80,2 & 68,12 \\
26 & 4,85 & 4,81 & 2,50 & 2,30 & - & 20,8 & 73,7 & 93,57 \\
27 & 3,75 & 4,23 & 3,00 & 2,49 & - & 21,2 & 68,2 & 100,04 \\
28 & - & 4,86 & 3,20 & 2,51 & - & 21,1 & 67,2 & 99,85 \\
29 & - & 5,49 & 3,30 & 2,43 & - & 20,4 & 61,6 & 113,78 \\
30 & - & 6,58 & 3,65 & 2,91 & - & 19,9 & 55,7 & 166,62 \\
31 & 5,65 & 5,76 & 3,70 & - & - & 20,5 & 62,2 & - \\
\hline
\end{tabular}


Mês: Agosto/1977

\begin{tabular}{ccccccccr}
\hline Dia & $\begin{array}{c}\text { TCAM } \\
\mathrm{mm} / \mathrm{dia}\end{array}$ & $\begin{array}{c}\text { TCA } \\
\mathrm{mm} / \mathrm{dia}\end{array}$ & $\begin{array}{c}\text { ETPM } \\
\mathrm{mm} / \mathrm{dia}\end{array}$ & $\begin{array}{c}\text { ETPE } \\
\mathrm{mm} / \mathrm{dia}\end{array}$ & $\begin{array}{c}\text { PP } \\
\mathrm{mm} / \mathrm{dia}\end{array}$ & $\begin{array}{c}\text { Tm } \\
\text { OC }\end{array}$ & $\begin{array}{c}\text { UR } \\
\%\end{array}$ & $\begin{array}{r}\mathrm{U}_{2} \\
\mathrm{~km} / \mathrm{dia}\end{array}$ \\
\hline 01 & 6,75 & 6,47 & 3,80 & 3,10 & - & 21,9 & 58,7 & 147,61 \\
02 & 6,95 & 5,26 & 3,20 & 2,50 & - & 19,9 & 78,6 & 202,47 \\
03 & 3,63 & 3,33 & 2,70 & 1,99 & - & 19,3 & 79,1 & 107,11 \\
04 & 5,38 & 5,27 & 3,50 & 2,81 & - & 21,0 & 69,9 & 143,55 \\
05 & 4,50 & 4,50 & 3,40 & 2,53 & - & 21,2 & 69,4 & 67,57 \\
06 & 4,88 & 5,51 & 4,30 & 3,02 & - & 21,8 & 62,0 & 125,82 \\
07 & 7,88 & 7,58 & - & 3,20 & - & 22,1 & 57,0 & 130,50 \\
08 & 6,00 & - & - & 2,84 & - & 20,6 & 61,6 & 112,70 \\
09 & 5,58 & 5,12 & - & 2,68 & - & 20,6 & 78,6 & 180,38 \\
10 & 4,53 & 4,28 & - & 2,51 & - & 19,2 & 71,5 & 92,60 \\
11 & 5,50 & 7,41 & - & 3,65 & - & 20,8 & 59,8 & 246,25 \\
12 & 5,33 & 6,15 & - & 3,92 & - & 24,5 & 62,0 & 146,58 \\
13 & 10,53 & 9,07 & - & 4,46 & - & 24,4 & 50,4 & 237,55 \\
14 & 7,03 & 6,40 & - & 2,94 & - & 21,9 & 80,5 & 191,57 \\
15 & 4,35 & 4,19 & - & 2,38 & - & 19,6 & 78,5 & 93,79 \\
16 & 6,15 & 5,42 & - & 3,00 & - & 22,2 & 67,7 & 96,79 \\
17 & 9,15 & 9,33 & - & 4,29 & - & 21,7 & 61,8 & 321,14 \\
18 & 7,18 & 6,27 & - & 2,82 & - & 17,0 & 72,2 & 209,95 \\
19 & 5,43 & 4,98 & - & 2,40 & - & 14,9 & 76,3 & 203,33 \\
20 & 6,43 & 5,83 & - & 2,68 & - & 16,2 & 69,2 & 163,73 \\
21 & 5,70 & 5,37 & - & 2,72 & - & 17,8 & 69,7 & 111,95 \\
22 & 5,78 & 5,66 & - & 2,90 & - & 17,9 & 63,7 & 122,50 \\
23 & 6,20 & 6,79 & - & 2,86 & - & 19,5 & 52,5 & 55,76 \\
24 & 6,83 & 6,17 & - & 3,76 & - & 21,0 & 60,0 & 233,12 \\
25 & 5,45 & 4,14 & - & 2,76 & - & 19,0 & 72,3 & 189,97 \\
26 & 6,70 & 6,15 & - & 3,04 & - & 18,3 & 67,8 & 138,25 \\
27 & 4,50 & 5,07 & 4,05 & 3,01 & - & 18,8 & 68,3 & 125,71 \\
28 & 5,32 & 5,66 & 3,60 & - & - & 20,0 & - & 103,84 \\
29 & - & - & 2,10 & 1,72 & 4,3 & 17,3 & 85,3 & 90,39 \\
30 & - & - & 2,10 & 1,59 & 15,4 & 18,2 & 93,0 & 149,12 \\
31 & 6,05 & 5,75 & 3,40 & 3,26 & - & 21,2 & 73,8 & 145,37 \\
\hline
\end{tabular}


Mês: Setembro/1977

\begin{tabular}{|c|c|c|c|c|c|c|c|c|}
\hline Dia & $\begin{array}{c}\text { TCAM } \\
\mathrm{mm} / \mathrm{dia}\end{array}$ & $\begin{array}{c}\text { TCA } \\
\mathrm{mm} / \mathrm{dia}\end{array}$ & $\begin{array}{l}\text { ETPM } \\
\mathrm{mm} / \mathrm{dia}\end{array}$ & $\begin{array}{c}\text { ETPE } \\
\mathrm{mm} / \mathrm{dia}\end{array}$ & $\begin{array}{c}\mathrm{PP} \\
\mathrm{mm} / \mathrm{dia}\end{array}$ & $\begin{array}{l}\mathrm{Tm} \\
{ }^{\circ} \mathrm{C}\end{array}$ & $\begin{array}{l}\text { UR } \\
\%\end{array}$ & $\stackrel{\mathrm{U}_{2}}{\mathrm{~km} / \mathrm{dia}}$ \\
\hline 01 & 6,35 & 5,28 & - & 1,96 & 2,8 & 17,0 & 86,0 & 241,40 \\
\hline 02 & 5,35 & 5,33 & - & 2,61 & - & 16,3 & 77,4 & 239,72 \\
\hline 03 & 5,80 & 5,01 & 3,00 & 3,02 & - & 18,9 & 72,6 & 138,72 \\
\hline 04 & 7,20 & 6,58 & 3,00 & 3,45 & - & 20,9 & 72,3 & 119,90 \\
\hline 05 & 5,38 & 5,24 & 3,05 & 3,18 & - & 19,2 & 70,2 & 163,76 \\
\hline 06 & - & - & - & 2,03 & 6,10 & 18,5 & 88,8 & 168,11 \\
\hline 07 & - & - & - & 2,83 & 27,40 & 19,9 & 85,4 . & 287,34 \\
\hline 08 & $5,73:$ & 5,17 & - & - & - & 20,9 & - & 137,14 \\
\hline 09 & 5,98 & 5,01 . & 2,40 & 3,57 & - & 23,1 & 70,4 & 70,76 \\
\hline 10 & 8,28 & 8,04 & 3,75 & 4,30 & - & 23,8 & 60,6 & 145,99 \\
\hline 11 & 7,48 & 7,83 & 3,45 & 4,06 & - & 23,2 & 48,4 & 119,84 \\
\hline 12 & - & 6,15 & 4,05 & 3,90 & - & 22,6 & 59,9 & 106,41 \\
\hline 13 & 8,20 & 7,33 & 4,35 & $4,12^{\prime}$ & - & 23,0 & 59,0 & 123,18 \\
\hline 14 & 8,10 & 7,06 & 4,50 & 4,19 & - & 23,9 & 61,0 & 120,74 \\
\hline 15 & 7,73 & 6,35 & 4,20 & 3,79 & - & 23,8 & 64,6 & 100,87 \\
\hline 16 & - & - & 3,75 & 3,94 & - & 23,9 & 73,2 & 184,57 \\
\hline 17 & 5,40 & - & 3,60 & 3,30 & 0,40 & 23,6 & 81,3 & 205,50 \\
\hline 18 & - & - & - & 2,78 & 12,00 & 22,1 & 81,3 & 81,91 \\
\hline 19 & 6,45 & - & - & 2,38 & - & 21,6 & 83,2 & 97,09 \\
\hline 20 & - & - & - & 3,09 & 12,9 & 21,7 & 83,7 & 220,26 \\
\hline 21 & 6,00 & 5,40 & 2,55 & 3,23 & - & 21,9 & 79,6 & 145,57 \\
\hline 22 & 5,45 & 3,85 & - & 3,44 & 1,00 & 22,4 & 79,6 & 120,84 \\
\hline 23 & - & - & - & 4,23 & 19,6 & 23,1 & 80,4 & 162,16 \\
\hline 24 & - & - & - & 2,33 & 9,2 & 19,6 & 89,6 & 124,63 \\
\hline 25 & - & - & 3,00 & 3,20 & - & 19,8 & 73,2 & 192,12 \\
\hline 26 & 4,63 & 4,90 & 3,00 & 3,52 & - & 17,8 & 69,3 & 99,92 \\
\hline 27 & 6,18 & 6,45 & 3,00 & 3,68 & - & 20,0 & 69,6 & 67,11 \\
\hline 28 & 7,20 & 6,49 & 3,75 & 4,29 & - & 22,1 & 60,8 & 105,30 \\
\hline 29 & 6,20 & 7,10 & 4,05 & 4,93 & - & 23,4 & 66,7 & 263,93 \\
\hline 30 & 8,00 & 7,75 & 3,90 & 4,33 & - & 22,1 & 70,8 & 310,84 \\
\hline
\end{tabular}


Mês: Outubro/1977

\begin{tabular}{|c|c|c|c|c|c|c|c|c|}
\hline Dia & $\begin{array}{c}\text { TCAM } \\
\mathrm{mm} / \mathrm{dia}\end{array}$ & $\begin{array}{c}\text { TCA } \\
\mathrm{mm} / \mathrm{dia}\end{array}$ & $\begin{array}{c}\text { ETPM } \\
\mathrm{mm} / \mathrm{dia}\end{array}$ & $\begin{array}{c}\text { ETPE } \\
\mathrm{mm} / \mathrm{dia}\end{array}$ & $\begin{array}{c}\mathrm{PP} \\
\mathrm{mm} / \mathrm{dia}\end{array}$ & $\begin{array}{l}\text { Tm } \\
{ }_{\mathrm{O}}\end{array}$ & $\begin{array}{l}\text { UR } \\
\%\end{array}$ & $\begin{array}{c}U_{2} \\
\mathrm{~km} / \mathrm{dia}\end{array}$ \\
\hline 01 & - & - & - & 2,44 & 46,5 & 21,7 & 86,2 & 134,23 \\
\hline 02 & 5,93 & 6,00 & - & 3,76 & - & 22,2 & 82,4 & 167,90 \\
\hline 03 & 6,28 & - & - & 3,50 & - & 19,7 & 77,7 & 166,91 \\
\hline 04 & 5,00 & 6,20 & 3,15 & 4,14 & - & 21,4 & 76,5 & 242,30 \\
\hline 05 & 7,25 & 7,80 & 3,60 & 4,32 & 0,2 & 21,8 & 74,8 & 240,50 \\
\hline 06 & 9,50 & 7,80 & 4,20 & 4,77 & - & 22,0 & 72,5 & 225,70 \\
\hline 07 & 6,45 & 7,30 & 4,80 & 4,38 & - & 22,6 & 70,2 & 197,22 \\
\hline 08 & $6,50:$ & 7,90 & 5,41 & 4,85 & - & 22,3 & 67,9 & 192,22 \\
\hline 09 & 6,58 & 7,05 & 5,26 & 4,38 & - & 22,0 & 66,1 & 96,00 \\
\hline 10 & - & - & 5,26 & 4,30 & - & 22,4 & 67,0 & 91,09 \\
\hline 11 & 8,13 & 9,25 & 6,01 & 5,28 & - & 24,4 & 58,6 & 175,19 \\
\hline 12 & 8,70 & 8,20 & 5,56 & 4,94 & - & 24,1 & 74,0 & 288,98 \\
\hline 13 & 6,38 & 6,65 & 5,26 & 4,27 & - & 23,2 & 79,3 & 246,59 \\
\hline 14 & 8,93 & 8,75 & 6,31 & 4,80 & _- & 24,5 & 72,2 & 147,21 \\
\hline 15 & 8,08 & 8,65 & 6,01 & 5,00 & - & 24,6 & 66,7 & 163,71 \\
\hline 16 & - & - & - & 3,32 & 14,2 & 23,4 & 75,2 & 211,63 \\
\hline 17 & 3,65 & 3,20 & - & 2,49 & - & 20,1 & 85,4 & 220,71 \\
\hline 18 & 6,40 & 6,55 & - & 3,23 & - & 20,9 & 82,5 & 171,27 \\
\hline 19 & 8,00 & 8,75 & 3,60 & 5,21 & - & 22,5 & 72,5 & 229,98 \\
\hline 20 & - & 8,50 & 4,05 & 4,90 & - & 22,5 & 69,6 & 176,07 \\
\hline 21 & 7,35 & 11,20 & - & 4,86 & - & 23,5 & 68,8 & 146,21 \\
\hline 22 & 8,55 & 7,25 & 5,40 & 5,00 & - & 22,9 & 64,6 & 122,10 \\
\hline 23 & 9,25 & 9,20 & 6,15 & 5,53 & - & 25,3 & 59,3 & 110,00 \\
\hline 24 & 9,35 & 9,80 & 6,15 & 5,57 & - & 25,6 & 52,6 & 168,40 \\
\hline 25 & 8,75 & 7,55 & 5,10 & 5,98 & - & 27,8 & 53,8 & 162,76 \\
\hline 26 & 10,55 & 11,40 & 5,85 & 5,63 & 0,3 & 27,8 & 70,1 & 251,41 \\
\hline 27 & - & $\begin{array}{c}- \\
-1+10\end{array}$ & - & - & 1,5 & 22,8 & 86,2 & - \\
\hline 28 & 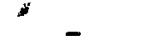 & - & - & 3,17 & 3,5 & 23,4 & 82,4 & 125,96 \\
\hline 29 & - & - & 6,75 & 3,45 & - & 23,9 & 79,5 & 191,28 \\
\hline 30 & 7,78 & 7,32 & 4,35 & 3,04 & - & 24,7 & 70,4 & 67,68 \\
\hline 31 & 8,55 & 8,78 & 5,10 & 4,89 & - & 25,1 & 64,0 & 115,76 \\
\hline
\end{tabular}


Mês: Novembro/1976/77

\begin{tabular}{|c|c|c|c|c|c|c|c|c|}
\hline Dia & $\begin{array}{l}\text { TCAM } \\
\mathrm{mm} / \mathrm{dia}\end{array}$ & $\begin{array}{c}\text { TCA } \\
\mathrm{mm} / \mathrm{dia}\end{array}$ & $\begin{array}{l}\text { ETPM } \\
\mathrm{mm} / \mathrm{dia}\end{array}$ & $\begin{array}{c}\text { ETPE } \\
\mathrm{mm} / \mathrm{dia}\end{array}$ & $\begin{array}{c}\mathrm{PP} \\
\mathrm{mm} / \mathrm{dia}\end{array}$ & $\begin{array}{l}\text { Tm } \\
{ }^{\circ} \mathrm{C}\end{array}$ & $\begin{array}{l}\text { UR } \\
\%\end{array}$ & $\begin{array}{c}\mathrm{U}_{2} \\
\mathrm{~km} / \mathrm{dia}\end{array}$ \\
\hline 01 & - & - & 4,50 & 5,23 & 4,20 & 28,1 & 70,5 & 247,45 \\
\hline 02 & 7,48 & 6,95 & 3,30 & 4,92 & 1,00 & 24,2 & 74,0 & 116,37 \\
\hline 03 & 8,25 & 7,75 & 4,80 & 5,50 & - & 26,2 & 69,5 & 186,57 \\
\hline 04 & 7,83 & 9,60 & 3,50 & 5,77 & - & 24,6 & 74,0 & 249,68 \\
\hline 05 & 10,25 & 9,60 & 6,31 & 5,58 & - & 23,7 & 64,5 & 243,77 \\
\hline 06 & - & - & 3,12 & 3,12 & 4,20 & 20,2 & 76,5 & 165,15 \\
\hline 07 & - & - & 4,99 & 4,99 & - & 21,6 & 71,7 & 225,95 \\
\hline 08 & - & - & - & 4,82 & - & 22,7 & 72,8 & 165,15 \\
\hline 09 & 7,38 & 6,83 & - & 4,39 & - & 22,8 & 71,4 & 121,14 \\
\hline 10 & 12,23 & 8,65 & - & 5,12 & - & 22,2 & 72,6 & 185,91 \\
\hline 11 & 8,53 & 8,64 & - & 5,16 & - & 23,3 & 68,6 & 145,15 \\
\hline 12 & 6,85 & 7,60 & - & 4,98 & - & 25,5 & 74,2 & 123,64 \\
\hline 13 & 4,40 & 3,89 & - & 4,34 & - & 22,3 & 78,2 & 92,60 \\
\hline 14 & 10,55 & 8,29 & - & 4,79 & - & 22,0 & $67 ; 0$ & 171,61 \\
\hline 15 & 9,78 & 9,08 & - & 5,58 & - & 24,5 & 66,2 & 176,64 \\
\hline 16 & - & 6,62 & - & 4,81 & 0,6 & 25,6 & 77,4 & 162,79 \\
\hline 17 & 6,83 & 7,63 & - & 5,14 & - & 24,6 & 74,9 & 167,65 \\
\hline 18 & 10,30 & 8,33 & - & 5,50 & - & 26,4 & 74,7 & 184,73 \\
\hline 19 & - & - & - & 3,55 & 6,3 & 25,5 & 82,5 & 193,51 \\
\hline 20 & 4,88 & 3,44 & - & 3,57 & - & 23,3 & 86,9 & 268,57 \\
\hline 21 & - & - & - & 2,62 & 60,6 & 19,1 & 85,2 & 188,48 \\
\hline 22 & 9,58 & 8,13 & 5,60 & 5,43 & - & 22,0 & 66,0 & 175,81 \\
\hline 23 & 10,78 & 7,58 & 4,70 & 5,13 & - & 23,5 & 66,4 & 91,62 \\
\hline 24 & 4,33 & 7,40 & 4,00 & 5,26 & - & 25,8 & 71,0 & 120,10 \\
\hline 25 & 8,20 & 7,66 & 4,70 & 4,46 & - & 26,2 & 71,7 & 145,08 \\
\hline 26 & 6,43 & 4,94 & 3,70 & 3,02 & 0,4 & 23,5 & 85,0 & 132,63 \\
\hline 27 & $.6,43$ & 5,72 & 4,70 & 3,85 & - & 23,9 & 79,3 & 129,50 \\
\hline 28 & 5,20 & 4,99 & 4,00 & 3,58 & 1,5 & 23,0 & 82,7 & 185,26 \\
\hline 29 & 8,23 & 8,40 & 4,60 & 5,40 & - & 24,2 & 69,4 & 147,53 \\
\hline 30 & 12,55 & 10,85 & 8,10 & 6,13 & - & 23,6 & 64,0 & 267,18 \\
\hline
\end{tabular}


Mês: Dezembro/1976

\begin{tabular}{|c|c|c|c|c|c|c|c|c|}
\hline Dia & $\begin{array}{c}\text { TCAM } \\
\mathrm{mm} / \mathrm{dia}\end{array}$ & $\begin{array}{c}\text { TCA } \\
\mathrm{mm} / \mathrm{dia}\end{array}$ & $\begin{array}{c}\text { ETPM } \\
\mathrm{mm} / \mathrm{dia}\end{array}$ & $\begin{array}{c}\text { ETPE } \\
\mathrm{mm} / \mathrm{dia}\end{array}$ & $\begin{array}{c}\text { PP } \\
\mathrm{mm} / \text { dia }\end{array}$ & $\begin{array}{l}\text { Tm } \\
{ }^{\circ} \mathrm{C}\end{array}$ & $\begin{array}{l}\text { UR } \\
\%\end{array}$ & $\begin{array}{c}\mathrm{U}_{2} \\
\mathrm{~km} / \mathrm{dia}\end{array}$ \\
\hline 01 & - & - & - & 2,64 & 16,4 & 22,8 & 89,2 & 187,82 \\
\hline 02 & - & - & - & 3,63 & 5,1 & 22,5 & 84,7 & 136,92 \\
\hline 03 & - & - & - & 5,40 & - & 25,9 & 77,9 & 152,06 \\
\hline 04 & 3,53 & 3,28 & - & - & - & 24,0 & 80,8 & 126,73 \\
\hline 05 & - & - & - & 3,69 & 40,1 & 23,3 & 87,1 & 168,06 \\
\hline 06 & 5,80 & 5,39 & 5,07 & 4,08 & - & 18,6 & 75,8 & 83,91 \\
\hline 07 & 6,08 & 6,25 & 6,56 & 2,83 & - & 19,6 & 73,5 & 100,28 \\
\hline 08 & - i & - & - & 3,12 & 43,0 & 20,9 & 90,6 & 164,39 \\
\hline 09 & - & - & - & 3,00 & 12,2 & 22,7 & 80,3 & 166,51 \\
\hline 10 & 5,70 & 6,40 & 5,70 & 3,80 & - & 22,3 & 78,2 & 220,12 \\
\hline 11 & 4,05 & 4,61 & 6,24 & 3,26 & - & 23,3 & 80,7 & 105,75 \\
\hline 12 & 4,50 & 3,73 & 5,50 & 2,85 & - & 25,5 & 84,5 & 107,13 \\
\hline 13 & 8,93 & 8,27 & 6,50 & 4,55 & - & 22,3 & 74,4 & 121,30 \\
\hline 14 & 6,83 & 8,72 & 7,37 & 4,90 & - & 22,0 & 79,7 & 293,78 \\
\hline 15 & - & - & - & 2,64 & 4,00 & 24,5 & 92,2 & 231,00 \\
\hline 16 & - & - & - & 3,09 & 1,00 & 25,6 & 86,3 & 246,12 \\
\hline 17 & 3,95 & 3,05 & $3 ; 80$ & 3,29 & 4,70 & 24,6 & 83,7 & 114,95 \\
\hline 18 & 7,03 & 7,24 & - & 4,30 & - & 26,4 & 78,0 & 230,97 \\
\hline 19 & 9,28 & 8,11 & - & 5,30 & - & 25,5 & 76,6 & 135,12 \\
\hline 20 & - & - & - & 3,64 & 16,60 & 23,2 & 84,4 & 136,90 \\
\hline 21 & 4,30 & 6,61 & 3,86 & 3,60 & - & 19,1 & 80,9 & 101,68 \\
\hline 22 & - & - & - & 3,31 & 2,60 & 22,0 & 85,6 & 115,48 \\
\hline 23 & - & - & - & 3,81 & 20,00 & 23,5 & 83,2 & 179,08 \\
\hline 24 & - & - & - & 2,98 & 3,20 & 25,8 & 90,0 & 83,96 \\
\hline 25 & - & - & - & 2,93 & 8,00 & 26,2 & 91,6 & 95,46 \\
\hline 26 & - & - & - & 3,06 & 5,20 & 23,5 & 88,7 & 66,21 \\
\hline 27 & $\therefore$ & - & - & 3,39 & 93,0 & 23,9 & 87,4 & 114,98 \\
\hline 28 & - & - & - & 3,09 & - & 23,0 & 81,7 & 197,48 \\
\hline 29 & 8,99 & 8,57 & 7,10 & 5,41 & - & 24,2 & 76,0 & 265,38 \\
\hline 30 & 8,08 & 6,68 & 5,67 & 6,23 & - & 23,6 & 76,7 & 142,37 \\
\hline 31. & - & - & - & - & - & - & 82,3 & - \\
\hline
\end{tabular}


TABELA II - Valores médios de Pentadas de Evapotranspiração Medida (ETPM) e Estimada (ETPE), Evaporação dos Tanques Classe A (TCA) e Classe A a Nível Constante (TCAM).

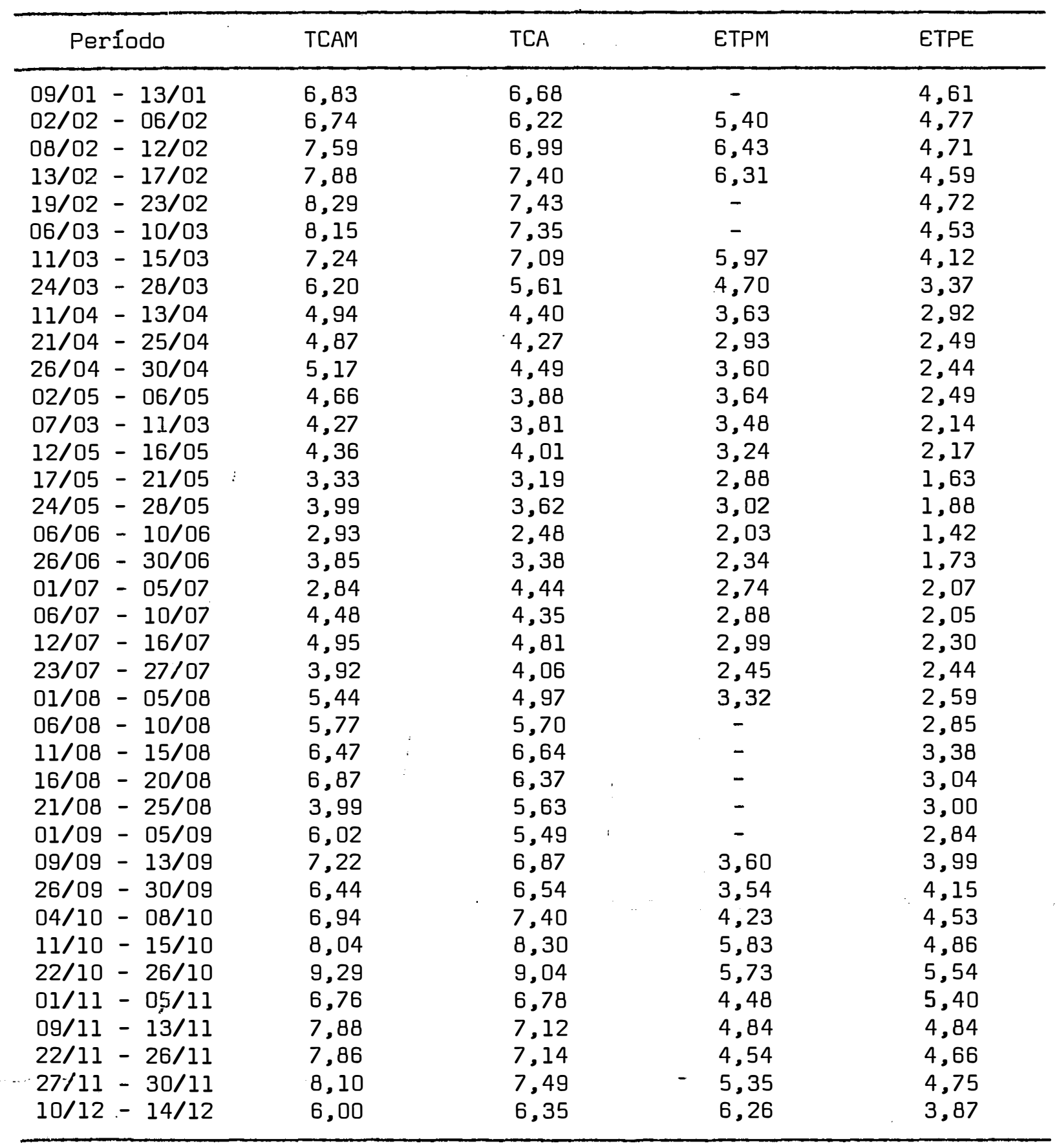


A análise de vạriância mostrou alta significância para. re . gressão linear tanto para períodos diários quanto para períodos de cinço dias.

Comparando-se os parâmetros das retas então obtidas verifí ca-se que não diferem entre si nos níveis de $5 \%$ e $1 \%$ de probabilidade, em bora para períodos de cinco dias tenha se observado um coeficiente de cor relação maior.

Testando-se os coeficientes lineares das equações observase que apenas o da referente a períodos de cinco dias não difere de zero.

: Tendo em vista a análise de variância assim efetuada, con clui-se que apenas uma única equação relaciona ETPM com ETPE na forma

$$
\text { ETPE }=0,81 \text { ETPM } 4.1 \text {. }
$$

com um coeficiente de correlação de 0,83, altamente significativo.

Dos 184 dados diários comparados, observa-se que os valores de ETPM correpondentes a dias subsequentes a chuva (cerca de 30) pratica mente igualaram-se aos de ETPE. Nos dados restantes, relativos a períodos de baixa umidade no solo adjacente, notaram-se sempre, valores de ETPM maiorés do que ETPE. Este fato deve ser explicado como um efeito local de advecção que não é computado pela fórmula de cálculo utilizada. Confirman do estas observações, o potencial da água no evapotranspirómetro (camada de 0 a $15 \mathrm{~cm}$ ) praticamente não variou de 0,1 atm durante todo o período de medida enquanto a região esteve sujeita a severos períodos de falta de chuva. 
4.2. Relativos à Comparação entre a Evapotranspiração Medida (ETPM) e a Evaporação dos Tanques Classe A (TCA) e Classe A à Nĩvel Constan te (TCAM).

Os dados referentes à ETPM, TCA e TCAM para períodos diā rios e de cinco dias, são apresentados nas Tabelas I e II, respectivamente. Na Tabela IV encontra-se o resultado da Análise de Variância.

Tabela IV - Análise de variāncia dos dados de evapotranspiração de medida e da evaporação dos tanques Classe $A$ e Classe $A$ à nível cons tante.

\begin{tabular}{|c|c|c|c|c|c|}
\hline $\begin{array}{l}\text { Períodos } \\
\text { (dias) }\end{array}$ & $\begin{array}{c}\text { Causa da } \\
\text { Variação }\end{array}$ & G.L. & Q.M. & $\begin{array}{c}\text { Equação de } \\
\text { Regressão }\end{array}$ & $\mathrm{R}$ \\
\hline $1(A)$ & $\begin{array}{l}\text { Dev. à Regressão } \\
\text { Linear } \\
\text { Desvio }\end{array}$ & $\begin{array}{r}1 \\
182\end{array}$ & $\begin{array}{c}222,3202^{\star *} \\
1,0739\end{array}$ & $E T P M=1,04+0,53$ TCAM & $0,73^{\star \star \star}$ \\
\hline $5(B)$ & $\begin{array}{l}\text { Dev. à Regressão } \\
\text { Linear } \\
\text { Desvio }\end{array}$ & $\begin{array}{r}1 \\
28\end{array}$ & $\begin{array}{c}35,0382 * * \\
0,5423\end{array}$ & ETPM $=0,25+0,65$ TCAM & $0,83^{\star \star \star}$ \\
\hline $1\left(C^{\prime}\right)$ & $\begin{array}{l}\text { Dev. à Regressão } \\
\text { Linear } \\
\text { Desvio }\end{array}$ & $\begin{array}{r}1 \\
182\end{array}$ & $\begin{array}{c}237,1678^{\star *} \\
1,0472\end{array}$ & $E T P M=1,12+0,54 \mathrm{TCA}$ & $0,73^{\star \star \star}$ \\
\hline 5 (D) & $\begin{array}{l}\text { Dev. à Regressão } \\
\text { Linear } \\
\text { Desvio }\end{array}$ & $\begin{array}{r}1 \\
28\end{array}$ & $\begin{array}{c}34,4525 * * \\
0,5632\end{array}$ & $E T P M=0,56+0,65 \mathrm{TCA}$ & $0,83^{\star \star \star}$ \\
\hline
\end{tabular}

\footnotetext{
** significativo ao nível de $1 \%$

*** significativo ao nível de $0,1 \%$
} 
.50 .

A anālise da Variància mostrou alta significancia para re gressao linear, confirmando resultados da literatura de que existe uma re lação linear entre evapotranspiração medida e evaporação de uma superfície livre de ägua (RIJTEMA, s/d).

Tabela V - Teste t para comparação dos parometros da equações de regressão da Tabela IV.

\begin{tabular}{|c|c|c|c|c|c|}
\hline \multirow{2}{*}{ Contrastes } & \multirow{2}{*}{ G.L. } & \multicolumn{2}{|c|}{ Limites para $t$} & \multirow{2}{*}{$t_{(a)}$} & \multirow{2}{*}{$t_{(b)}$} \\
\hline & & $5 \%$ & $1 \%$ & & \\
\hline$A-B$ & 155,11 & 1,96 & 2,58 & $1,44 \mathrm{~ns}$ & $1,37 \mathrm{~ns}$ \\
\hline$A-C$ & 363,92 & 1,96 & 2,58 & $0,26 \mathrm{~ns}$ & $1,19 \mathrm{~ns}$ \\
\hline$B-D$ & 55,98 & 2,00 & 2,66 & $0,45 \mathrm{~ns}$ & $0,15 \mathrm{~ns}$ \\
\hline$C-D$ & 149,06 & 1,96 & 2,58 & $1,08 \mathrm{~ns}$ & $1,00 \mathrm{~ns}$ \\
\hline
\end{tabular}

0 teste "t" aplicado na comparação dos parāmetros das retas então obtidas (Tabela V) revelou que não existe diferença "significativa en tre as equações $A, B, C$ e D. Entretanto, como se observa na Tabela IV, me lhores estimativas de ETPM a partir de ET, parecem ser obtidas em períodos de cinco dias, pois nestas condições os coeficientes de correlação são mai ores. e os valores dos coeficientes lineares tendem para zero. 


\subsubsection{O Coeficiente de Tanque (Kp)}

Ús valores dos coeficientes de conversão das medidas de Eva poração em Tanques para estimativa da Evapotranspiração Medida, são apresentados na Tabela V.

Tabela VI - Valores dos Coeficientes de Conversão das Medidas de Evaporação em Tanques para Estimativa da Evapotranspiração Medida em Eva potranspirómetro.

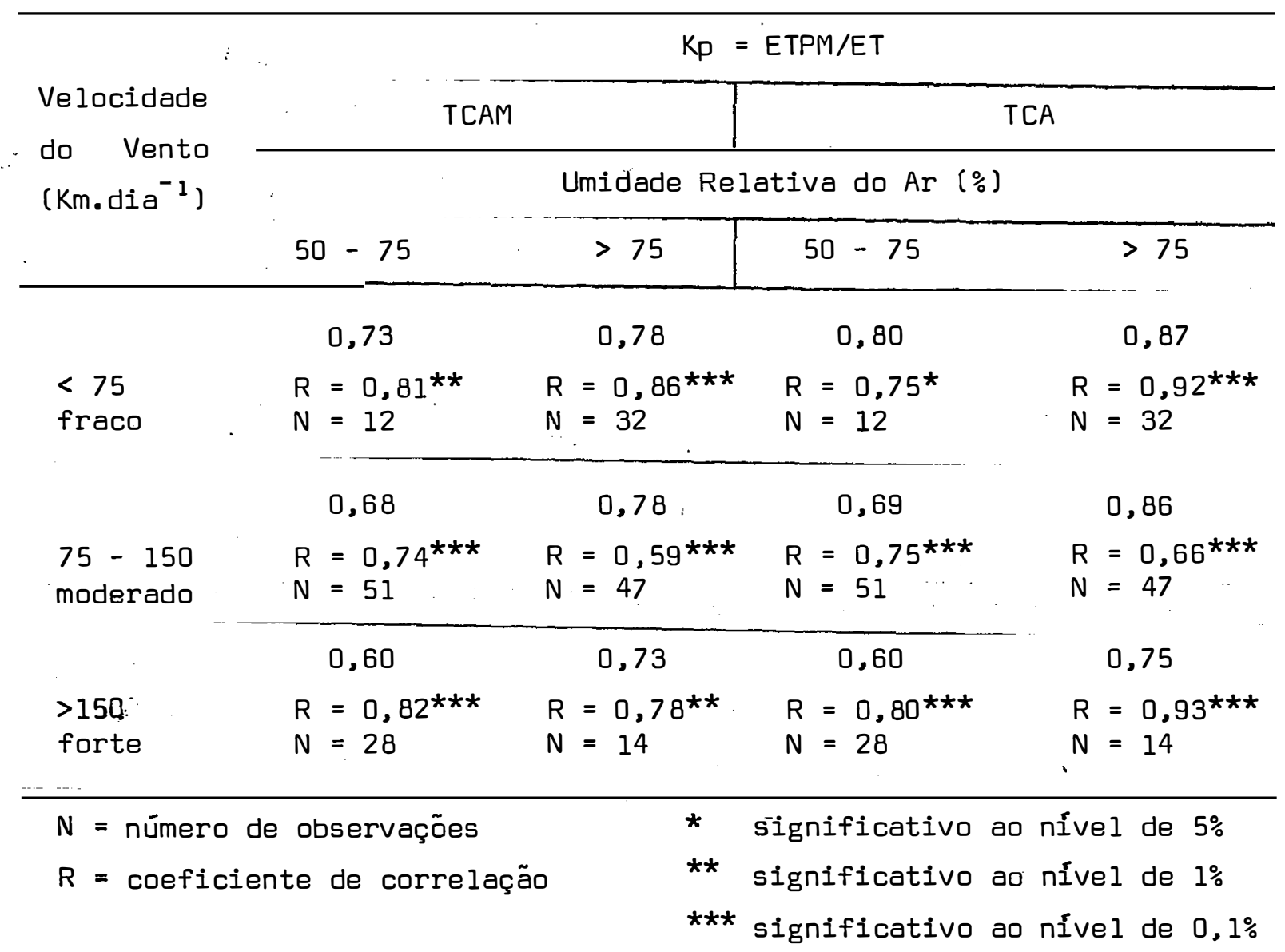


Os coeficientes de correlação simples entre ETPM e evaporạ ção dos tanques, nas diversas combinações de umidade relativa do Ar coṃ velocidade do verito, também são apresentados na Tabela V.

Estes resultados são coerentes com aqueles apresentados por DODRENBOS e PRUITT (1975) e PRUITT e DOORENBOS (1977) para um tanque Clas se A instalado no centro de um gramado com 10 metros de raio. Isto é, para um mesmo nível de UR os valores de Kp decrescem com o aumento da velocida de do vento. Tendéncia contrária a esta é observada quando a UR cresce num dado nivel de velocidade do vento.

A variação observada nos valores de Kp é mais devida à vạ riação dos :valores de evaporação dos tanques do que da evapotranspiração. Isto pode ser observado através dos dados da Tabela VII. Ali são apresentạ dos os valores médios de ETPM e ET usados no cálculo de Kp.

Tabela VII - Valores médios de ETPM e ET utilizados na determinação de KP.

\begin{tabular}{|c|c|c|c|c|c|}
\hline \multirow[b]{2}{*}{ Velocidade } & & \multicolumn{4}{|c|}{$K_{p}=\overline{E T P M} / \overline{E T}$} \\
\hline & & \multicolumn{2}{|c|}{ TCAM } & \multicolumn{2}{|c|}{$\overline{T C A}$} \\
\hline \multirow{2}{*}{$\begin{array}{l}\text { do Vento } \\
\mathrm{Km} \text {. dia }{ }^{-1}\end{array}$} & & \multicolumn{4}{|c|}{ Umidade Relativa do Ar $(\%)$} \\
\hline & & $50-75$ & $>75$ & $50-75$ & $>75$ \\
\hline \multirow{2}{*}{$<75$} & $\overline{\text { ETPM }}$ & 4,40 & 3,72 & 4,40 & 3,72 \\
\hline & $\overline{\mathrm{ET}}$ & 6,02 & 4,77 & 5,52 & 4,29 \\
\hline \multirow{2}{*}{$75-150$} & $\overline{\text { ETPM }}$ & 4,39 & 4,07 & 4,39 & 4,07 \\
\hline & $\overline{\mathrm{ET}}$ & 6,69 & 5,21 & 6,41 & 4,74 \\
\hline \multirow{2}{*}{$>150$} & ETPM & 4,51 & 4,64 & 4,51 & 4,64 \\
\hline & ET & 7,51 & 6,32 & 7,45 & 6,15 \\
\hline
\end{tabular}


Como se pode notar os valores médios de ETPM são bem seme Ihantes, tanto no sentido do aumento de UR como no da velocidade do vento. Por outro lado, os valores médios de ET aumentam ou diminuem conforme seja fixado um dado nível de UR ou de velocidade do vento, respectivamente.

Estes resultados estão relacionados às diferenças entre as duas superfícies (gramado e água livre) tanto do ponto de vista aerodinâmi co quanto ao de resisténcia à difusão de vapor d'água (TANNER, 1968; FRIT $\underline{S}$ CHEN E SHAW, 1961).

Em função dos dados de Velocidade do Vento e Umidade Relä tiva do Ar observados neste trabalho, os valores de Kp esperados para os diversos méses do ano são mostrados na Tabela VIII.

Tabela VIII - Valores Médios Mensais dos coeficientes dje Conversão das Medi das de Evaporação em Tanques para estimativa da Evapotranspí ração Medida em Evapotranspirōmetro.

\begin{tabular}{|c|c|c|c|c|c|c|c|c|c|c|c|}
\hline \multirow{2}{*}{$\begin{array}{l}\text { Meses } \\
\text { Umidade Rela, } \\
\text { tiva do Ar } \overline{(\%)}\end{array}$} & Jan. & Fev. & Mar. & Abr. Mai. & Jun. & Jul. & Ago. & Set. & Dut. & Nov. & Dez. \\
\hline & & $>$ & 75 & & & 50 & -7 & & 1 & & $>75$ \\
\hline $\begin{array}{l}\text { Velocidade do } \\
\text { Vento (km/dia) }\end{array}$ & & & & $75-150$ & & & & & & 150 & \\
\hline$K p=E$ ETPM/TCAM & 0,78 & 0,78 & 30,78 & $0,780,78$ & 0,66 & 0,66 & 0,60 & 0,60 & 0,60 & 0,60 & 0,73 \\
\hline $\mathrm{K} p=\mathrm{ETPM} / \mathrm{TCA}$ & 0,86 & 0,86 & 0,86 & $0,860,86$ & 0,69 & 0,69 & 0,60 & 0,60 & 6,60 & 0,60 & 0,75 \\
\hline
\end{tabular}




\subsection{Relativos à Utilização do Tanque Classe A à Nỉvel Constante}

A montagem proposta para o Tanque Classe A, neste trabalho, foi descrita nos parágrafos 3.1 .2 e 3.2.2.

De um modo geral a nova montagem exigiu mais cuidados na sua operação e manutenção do que a convencional. Como descrito em 3.2.2, o nível da superfície evaporante deve ser o mesmo do respiro do reservatório onde se efetuam as medidas. De modo que, quer durante a limpeza e renovação da água do tanque, quer durante a recarga do:reservatório deve-se esperar um tempo para que os níveis se restabeleçam normalmente.

0 tubo plástico que liga o tanque ao reservatório de recar ga, exigiu observação constantes e trocas periódicas devido ao crescimento de algas e deposição de limo com consequente entupimento.

Por outro lado, a operação de medida na montagem proposta é mais fácil do que na convencional, principalmente por ocasião de ventos fortes, quando o poço tranquilizador, para uso do parafuso micrométrico, não se mostrou tão eficiente.

A partir da equação 3.9. (parágrafo 3.2.2) construiu-se as curvas da Figura 8 através dạs quais se obtém o erro de medida de evaporação no TCAM, em função da altura da cámara do reservatório e da diferença

de témperatura entre duas leituras consecutivas. Referimo-nos à temperatü ra do ar úmido no interior da câmara, considerada em fase com a temperatü ra do ar medida em abrigo meteorológico.

Por facilidade as curvas foram construídas em função do quociente entre a diferença de temperatura em duas leituras consecutivas e a temperatura na leitura atual. O valor 0,10 no eixo horizontal correspon 
de a um $\frac{\Delta T}{T}=\frac{30^{\circ} \mathrm{C}}{273+7}$ aproximadamente. Naturalmente um $\Delta T$ desta magnitude é de ocorréncia pouco provável, principalmente porque as medidas são sem pre efetuadas no mesmo horário. Deste modo, observando-se as temperaturas na hora de medida em todo o período de duração do experimento, o valor mä ximo de $\Delta T$ encontrado foi de $12^{\mathrm{D}} \mathrm{C}$ em apenas um dia do ano. Todos os outros valores foram inferiores a $3^{\circ} \mathrm{C}$. Assim o valor mais frequente de $\Delta T / T$, está em torno de 0,00 e 0,01. Neste intervalo de variação de $\Delta T / T$ o erro máximo provável de medida é de $0,38 \mathrm{~mm}$. 


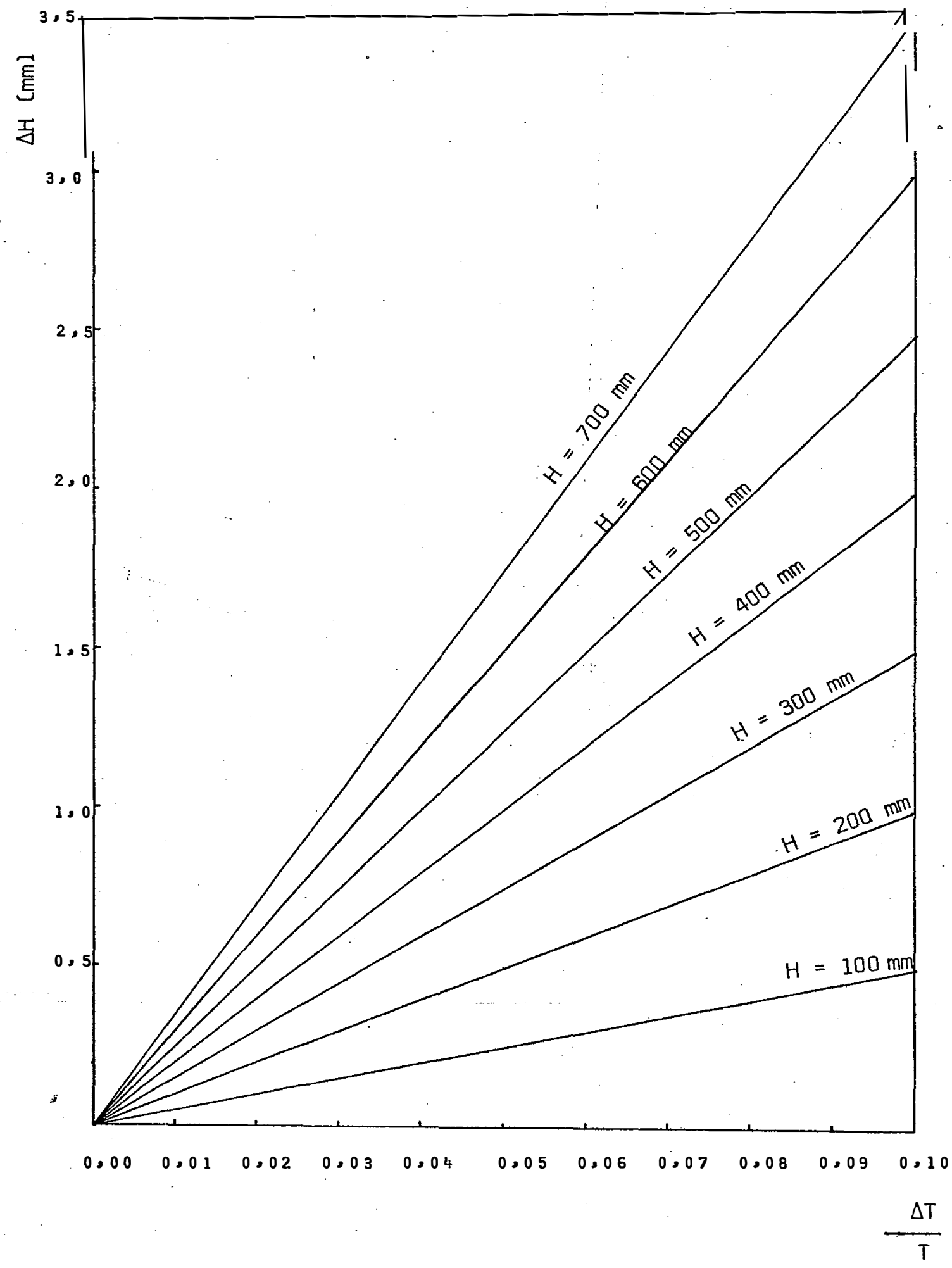

Fig. 8 - Curva para Correção das Medidas de Evaporação no Tanque Classe A à Nível Constante 


\subsection{Relativos a Utilização do Evapotranspirômetro com Nĩvel D'Água} Constante e Sistema de Registro.

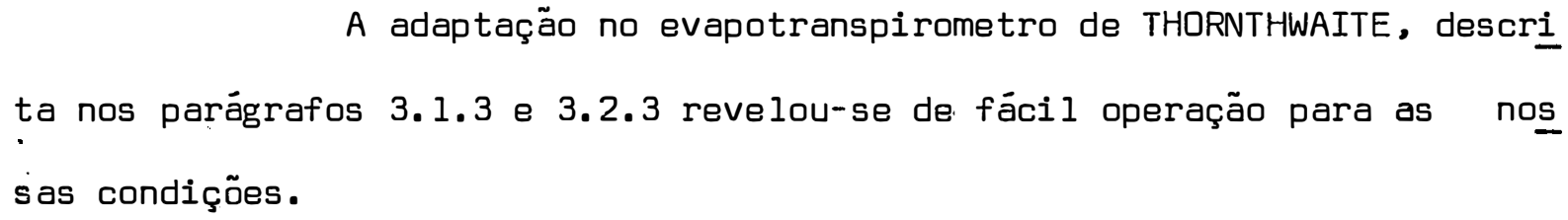

Durante todo o período de observação ( 1 ano) o principal problema surgido foi o da manutenção do tubo: de borracha que liga o sistema de bóia e válvula ao sistema de registro. Trocas periódicas (intervalos de 90 dias aproximadamente) foram necessários devido ao crescimento de algas e deposição de limo com consequente éntupimento.

Um gráfico típico, fornecido pelo sistema de registro é mostrado na Fig. 9 . Na Figura 10 é apresentạdo um diagrama obtido em dia de chuva que dá uma idéia da sensibilidade do instrumento. Poucos instan tes antes do início da chuva os tanques foram protegidos. 


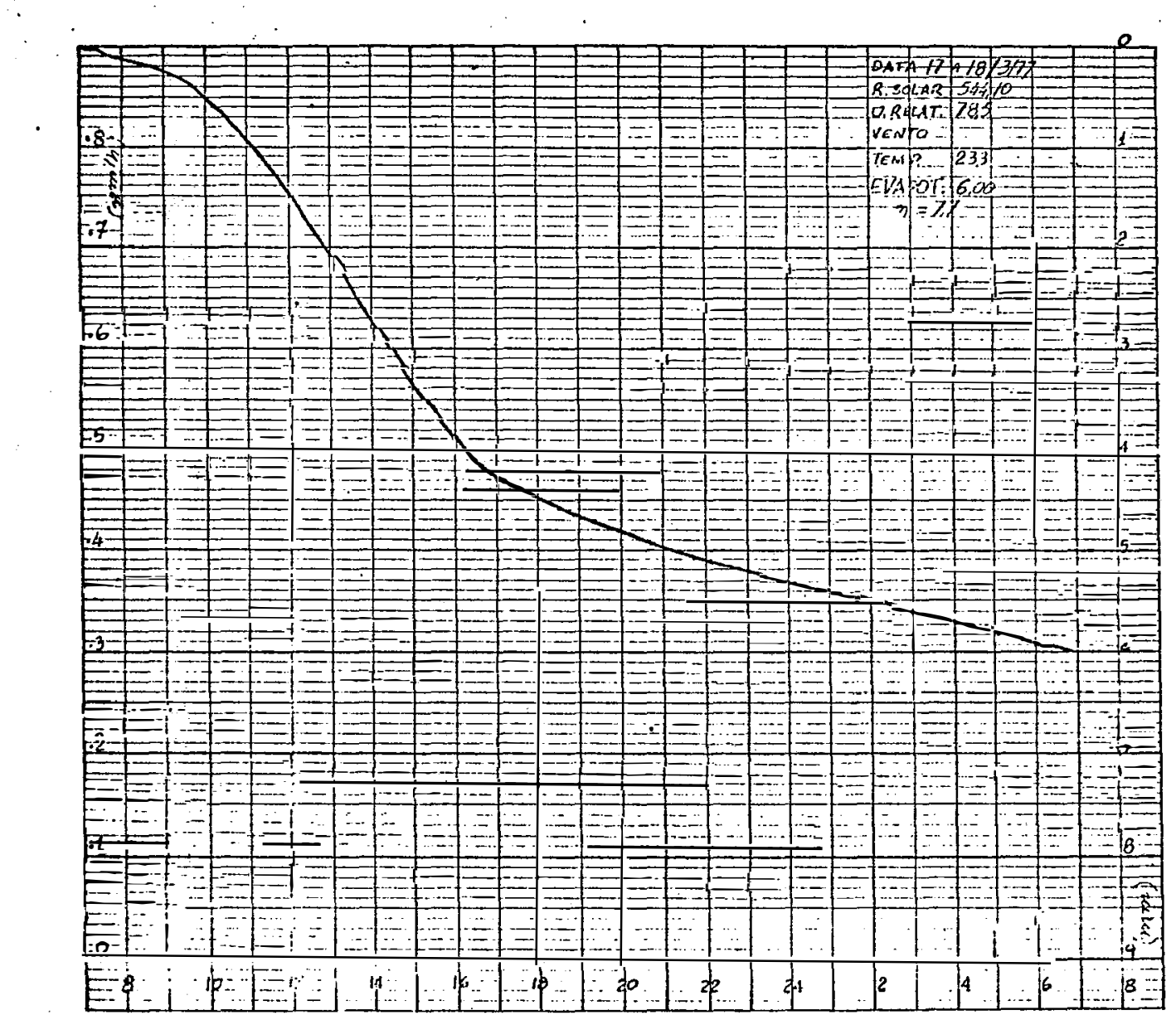

Fig. 9 - Diagrama obtido no Evapotranspirómetro em um dia típico 


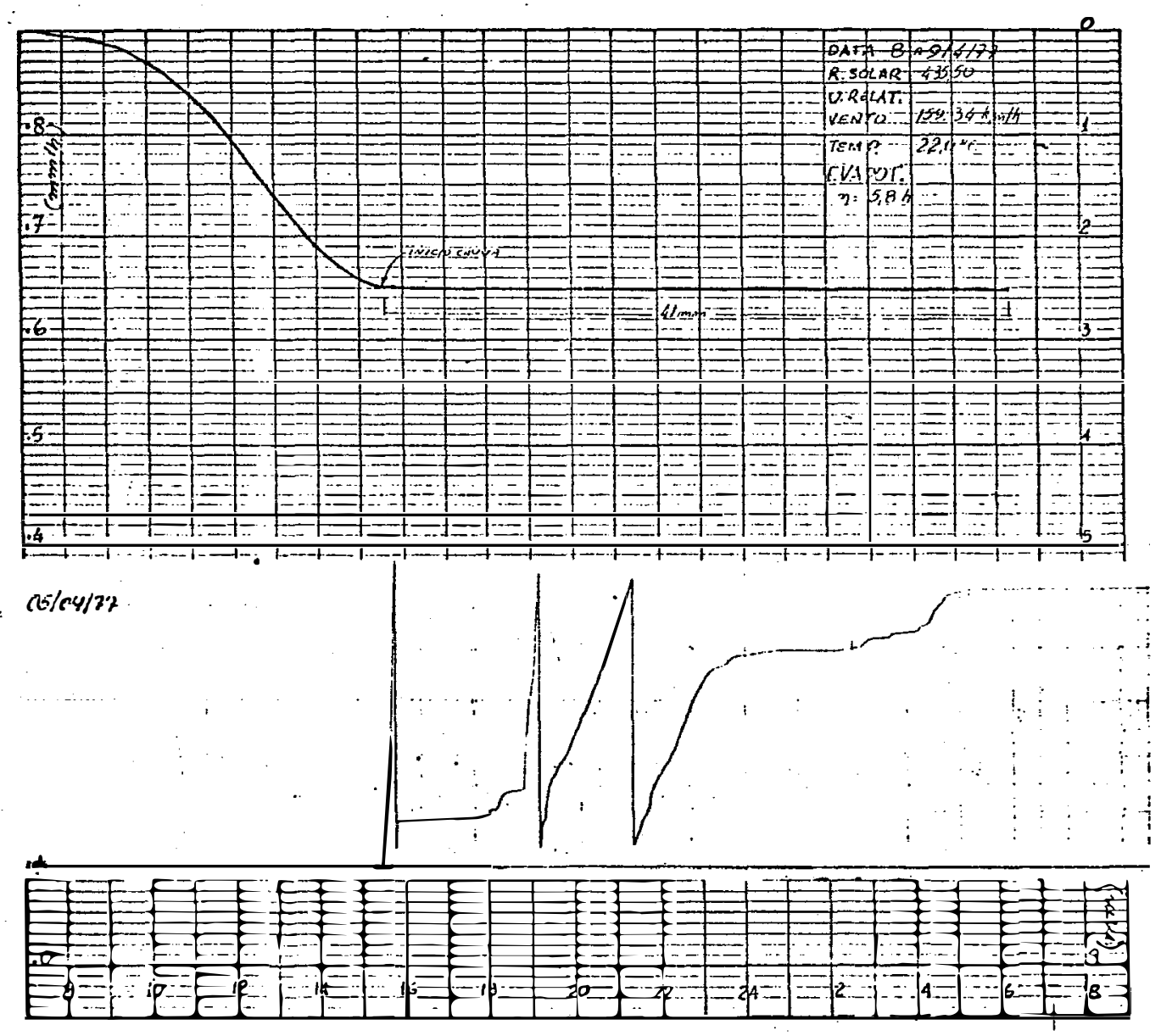

Fig. 10 - Diagrama obtido no Evapotranspirómetro em um dia de chuva 


\section{CONCLUSOES}

Os resultados obtidos no presente trabalho, suportam as se guintes conclusões:

1. :0 Evapotranspirómetro de nível d'água çonstante com sis tema de registro diário acoplado, apresenta características suficientes pa ra ser utilizado em estudos de evapotranspiração em escala diária.

2. A análise de regressão simples revelou que a relação en tre valores estimado (ETPE) e medidas (ETPM) de evapotranspiração, em base diária, nas condições da região de Piracicaba, é da forma

$$
E T P E=0,81 E T P M
$$

3. A evapotranspiração medida no Evapotranspirómetro é in fluericiada pela advecção local não computada pela fórmula de estimativa (Penman).

4. A adaptação efetuada no método de leitura da evaporação no Tanque Classe A (nível d’água constante com reservatório de recarga) mos trou-se praticável para as nossas condições.

5. As medidas de evaporação no Tanque Classe A à Nível Cons 
tante sao influenciadas pela temperatura do ar úmido no interior da câmara livre do reservatório de recarga.

6. O erro de medida da evaporação devido ao efeito da tempe ratura no reservatório de recarga do Tanque Classe A à Nível Constante po de ser estimado, sendo praticamente desprezível nas condições do experimen to.

7. Houve correlação altamente significativa entre valores (diários e médios de pèntadas) de evaporação medidos nos Tanques Classe A e Classe A à Nível Constante e a evapotrạnspiração medida no evapotranspirōmetro.

8. As relações entre evapotranspiração medida e a evapora ção dos Tanques Classe A e Classe A à Nível Cónstante, em períodos médios de pêntadas não diferem daquelas em períodos diārios, embora para períodos de pèntadas os coeficientes de correlação simples sejam aparentemente maio res.

9. As medidas de evaporação obtidas no Tanque Classe A à Nível Constante não diferem,significativamente, daquelas obtidas no Tanque Classe A (convencional). 


\section{SUMMARY}

This work deals with the study of some relations among evapotranspiration measured in evapotranspirometers and evaporation pans, and estimated by Penman's equation.

The measurement of evapotranspiration was made through a Thornthwaite evapotranspirometer with a constant water level, in which a dayly record system was adapted. A modification of the Class A pan based on the maintenance of the evaporation surface by a constant water level, hence with out micrometric screw, is described and discussed.

The analysis of the data showed that the ratio between estimated and measured evapotranspiration, on a dayly basis, was 0,81 , for the région of Piracicaba - SP. This value was atributed to local advection that is not computed in Penman's equation.

Monthly average values of conversion coefficients from

measurement of evapotranspiration obtained by traditional Class A pans and Class $A$ with Constant water level device are presented. 


\section{LITERATURA CITADA}

- AGUIAR, M.J.N. 1975 - Evapotranspiração em feijão comum (Phaseolus vulga ris L.) estimada por evaporímetros e fórmulas empíricas. Piracicaba , ESALQ-USP, 55p. (Dissertação Mestre).

- ARMY, T.J.; OSTLE, B. 1957 - The association between free-water. evaporation and evapotranspiration of spring wheat under the prevailing climatic conditions of the plains of Montana. Soil Sci. Soc. Amer. Proc. 21(5):469-472.

- BAHRANI, B.; TAYLOR, S.A. 1961 - Influence of soil moisture potential and evaporative demand on the actual evapotranspiration from alfafa . field. Agron. J. 53(4):233-237.

- BLACK, T.A.; THURTELL, G.W.; TANNER, C.B. 1968 - Hydraulic loadcell lysimeter construction, calibration and tests. Soil Sci. Soc. Amer. Proc. 32(5):623-629.

- BLAINER, B.L.; ROSEMBERG, N.J. 1974 - Lysimetric calibration of the Bowen ration-energy balance methods for evapotranspiration estimation in the central great plains. J. Appl. Meteorol. 13(2):227-236.

- BOHOMME, R.; GRANCHER, C.V. 1973 - Measurements and estimation of - evapotranspiration in french west Indies. In: Annual Meeting of the Caribbean Food Crops Society, 1192, Barbados, July, 1-7, 6p.

CAMARGO, A.P. 1966 - Contribuição para a determinação da evapotranspira çao potencial no Estado de São Paulo. Campinas, IAC, 54p. (BC-161).

- CHANG, J.H. 1968 - Climate and agriculture - an ecological survey. Chicago, Aldine, 296 p. 
- CRUCIANI, D.E. 1972 - Balanço hídrico em solo cultivado com cana-de-açú car - Utilização do método da moderação de nēutrons. Piracicaba, CENA, 36p. $(B C-006)$.

- DALE, R.F.; SCHCERINGA, K.L. 1977 - The effect of soil moisture on pan evaporation. Agric. Meteorol. 18:463-474.

- OENMEAD, O.T.; McILROY, I.C. 1970 - Measurements of non-potential evaporation from wheat. Agric. Meteorol, 7:285-302.

- OENMEAD, O.T.; SHAW, R.H. 1962 - Availability of soil water to plants as affected by soil-moisture content and meteorological conditions. Agron. J. 54(5): 385-390.

- DILLEY, A.C.; SHEPHERD, W. 1972 - Potential evaporation from pastures and potatoes at Aspendale. Agric. Meteorol. 10:283-300.

- DOORENBOS, J.; PRUITT, W.O. 197.5 - Guidelines for predicting crop water requirements, RDMA, FAO, 180p. (Irr. and Drainage Paper 24).

- OOSS, B.D.; BENNETT, O.L.; ASHLEY, D.A. 1964 - Moisture net by forage species as rellated to pan evaporation and net radiation. Soil Sci., $98(5): 322-327$.

- EAgleman, J.R. 1967 - Pan evaporation, potential and actual evapotranspiration. J.Apll. Meteorol. 6:482-488,

- EAGLEMAN, J.R.; DECKER, W.I. 1965 - The role of soil moisture in evapotranspiration. Agron. J. 57:626-629.

- EKERN, P.C. 1966 - Evapotranspiration by bermuda-grass sod, Cinodon dactylon L. Pers. Agron. J. 58(4):387-390.

- EVANS, G.N. 1971 - Evaporation from rice at griffith new south wales. Agric. Meteorol. 8:117-127, 
- FERRAZ, E.S.B. 1972 - Estudo da evapotranspiração real através da medida de umidade do solo por moderação de néutrons. Piracicaba, CENA, 40p. $(\mathrm{BC}-005)$

- FRITSCHEN, L.J.; SHAW, R.H. 1961 - Evapotranspiration for corn as related to pan evaporation. Agron. J. 53(3) : 149-150.

- GANGOPADHYAYA, M. et alli. 1966 - Measurements and estimation of evaporation and evapotranspiration. Geneva, WMO, 12lp. (Technical Note 83).

- GLDVER, J.; FDRSGATE, J. 1964 - Transpiration from short grass. Quart. J. Roy. Meteorol. Soc. 90(385): 320-324.

- GOLTZ, S.M.; TANNER, C.B.; THURTELL, G.W. 1970 - Evaporation measurements by an eddy correlation methods. Water Resources Res. 6(2):440-446.

- GOMES, F.P. 1970 - Curso de estatística experimental. São Paulo, Nobel. 431p.

- GORNAT, B.; GOLDBERG, D: SADAN, D. 1971 - Changes in the ratio between : sugar beet evapotranspiration and pan evaporation during the growing season. Agron. J. 63(2):256-258.

- GRANT, D.R. 1975 - Comparison of evaporation measurements using different methods. Quart. J. Roy. Meteorol. Soc. $101(429): 543-550$.

- HALSTEAD; M.H.; COVEY, W. 1957 - Some meteorological aspects of evapotranspiration. Soil Sci. Soc. Amer. Proc. 21(5): 461-464.

- HANSON, C.L.; RAUZI, F. 1977 - Class A pan evaporation as affected by shelter and daily prediction equation. Agric. Meteorol. 18:27-35. 
- HARGREAVES, G.H. 1974 - Potential evapotranspiration and irrigation requirements for northeast Brazil. Salt Lake City, Utah State University. 55p.

- KING, K.H.; TANNER, C.B.; SUOMI, V.E. 1957 - A floating lysimeter and its evaporation recorder. Trans. Amer. Geophys. Union 37:738-742. and discussion 38:765-768.

- KRISHNAN, A.; KUSHAWAHA, R.S. 1973 - A multiple regression analysis of evaporation during the growing season of vegetation in the arid zone of India. Agric. Meteorol. $12: 297-307$.

- LEMON, E.R. 1956 - The potentialities for decreasing soil moisture evapóration loss. Soil Sci. Soc. Amer. Proc. 20(1):120-125.

- LEMON, E.R.; GLASER, A.H.; SATTERWHITE, L.E. 1957 - Some aspects of the relationship of soil, plant and meteorological factors to evapotranspiration. Soil Sci. Soc. Amer. Proc. 21(5): 464-468.

- MAKKINK, G.E.A.; HEEMST, H.O.J. 1956 - The actual evapotranspiration as a function of the potential evapotranspiration and the soil moisture tension. Neth. J. Agric. Sci. 4(1):67-72.

- MARQUES, V.S. 1972 - Sobre as limitações dos evapotranspirômetros São Carlos, Escola de Engenharia, 56p. (Dissertação Mestre).

- McILROY, I.C.; ANGUS, D.E. 1964 - Grass, water and soil evaporation at Aspendale. Agric. Meteorol. . i:201-224.

- OLIVEIRA, A.S. 1971 - Estudos comparativos da evaporaçao potencial estị mada por tanques e pelo método. de Penman. Piracicaba, ESALQ-USP, 90p. (Tese Livre Docēncia).

- PARMEIE, L.H.; McGUINNESS, J.L. 1974 - Comparison of measured and 
estimates daily potential evapotranspiration in a humid region.

J. of Hydrology, 22(3/4):239-251.

- PECK, N.H.; VITTUM, M.T.; GIBBS, G.H. 19968 - Evapotranspiration rates for irrigated crops at Geneva, New York. Agron. J. 60(1):23-26.

- PELTON, W.L.; KING, K.M.; TANNER, C.B. 1960 - An evaluation of the Thornthwaite and mean temperature methods for determining potential evapotranspiration. Agron. J. 52(7):387-395.

- PENMAN, H.L. 1948 - Natural evaporation from open water, bare soil and grass. Proc. Roy. Soc. of London, Ser. A 193: 120-145.

- PENMAN, H.L. 1956 - Evaporation: an introductory survey. Neth. J. Agric. Sci. 4(1):9-29.

- PHENE, C.J.; CAMPBELL, R.B. 1975 - Automating pan evaporation measurements for irrigation control. Meteorol. : 15:181-191.

- PRUITT, W.O. 1966 - Empirical methods of estimating evapotranspiration using primarily evaporation pans. Proc. Conf. Evapotranspiration, Amer. Soc. Agric. Eng., Chicago, pp 57-61.

- PRUITT, W.O.; ANGUS, O.E. 1960 - Large weighing lysimeter fbr measuring evapotranspiration. Amer. Soc. Agr. Eng. Trans. 3:13-15.

- PRUITT, W.O.; DOORENBOS, J. 1977 - Empirical calibration a requisite for evapotranspiration formulae based on daily or longer mean climatic data? In: International Round Table Conference on Evapotranspiration, Budapest, May 26-28.

- RANZANI, G.0.; FREIRE, 0.; KINJO, T. 1966 - Carta de solos do municí pio de Piracicaba, Piracicaba, ESALQ, 85p. 
- RIJTEMA, P.E. (s/d) - Derived meteorological transpiration. In: UNESCO, Agroclimatological methods. Proc. of the Readings Syposium.

- RITCHIE, J.T.; BURNET, E. 1968 - A precision weighting lysimeter for row crop water studies. Agron. J. 60(5):545-549.

- ROSEMBERG, N.J. 1974 - Microclimate . Chicago, John Willy \&-Sons, 30lp.

- SALATI, E. et alli. 1967 - Estimativa da radiação solar que atinge uma ărea horizontal unitária, admitindo-se a ausēncia da atmosfera.Rio de Janeiro, Ministério da Agricultura. (BC-6).

- SCALOPI, E.J. 1972 - Métodos climatológicos para avaliar a evapotranspiração. Piracicaba, ESALQ-USP. 7lp. (Dissertação Mestre).

- SCARDUA, R. 1970 - Evapotranspiração real da cultura do milho como base aos projetos de irrigação. Piracicaba, ESALQ-USP. 160p. (Tese Doutora mentol.

- SEGINER, I. 1969 - The effect of albedo on the evapotranspiration rate Agric. Meteorol. $6: 5-31$.

- SEGINER, I. 1971 - Wind effect on the evaporation rate. J. Appl. Meteorol. 10(2): 215-220.

- SLATIER, R.0. 1956 - Evapotranspiration in relation to soil moisture ,Neth. J. Agric. Sci. 4(1):73-76.

- SLATIER, R.O.; McILROY, I.C. 1961 - Evaporation and the principies of its measurements. In: Practical Microclimatology - with special reference to the water factors in soil-plant-atmosphere relationships Australia, C.S.I:R.0. - UNESCO, pp 47-134.

- TANNER, C.B. 1960 - Energy balance approach to evapotranspiration crops. Soil Sci Soc. Amer. Proc. 24(1):1-9. 
- TANNER, C.B. 1968 - Evaporation of water from plants and soil. In: KOSLOWSKI, T.T. Water deficits and plant growth (vol. I) New York, Academic Press. pp. 73-186.

- TANNER, C.B.; LEMON, E.R. 1962 - Radiant energy utilized in evapotranspiration. Agron. J. 54(3):207-212.

- THOMPSON, G.D.; BOYCE, J.P. 1967 - Daily measurement of potential evapotranspiration from fully canopied sugar cane. Agric. Meteorol. 4:267-279.

- THORNTHWAITE, C.W.; HARE, F.K. 1965 - The loss of water to the air Meteorol. Monographs 6:163-170.

- UBING, P.W.S. 1961 - Solar and net radiation, available energy and its influence on evapotranspiration from grass. Neth J. Agric. Sci. $9(2): 81-93$.

- Van BAVEL, S.H.M.; HARRIS, D.C. 1962 - Evapotranspiration rates from bermuda grass and corn at Raleigh North Carolina. Agron. J. 54(4): 319-322.

- VEIHMEYER, F.J.; HENDRICKSON, A.H. 1955 - Does transpiration decrease as the soil moisture decreases? Trans. Amer. Geophys. Union 36:425-448.

- VILLA NOVA, N.A. 1967 - A estimativa da evaporação potencial no Estado de São Paulo, Piracicaba, ESALQ-USP. 66p. (Tese Doutoramento).

- YU, S.L.; BRUTSAERT, W. 1967 - Evaporation from very shallow pans. J.Appl. Meteorol. 6(2):265-271. 
8. APENDICE 
TABELA I - Tensão máxima do vapor, sobre água, em milímetros.

\begin{tabular}{|c|c|c|c|c|c|c|c|c|c|c|}
\hline$(t)$ & 0,0 & 0,1 & 0,2 & 0,3 & 0,4 & 0,5 & 0,6 & 0,7 & 0,8 & 0,9 \\
\hline 0 & 4,58 & 4,61 & 4,65 & 4,68 & 4,72 & 4.75 & 4,79 & 4,82 & 4,86 & 4,89 \\
\hline 1 & 4,93 & 4,96 & 5,00 & 5,03 & 5,07 & 5,11 & 5,14 & 5,18 & 5,22 & 5,26 \\
\hline 2 & 5,29 & 5,33 & 5,37 & 5,41 & 5,45 & 5,49 & 5,53 & 5,57 & 5,61 & 5,65 \\
\hline 3 & 5,69 & 5,73 & 5,77 & 5,81 & 5,85 & 5,89 & 5,93 & 5,97 & 6,02 & 6,06 \\
\hline 4 & 6,10 & 6,14 & 6,19 & 6,23 & 6,27 & 6,32 & 6,36 & 6,41 & 6,45 & 6,50 \\
\hline 5 & 6,54 & 6,59 & 6,64 & 6,68 & 6,73 & 6,78 & 6,82 & 6,87 & 6,92 & 6,97 \\
\hline 6 & 7,01 & 7,06 & 7,11 & 7,16 & 7,21 & 7,26 & 7,31 & 7,36 & 7,41 & 7,46 \\
\hline 7 & 7,51 & 7,57 & 7,62 & 7,67 & 7,72 & 7,78 & 7,83 & 7,88 & 7,94 & 7,99 \\
\hline 8 & 8,05 & 8,10 & 8,16 & 8,21 & 8,27 & 8,32 & 8,38 & 8,44 & 8,49 & 8,55 \\
\hline 9 & 8,61 & 8,67 & 8,73 & 8,79 & 8,85 & 8,91 & 8,97 & 9,03 & 9,09 & 9,15 \\
\hline 10 & 9,21 & 9,27 & 9,33 & 9,40 & 9,46 & 9,52 & 9,59 & 9,65 & 9,71 & 9,78 \\
\hline 11 & 9,84 & 9,91 & 9,98 & 10,04 & 10,11 & 10,18 & 10,24 & 10,31 & 10,38 & 10,45 \\
\hline 12 & 10,52 & 10,59 & 10,66 & 10,73 & 10,80 & 10,87 & 10,94 & 11,01 & 11,09 & 11,16 \\
\hline 13 & 11,23 & 11,31 & 11,38 & 11,45 & 11,53 & 11,60 & 11,68 & 11,76 & 11,83 & 11,91 \\
\hline 14 & 11,99 & 12,07 & 12,14 & 12,22 & 12,30 & 12,38 & 12,46 & 12,54 & 12,62 & 12,71 \\
\hline 15 & 12,79 & 12,87 & 12,95 & 13,04 & 13,12 & 13,21 & 13,29 & 13,38 & 13,46 & 13,55 \\
\hline 16 & 13,63 & 13,72 & 13,81 & 13,90 & 13,99 & 14,08 & 14,17 & 14,26 & 14,35 & 14,44 \\
\hline 17 & 14,53 & 14,62 & 14,72 & 14,81 & 14,90 & 15,00 & 15,09 & 15,19 & 15,28 & 15,38 \\
\hline 18 & 15,48 & 15,58 & 15,67 & 15,77 & 15,87 & 15,97 & 16,07 & 16,17 & 16,27 & 16,37 \\
\hline 19 & 16,48 & 16,58 & 16,69 & 16,79 & $16,89^{\circ}$ & 17,00 & 17,11 & 17,21 & 17,32 & 17,43 \\
\hline 20 & 17,54 & 17,64 & 17,75 & 17,86 & 17,97 & 18,09 & 18,20 & 18,31 & 18,42 & 18,54 \\
\hline 21 & 18,65 & 18,77 & 18,88 & 19,00 & 19,11 & 19,23 & 19,35 & 19,47 & 19,59 & 19,71 \\
\hline 22 & 19,83 & 19,95 & 20,07 & 20,19 & 20,32 & 20,44 & 20,57 & 20,69 & 20,82 & 20,94 \\
\hline 23 & 21,07 & 21,20 & 21,32 & 21,45 & 21,58 & 21,71 & 21,85 & 21,98 & 22,11 & 22,24 \\
\hline 24 & 22,38 & 22,51 & 22,65 & 22,79 & 22,92 & 23,06 & 23,20 & 23,34 & 23,48 & 23,62 \\
\hline 25 & 23,76 & 23,90 & 24,04 & 24,18 & 24,33 & 24,47 & 24,62 & 24,76 & 24,91 & 25,06 \\
\hline 26 & 25,21 & 25,36 & 25,51 & 25,66 & 25,81 & 25,96 & 26,12 & 26,27 & 26,43 & 26,58 \\
\hline 27 & 26,74 & 26,90 & 27,06 & 27,21 & 27,37 & 27,54 & 27,70 & 27,86 & 28,02 & 28,19 \\
\hline 28 & 28,35 & 28,51 & 28,68 & 28,85 & 29,02 & 29,18 & 29,35 & 29,53 & 29,70 & 29,87 \\
\hline 29 & 30,04 & 30,22 & 30,39 & 30,57 & 30,75 & 30,92 & 31,10 & 31,28 & 31,46 & 31,64 \\
\hline 30 & 31,82 & 32,01 & 32,19 & 32,38 & 32,56 & 32,75 & 32,93 & 33,12 & 33,31 & 33,50 \\
\hline 31 & 33,70 & 33,89 & 34,08 & 34,28 & 34,47 & 34,67 & 34,86 & 35,06 & 35,26 & 35,46 \\
\hline 32 & 35,66 & 35,87 & 36,07 & 36,27 & 36,48 & 36,68 & 36,89 & 37,10 & 37,31 & 37,52 \\
\hline 33 & 37,73 & 37,94 & 38,16 & 38,37 & 38,58 & 38,80 & 39,02 & 39,24 & 39,46 & 39,68 \\
\hline 34 & $3.9,90$ & 40,12 & 40,34 & 40,57 & 40,80 & 41,02 & 41,25 & 41,48 & 41,71 & 41,94 \\
\hline 35 & 42,18 & 42,41 & 42,64 & 42,88 & 43,12 & 43,36 & 43,60 & 43,84 & 44,08 & 44,32 \\
\hline 36 & 44,56 & 44,81 & 45,05 & 45,30 & 45,55 & 45,80 & 46,05 & 46,30 & 46,56 & 46,81 \\
\hline 37 & 47,07 & 47,32 & 47,58 & 47,84 & 48,10 & 48,36 & 48,63 & 48,89 & 49,16 & 49,42 \\
\hline 38 & 49,69 & 49,96 & 50,23 & 50,50 & 50,77 & 51,05 & 51,32 & 51,60 & 51,88 & 52,16 \\
\hline 39 & 52,44 & 52,73 & 53,01 & 53,29 & 53,58 & 53,87 & 54,16 & 54,45 & 54,74 & 55,03 \\
\hline 40 & 55,32 & 55,61 & 55,ต่ & 56,21 & 56,51 & 56,81 & 57,11 & 57,41 & 57,72 & 58,03 \\
\hline 41 & 58,34 & 58,65 & 58,96 & 59,27 & 59,58 & 59,90 & 60,22 & 60,54 & 60,86 & 61,18 \\
\hline 42 & 61,50 & 61,82 & 62,14 & 62,47 & 62,80 & 63,13 & 63,46 & 63,79 & 64,12 & 64,46 \\
\hline 43 & 64,80 & 65,14 & 65,48 & 65,82 & 66,16 & 66,51 & 66,86 & 67,21 & 67,56 & 67,91 \\
\hline 44 & 68,26 & 68,61 & 68,97 & 69,33 & 69,69 & 70,05 & 70,41 & 70,77 & 71,14 & 71,51 \\
\hline
\end{tabular}


TABELA II - Radiação Solar Global recebida por uma Superfície Horizontal, unitāria, na Ausência da Atmosfera (cal. $\mathrm{cm}^{-2}$. dia ${ }^{-1}$ ) na Latitude de $22^{\circ} 43^{\prime}$ Sul.

\begin{tabular}{|c|c|c|c|c|c|c|c|c|c|c|c|c|}
\hline Dia & JAN & FEV & MAR & $A B R$ & MAI & JUN & JUL & AGO & SET & OUT & NOV & $\mathrm{DEZ}$ \\
\hline 1 & 1012 & 978 & 903 & 778 & 656 & 551 & 534 & 600 & 720 & 845 & 947 & 998 \\
\hline 2. & 1011 & 976 & 896 & 774 & 649 & 549 & 535 & 604 & 725 & 849 & 949 & 999 \\
\hline 3 & 1011 & 974 & 894 & 771 & 645 & 548 & 535 & 604 & 730 & 853 & 950 & 1000 \\
\hline 4 & 1011 & 972 & 893 & 767 & 640 & 547 & 537 & 612 & 734 & 857 & 954 & 1001 \\
\hline 5 & 1011 & 970 & 891 & 762 & 637 & 544 & 538 & 614 & 738 & 861 & 956 & 1002 \\
\hline 6 & 1009 & 968 & 887 & 758 & 632 & 543 & 539 & 618 & 742 & 865 & 958 & 1003 \\
\hline 7 & 1009 & 966 & 882 & 754 & 628 & 541 & 540 & 621 & 746 & 868 & 960 & 1004 \\
\hline 8 & 1008 & 964 & 880 & 749 & 624 & 540 & 542 & 625 & 750 & 871 & 963 & 1005 \\
\hline 9 & 1007 & 961 & 875 & 745 & 622 & 539 & 543 & 628 & 755 & 876 & 965 & 1006 \\
\hline 10 & 1007 & 959 & 872 & 740 & 619 & 537 & 545 & 632 & 759 & 879 & 967 & 1007 \\
\hline 11 & 1007 & 956 & 870 & 736 & 616 & 536 & 546 & 636 & 763 & 883 & 969 & 1008 \\
\hline 12 & 1005 & 954 & 865 & 731 & 612 & 535 & 548 & 639 & 767 & 887 & 971 & 1009 \\
\hline 13 & 1005 & 951 & 865 & 726 & 605 & 534 & 560 & 643 & 771 & 889 & 973 & 1008 \\
\hline 14 & 1003 & 949 & 854 & 720 & 609 & 534 & 552 & 647 & 776 & 894 & 975 & 1008 \\
\hline 15 & 1002 & 946 & 850 & 714 & 601 & 533 & 554 & 651 & 781 & 897 & 977 & 1008 \\
\hline 16 & 1001 & 943 & 846 & 710 & 597 & 532 & 556 & 655 & 785 & 900 & 978 & 1008 \\
\hline 17 & 1000 & 940 & 842 & 705 & 592 & 531 & 558 & 659 & 789 & 904 & 979 & 1009 \\
\hline 18 & 999 & 937 & 838 & 703 & 588 & 531 & 560 & 663 & 793 & 907 & 982 & 1009 \\
\hline 19 & 998 & 935 & 834 & 699 & 586 & 531 & 562 & 667 & 797 & 910 & 983 & 1009 \\
\hline 20 & 997 & 932 & 832 & 694 & 584 & 530 & 565 & 671 & 802 & 913 & 985 & 1009 \\
\hline 21 & 995 & 928 & 828 & 690 & 580 & 530 & 567 & 675 & 806 & 916 & 987 & 1009 \\
\hline 22 & 994 & 926 & 824 & 685 & 576 & 530 & 570 & 679 & 810 & 920 & 988 & 1010 \\
\hline 23 & 993 & 923 & 818 & 681 & 573 & 530 & 572 & 683 & 814 & 922 & 989 & 1010 \\
\hline 24 & 992 & 920 & 815 & 677 & 530 & 575 & 687 & 817 & 817 & 928 & 989 & 1010 \\
\hline 25 & 990 & 917 & 811 & 673 & 568 & 529 & 578 & 691 & 822 & 965 & 992 & 1010 \\
\hline 26 & 988 & 913 & 806 & 669 & 566 & 529 & 580 & 695 & 826 & 930 & 993 & 1010 \\
\hline 27 & 986 & 910 & 800 & 665 & 563 & 529 & 583 & 700 & 830 & 933 & 995 & 1010 \\
\hline 28 & 985 & 907 & 796 & 663 & 560 & 531 & 586 & 704 & 834 & 936 & 996 & 1010 \\
\hline 29 & 983 & - & 791 & 656 & 558 & 531 & 589 & 708 & 838 & 939 & 998 & 1010 \\
\hline 30 & 981 & - & 787 & 652 & 556 & 532 & 592 & 712 & 841 & 941 & 999 & 1010 \\
\hline 31 & 980 & - & 782 & - & 553 & - & 596 & 717 & - & 944 & - & 1010 \\
\hline
\end{tabular}




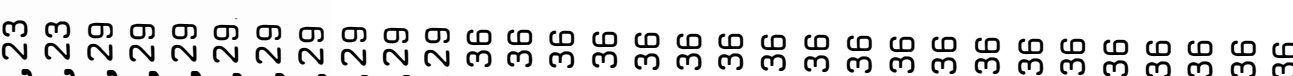

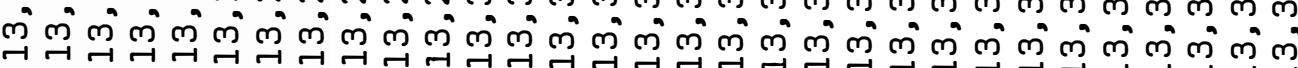

の $\min (m)$

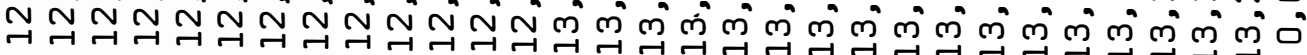

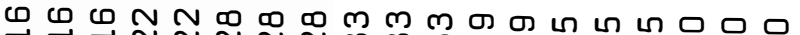
n

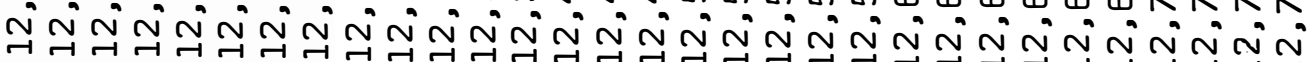

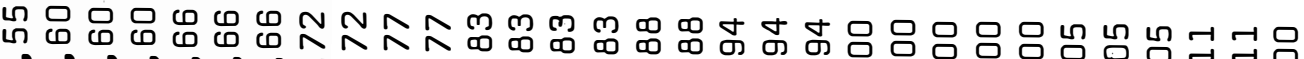

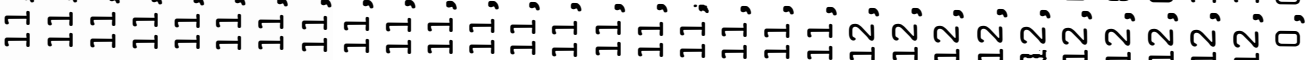

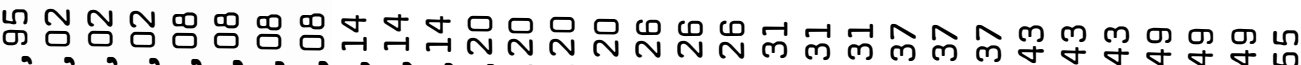
m

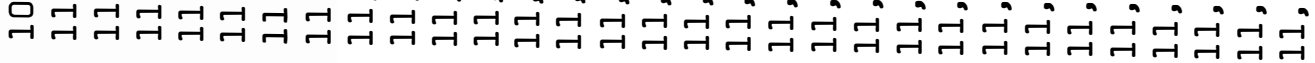

m

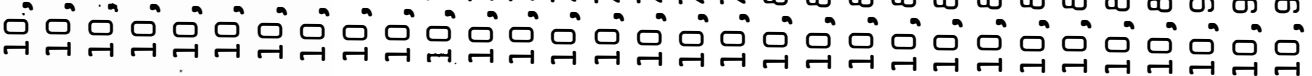

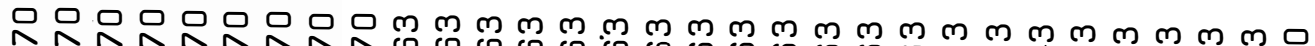
กヘ

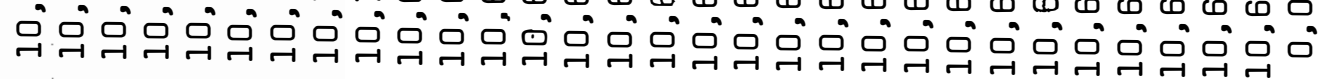

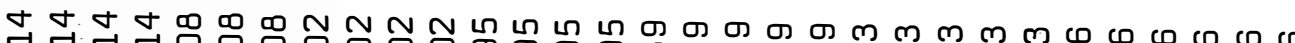
r

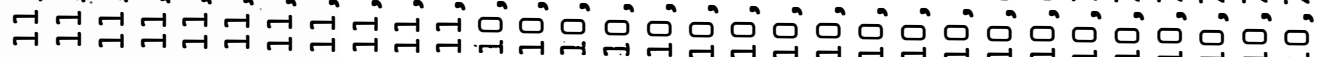

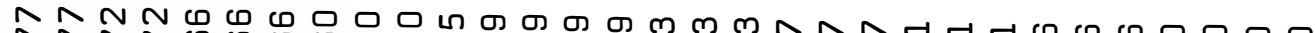

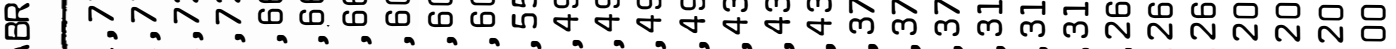

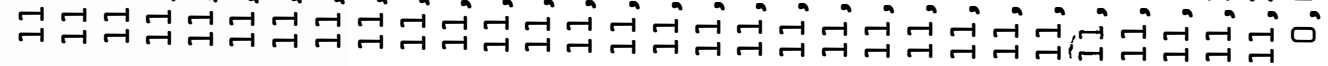

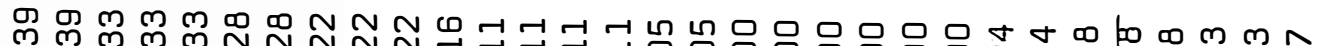

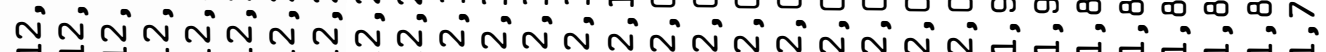

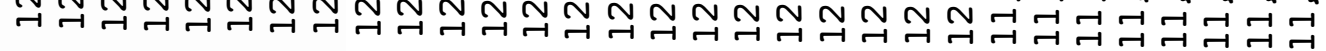

踇 i $\sim$ in

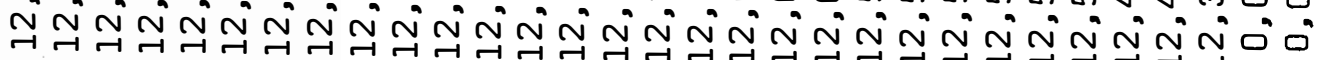
-

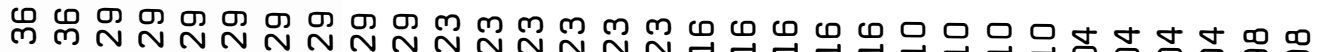

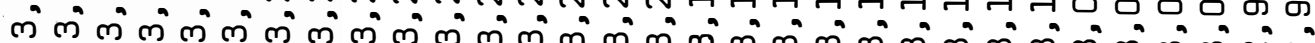

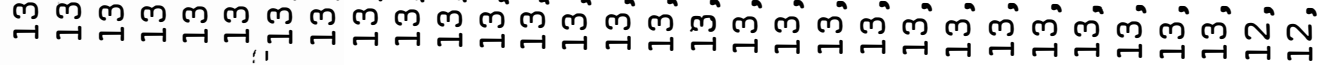


TABELA IV - Razão de Insolação Diária.

\begin{tabular}{|c|c|c|c|c|c|c|c|c|c|c|c|c|}
\hline Dia & JAN & FEV & MAR & ABR & MAI & JUN & JUL & AGO & SET & OUT & NOV & DEZ \\
\hline 1 & 0,23 & 0,69 & 0,74 & 0,05 & 0,05 & 0,01 & 0,86 & 0,83 & 0,02 & 0,09 & 0,41 & 0,00 \\
\hline 2 & 0,38 & 0,87 & 0,58 & 0,17 & 0,51 & 0,33 & 0,91 & 0,65 & 0,36 & 0,64 & 0,76 & 0,34 \\
\hline 3 & 0,60 & 0,78 & 0,32 & 0,28 & 0,84 & 0,00 & 0,87 & 0,33 & 0,68 & 0,57 & 0,70 & 0,71 \\
\hline 4 & 0,25 & 0,39 & 0,41 & 0,05 & 0,86 & 0,00 & 0,85 & 0,84 & 0,91 & .65 &, 85 &, 40 \\
\hline 5 & 0,00 & 0,64 & 0,51 & 0,75 & 0,74 & 0,14 & 0,84 & 0,81 & 0,62 & 0,67 & 0,69 & 0,33 \\
\hline 6 & 0,00 & 0,57 & 0,82 & 0,85 & 0,72 & 0,67 & 0,88 & 0,84 & 0,17 & 0,87 & , & .67 \\
\hline 7 & 0,00 & 0,58 & 0,61 & 0,85 & 0,87 & 0,37 & 0,88 & 0,91 & 0,42 & 0,73 & 0,73 & 0,00 \\
\hline 8 & 0,55 & 0,55 & 0,76 & 0,50 & 0,52 & 0,46 & 0,88 & 0,81 & 0,78 & 0,87 & 0,69 & 0,25 \\
\hline 9 & 0,31 & 0,65 & 0,82 & 0,05 & 0,00 & 0,53 & 0,51 & 0,71 & 0,80 & 0,85 &, 65 & 00 \\
\hline 10 & 0,33 & 0,41 & 0,76 & 0,14 & 0,66 & 0,61 & 0,91 & 0,86 & 0,87 & 0,78 & 0,80 & 0,22 \\
\hline 11 & 0,63 & 0,71 & 0,69 & 0,77 & 0,77 & 0,75 & 0,88 & 0,74 & 0,63 & 0,81 & 0,78 & 0,15 \\
\hline 12 & 0,68 & 0,78 & 0,53 & 0,43 & 0,63 & 0,61 & 0,89 & 0,65 & 0,81 & 0,64 & 0,65 & 0,00 \\
\hline 13 & 0,70 & 0,66 & 0,75 & 0,50 & 0,79 & 0,35 & 0,83 & 0,80 & 0,84 & 0,56 & 0,65 & 0,59 \\
\hline 14 & 0,41 & 0,27 & 0,41 & 0,84 & 0,81 & 0,04 & 0,86 & 0,75 & 0,81 & 0,76 & 0,61 & 0,61 \\
\hline 15 & 0,15 & 0,35 & 0,63 & 0,82 & 0,63 & 0,38 & 0,64 & 0,62 & 0,63 & 0,74 & 0,76 & 0,00 \\
\hline 16 & 0,18 & 0,72 & $\overline{0}, 3^{2}<$ & $=-5.3$ & 0,05 & 0,00 & 0,14 & 0,77 & 0,60 & 0,06 & 0,55 & 0,00 \\
\hline 17 & 0,02 & 0,79 & 0,63 & 0,69 & 0,49 & 0,20 & 0,65 & 0,87 & 0,37 & 0,00 & 0,69 & 0,14 \\
\hline 18 & 0,01 & 0,66 & 0,12 & 0,56 & 0,46 & 0,89 & 0,44 & 0,82 & 0,34 & 0,31 & 0,68 & 0,23 \\
\hline 19 & 0,08 & 0,67 & 0,50 & 0,32 & 0,57 & 0,71 & 0,82 & 0,66 & 2 & 0,91 & 0,15 & 0,69 \\
\hline 20 & 0,68 & 0,66 & 0,53 & 0,00 & 0,61 & 0,57 & 0,67 & 0,22 & 0,37 & 0,82 & 0,24 & 0,30 \\
\hline 21 & 0,77 & 0,63 & 0,27 & 0,44 & 0,37 & 0,82 & 0,52 & 0,88 & 0,45 & 0,79 & 0,03 & 0,44 \\
\hline 22 & 0,49 & 0,72 & 0,42 & 0,24 & 0,72 & 0,11 & 0,48 & 0,88 & 0,58 & $0,88^{1}$ & 0,85 & 0,25 \\
\hline 23 & 0,49 & 0,59 & 0,38 & 0,71 & 0,00 & 0,35 & 0,81 & 0,85 & 0,90 & 0,95 & 0,79 & 0,30 \\
\hline 24 & 0,46 & 0,82 & 0,65 & 0,84 & 0,71 & 0,73 & 0,40 & 0,57 & 0,23 & 0,67 & 0,68 & 0,10 \\
\hline 25 & $0 ; 38$ & 0,56 & 0,48 & 0,84 & 0,42 & 0,79 & 0,38 & 0,30 & 0,29 & 0,74 & 0,34 & 0,09 \\
\hline 26 & 0,01 & 0,67 & 0,78 & 0,84 & 24 & 0,73 & 5 & 0,90 & 7 & 0,59 & 0,08 & 0,18 \\
\hline 27 & 0,11 & 0,84 & 0,49 & 0,82 & 0,83 & 0,66 & 0,77 & 0,83 & 0,86 & 0,02 & 0,31 & 0,24 \\
\hline 28 & 0,10 & 0,74 & 0,51 & 0,73 & 0,84 & 0,78 & 0,78 & 0,62 & 0,87 & 0,19 & 0,23 & 0,01 \\
\hline 29 & 0,25 & - & 0,34 & '0, 68 ' & 0,88 & 0,77 & 0,00 & 0,02 & 0,72 & 0,17 & 0,75 & 0,64 \\
\hline 30 & 0,55 & - & 0,13 & 0,24 & 0,49 & 0,72 & 0,00 & 0,02 & 0,45 & 0,86 & 0,78 & 0,69 \\
\hline 31 & 0,09 & - & 0,19 & - & 0,25 & - & 0,00 & 0,73 & - & 0,62 & - & 0,44 \\
\hline
\end{tabular}

